

\section{Increasing productivity and improving livelihoods in aquatic agricultural systems: A review of interventions}

\section{Authors}

Sarah A. Castine ${ }^{* 1}$, Sonali Senaratna Sellamuttu², Philippa Cohen ${ }^{3}$, Dorothy Chandrabalan ${ }^{4}$, and Michael Phillips ${ }^{1}$

\author{
Affiliations \\ ${ }^{1}$ WorldFish, Jalan Batu Maung, Batu Maung, 11960 Bayan Lepas, \\ Penang, Malaysia. \\ ${ }^{2}$ International Water Management Institute (IWMI), Southeast Asia \\ Regional Office, Vientiane, Lao PDR. \\ ${ }^{3}$ WorldFish, Honiara, Solomon Islands. \\ ${ }^{3}$ ARC Centre of Excellence for Coral Reef Studies, James Cook \\ University, Townsville, Australia. \\ ${ }^{4}$ Bioversity International, Serdang, 43400 Selangor Darul Ehsan, \\ Malaysia. \\ * Corresponding author: Address: WorldFish, Jalan Batu Maung, Batu \\ Maung, 11960 Bayan Lepas, Penang, Malaysia. \\ Email:worldfishcenter@cgiar.org
}

\section{Acknowledgments}

This working paper has been developed under the CGIAR Research Program on Aquatic Agricultural Systems, Sustainable Increases in System Productivity theme. We gratefully acknowledge the constructive comments and feedback received from a number of colleagues, including Leo Sebastian, Yumiko Kura, Olivier Joffre, Gareth Johnston, Everisto Mapedza, Marina Apgar, and Anne-Maree Schwarz.

\section{Summary}

Aquatic agricultural systems (AAS) are food production systems in which the productivity of freshwater or coastal ecosystems contributes significantly to total household nutrition, food security, and income in developing countries (CGIAR 2012). However, a range of stressors, including population growth, environmental degradation, and climate change, are acting upon these systems, threatening the livelihoods and wellbeing of millions of people. The Consultative Group of International Agricultural Research (CGIAR) engages in research in development to address this challenge. The goal of the CGIAR research program on Aquatic Agricultural Systems (referred to in this paper as "the AAS program") is to harness the development potential of aquatic agricultural systems to improve the livelihood security and well-being of an estimated 10 million by 2016 poor people who are dependent on these systems (aas.cgiar.org). The initial target countries are Bangladesh, Cambodia, the Philippines, Solomon Islands, and Zambia. The AAS program has six objectives, one of which is to increase benefits to AAS-dependent households through environmentally sustainable increases in productivity. This working paper draws lessons from the target countries through a review of productivity interventions such as modifying habitats, harnessing underutilized productive resources, improving the integration of production commodities, supporting community-based natural resource management, and genetically improving strains. In total, we reviewed 20 productivity interventions.

Although there was evidence in half of the cases reviewed indicating that interventions lead to improved economic outcomes, evidence linking productivity interventions with improvements to environmental, social, and nutritional conditions in households was scarce, particularly for the most marginalized groups of people. Further, reported outcomes were generally restricted to the time and place of particular interventions, and we found few reports of sustained or broader-scale outcomes achieved via longer-term, widespread uptake of the new methods or technologies. Aquatic agricultural systems commonly operate in highly heterogeneous ecological and socioeconomic conditions, so new methods or technologies need to be delivered and adapted to different contexts. In most cases, adaptations were not reported, potentially due to the short-term nature of projects relative to the longer time frames required for new technologies and methods to be adapted and spread to other farmers. The lack of sustained use of new methodologies or technologies highlights the importance of, first, implementing simple and appropriate technologies that do not rely on enduring external assistance, and second, ensuring that projects are farmer-led to facilitate appropriate adaptations during and after project interventions.

Finally, in the 20 cases reviewed, there was a lack of robust data on changes in productivity, the distribution of benefits among individuals within communities, and environmental outcomes from interventions. To reach goals of reduced poverty and improved livelihoods in aquatic agricultural systems, it is necessary to understand how and in which contexts productivity interventions lead to development outcomes. Therefore, improvements in monitoring and evaluation systems are necessary. The resulting data will help researchers and stakeholders to design and adapt new methods and approaches that take into account productivity and environmental goals, and to manage tradeoffs between different options for resource use-tradeoffs that will increasingly emerge as competition for resources continues to intensify. 


\section{Table of contents}

Introduction

Method

Program country context

Asian mega deltas

Coral Triangle

African inland floodplains

Lessons and challenges

References

Annexes 


\section{Introduction}

Aquatic agricultural systems are agro-ecological systems that occur widely along freshwater floodplains, coastal deltas, and inshore marine waters (WorldFish 2011a). AAS productivity derives from terrestrial and aquatic plants and animals, both wild and cultivated. An estimated 700 million poor and vulnerable households depend on aquatic agricultural systems to farm, catch, or gather produce, and it is estimated that many more are indirectly reliant on these systems for food and other ecosystem services (aas.cgiar.org). However, aquatic agricultural systems are subject to environmental fluctuations, and social and economic drivers, that can drastically alter food productivity and access to that productivity (WorldFish 2011a; Ratner et al. 2012).

The ecosystems upon which aquatic agricultural systems are based support biodiversity and ecosystem services such as nutrient assimilation and cycling, soil formation, water provision, coastal protection, and nursery grounds for aquatic animals -services which are of paramount importance for sustainable food production in farming landscapes (Amilhat et al. 2009; Hill \& Mustafa 2011). However, intensive exploitation of natural resources and unsustainable farming practices have led to biodiversity loss, environmental degradation, and loss of ecosystem function, diminishing productivity in many aquatic agricultural systems (Foley et al. 2005; Datta et al. 2012). Simultaneously, reliance on aquatic agricultural systems for food production and other services is increasing. To meet the demand of an expanding global population, food supply will have to increase by $70 \%$ by 2050 (Pretty et al. 2011). Declines in AAS productivity will increase the gap between productivity and demand, further threatening the food security of millions of poor and vulnerable people (Pretty et al. 2011).

This situation has sparked resurgent investment in agricultural intensification, taking into consideration the valuable lessons that came out of the Green Revolution (Pingali 2012). During the Green Revolution (1966-1985), agricultural productivity was enhanced through development of new technologies, increased external input regimes, and improved access to markets (Pingali 2012). However, efforts were focused solely on increasing productivity and failed to consider implications for the wider development context. As a result, there were unintended environmental and social repercussions (Pingali 2012). Green Revolution researchers focused their efforts on more favorable ecosystems (and by default, richer farmers), where increases in food production were easily attainable, with less effort focused on the more marginal ecosystems where poorer farmers contend with infertile soils or erratic rainfall (Pingali 2012). Agricultural intensification resulted in pervasive chemical run-off, soil structure degradation, loss of biodiversity, and loss of fertility in some regions (Burney et al. 2010). Policies such as fertilizer subsidies and a lack of awareness of the potential environmental impacts exacerbated the situation by allowing uncontrolled use of external inputs (Pingali 2012). In response to these negative effects, sustainable management of natural resources is now recognized as a key foundation for increasing productivity in agricultural systems, and similarly in aquatic agricultural systems.

Improvements to AAS productivity ${ }^{1}$ are often described in terms of increasing yields via new farming practices, higher-yielding varieties, and natural resource management strategies. However, relatively little attention has been given to the factors that influence whether poor households benefit from productivity improvements. Focusing on benefits to poor households, using a livelihood approach, has become a useful tool to capture these factors and understand productivity outcomes for poor people's lives, well-being, and vulnerability (Ashley \& Carney 1999; Adato \& Meinzen-Dick 2002). According to Carney (1998), "a livelihood comprises the capabilities, assets (including both material and social resources) and activities required for a means of living." Livelihood approaches are considered useful because they seek to gain an understanding of people's assets or capital endowments (human, social, natural, physical, and financial) and how these are transformed into positive livelihood outcomes through a range of livelihood strategies (Ashley \& Carney 1999). People's access to different levels and combinations of assets (capitals) is a major influence on their choices of livelihood strategies (Scoones 1998). Therefore, differences in the characteristics and levels of assets can lead to disparities within a household or community regarding who benefits and who is disadvantaged through a productivity intervention. This paper takes guidance from the livelihoods approach alongside reports of increased productivity, in an attempt to glean information regarding access to assets that are reported to affect the benefits received from productivity interventions.

The AAS program has a goal of improving the well-being of AAS-dependent peoples by bringing together the strengths of CGIAR agricultural research with those of partners in research and development. The program has six objectives, of which the first is "increased benefits to AAS-dependent households from environmentally sustainable increases in productivity." One of the key research themes of the program also concerns "sustainable increases in system productivity." The objective and research theme crucially link the elements of increased benefits to households and increases in system productivity.

The purpose of this review is to bring together current knowledge of the relations between these two dimensions, and to draw together lessons relevant to achieving key livelihood or development outcomes; that is, improvement of household income, nutrition, and food security. The review is organized into three sections. First, we provide a summary of household-level asset bases and livelihood strategies in the five focal countries of this review-Bangladesh, Cambodia, the Philippines, Solomon Islands, and Zambia-and provide an inventory of yield and productivity interventions in aquatic agricultural systems in each country. Second, we review the development outcomes of a selection of productivity-related interventions in each country. And third, we present a synthesis of the lessons and challenges of increasing AAS productivity and the factors that influence the uptake, adoption, and development outcomes of these interventions.

The case studies considered yield and productivity interventions. Four research questions were used to guide the analysis of each:

1. How and to what degree do interventions increase crop, fish, and livestock productivity in different aquatic agricultural systems, and are these increases sustainable?

2. What productivity gains have been realized by integrating crop, fish, and livestock production?

3. What are the development outcomes associated with productivity interventions, and which social groups benefit from each intervention?

4. How have AAS technologies and management practices been disseminated and adopted for the benefit of smallholder producers? 


\section{Method}

The paper was prepared in two stages. First, an inventory of studies of AAS productivity interventions was compiled for each of the five target countries. This inventory was conducted by way of an online literature search (primarily with Web of Science and Google Scholar), using the search terms productivity, yield, household, homestead, food security, nutrition, income, agriculture, aquaculture, integration, natural resource management, food production, poverty, fish, crops, livestock, Bangladesh, Cambodia, Solomon Islands, Philippines, and Zambia. These searches returned approximately 450 studies which, based on their titles, appeared relevant. These 450 studies were further screened to discard studies that did not address any of the research questions. Approximately 75 studies remained, from which an inventory was formed (Annex 2).

Case studies for in-depth analysis were selected from the inventory by tabulating the key findings from each study and generating a score based on the number of research questions that were addressed by the study (Annex 2). Studies which scored well were selected. In most instances, more than one article reported on the same intervention, so these were discussed together, as a single case study. Between two and five case studies (interventions) from each of the five target countries were reviewed; we discuss the process and results reported for each intervention.

\section{Program country context}

The AAS program initially focuses on Bangladesh, Cambodia, Zambia, the Philippines and Solomon Islands, where people are dependent on the productivity of a diverse range of aquatic agricultural systems comprising deltaic systems, inland floodplains, wetlands, mangroves, and marine ecosystems (Table 1). The particular characteristics of each country are described in more detail below.

\section{Asian mega deltas}

\section{Bangladesh}

Key ecosystems and ecosystem services underpinning aquatic agricultural systems. In Bangladesh, aquatic agricultural systems are situated in inland floodplains, the coastal delta, and the coastline, which stretches 500 km (Jahan and Pemsl 2011; Annex 1). The alluvial floodplain soils are typically fertile, making land a key natural asset for production of aquatic and agricultural crops. The extensive mangrove system fringing the coastal zone facilitates nutrient retention, waste assimilation, and habitat provision, while freshwater ecosystems provide resources for rice and crop cultivation and habitat for freshwater fisheries (Annex 1). In the 1960s and 1970s, an extensive polder (large circular embankment) system was developed in the southwestern coastal zone, under the Coastal Embankment Project (Islam 2006). The embankments were designed to offer crops protection against floods and saline water intrusion (Islam 2006). Anecdotal evidence suggests that yields initially increased inside these human-made systems; however, the natural ecosystems were permanently modified. Ecosystem services such as river flushing were disrupted, resulting in drainage congestion and extensive sedimentation (Islam 2006). Today, entrainment of saline water into the polder system for land-based shrimp production contributes an additional complication, with freshwater resources difficult to attain at crucial times during the production cycle, particularly when rice seedlings are ready to be transplanted (Molden 2007). However, the diversity of ecological systems both inside and outside polders offers an opportunity to improve productivity by optimizing knowledge and management, integrating synergistic crops, and introducing improved strains of rice, crops, and fish (Belton et al. 2011).

Table 1. An overview of agro-ecological aspects of aquatic agricultural systems in the five program countries.

\begin{tabular}{|c|c|c|}
\hline & Key ecosystems underpinning aquatic agricultural systems & Major productivity challenges \\
\hline \multicolumn{3}{|c|}{ Asian mega deltas } \\
\hline Bangladesh & $\begin{array}{l}\text { Coastal deltas and mangrove habitats } \\
\text { Inland lakes and rivers } \\
\text { Floodplains and wetlands } \\
\text { Irrigated, rain-fed, and seasonally flooded farming systems }\end{array}$ & $\begin{array}{l}\text { Salinity intrusion (seasonal) } \\
\text { Seasonal flooding } \\
\text { Cyclone and storm surges }\end{array}$ \\
\hline Cambodia & $\begin{array}{l}\text { Freshwater lakes and rivers } \\
\text { Floodplains and recession zones } \\
\text { Irrigated, rain-fed, and flooded farming systems }\end{array}$ & $\begin{array}{l}\text { Seasonal flooding cycles } \\
\text { Disrupted hydrological flows due to construction } \\
\text { of hydropower dams }\end{array}$ \\
\hline \multicolumn{3}{|l|}{ Coral Triangle } \\
\hline Philippines & $\begin{array}{l}\text { Coral reefs } \\
\text { Mangroves, seagrass beds, and other diverse coastal ecosystems } \\
\text { Floodplains and wetlands } \\
\text { Hilly upland coastal systems } \\
\text { Rivers and lakes } \\
\text { Irrigated, rain-fed, and flooded farming systems }\end{array}$ & $\begin{array}{l}\text { Deteriorating coastal resources } \\
\text { Typhoons and flash floods } \\
\text { Unpredictable dry spells } \\
\text { Coastal salinity intrusion }\end{array}$ \\
\hline Solomon Islands & $\begin{array}{l}\text { Coral reefs } \\
\text { Mangroves, seagrass beds, and other diverse coastal ecosystems } \\
\text { Small rivers and a few small lakes } \\
\text { Gardens } \\
\text { Rain-fed lowland and estate crop land } \\
\text { Sloping landscapes }\end{array}$ & $\begin{array}{l}\text { Deteriorating coastal resources } \\
\text { Soil erosion }\end{array}$ \\
\hline \multicolumn{3}{|c|}{ African inland floodplains } \\
\hline Zambia & $\begin{array}{l}\text { Floodplains and wetlands } \\
\text { Rivers and lakes } \\
\text { Rain-fed and flooded farming systems }\end{array}$ & $\begin{array}{l}\text { Seasonal flooding } \\
\text { Natural resources degradation }\end{array}$ \\
\hline
\end{tabular}

Source: Based on cropping and farming systems typologies in Cassman and Wood (2005) 
Current population and poverty rate. The population of Bangladesh is 151 million people, 100 million of whom live in rural areas, with many dependent on aquatic agricultural systems (The World Bank 2012c). The national incidence of poverty in 2010 was 32\%, with rural areas experiencing higher incidences of poverty than their urban counterparts (The World Bank 2012c). While substantial development progress has been made in recent years, many rural households remain in poverty. The Barisal and Khulna Divisions are among the poorest in the country and have been selected as the initial geographic focus for the AAS program (Bangladesh Bureau of Statistics 2010). In these areas, many factors contribute to poverty, including large family sizes, low education levels, female-headed households with limited access to inputs and markets, and dependence on low-paying daily wage work (The World Bank 2008). Many households are reliant on remittances to alleviate poverty (The World Bank 2008).

Household demographics and assets. Landholdings of $0.2-4.0$ ha are common in rural Bangladesh, and $65 \%$ of households own or rent $<0.2$ ha of land, classifying them as functionally landless (Bangladesh Bureau of Statistics 2010; Belton et al. 2011). These small landholdings have implications for poverty and food security, because livelihoods are largely reliant on agricultural production in rural areas. In 2005, 57\% of landless people were below the poverty line, compared to $24 \%$ and $13 \%$ for small and medium-to-large landholders, respectively (The World Bank 2008). There is a positive correlation between per capita consumption and land size ownership in rural areas, so development projects in Bangladesh have a strong focus on the functionally landless and small landholders (The World Bank 2008).

Livelihood and food security strategies. Households in rural Bangladesh utilize diverse livelihood strategies, comprising a combination of subsistence agriculture, aquaculture, commercial activities and off-farm income-generating activities and reliance on remittances (Annex 1). Goods produced through agriculture and fisheries include fish, brackish water shrimp (locally known as bagda), freshwater prawn (locally known as golda), vegetables (bitter gourd, ridge gourd, onion, chili, bringal, cucumber, wax gourd), fruit (tomato, mango, coconut, jackfruit, lychee), vegetable oils (sesame, sunflower, mustard), fiber (jute), grains (maize, rice), livestock (chickens, ducks, goats, cattle), and timber trees. Fisheries play a major role for both income generation and food security. They are worth $10 \%$ of the combined export earnings and gross domestic product, and contribute $63 \%$ of the animal-source protein of the country (Hussain 2010). In 2010, inland capture fisheries produced 1.7 million metric tons, and a further 1.3 million metric tons were produced through aquaculture, ranking Bangladesh among the top ten aquaculture producers in the world (FAO 2012a). Reports indicate that aquaculture production is higher than the official statistics suggest, with 399,000 metric tons produced through low-input homestead pond production, 390,000 metric tons from commercial, semi-intensive carp culture, 395,000 metric tons from intensive systems, and 98,000 metric tons from shrimp and prawn production (Belton et al. 2011). Homestead pond culture is an integral component of the livelihood and food security strategy for 4.27 million households (Belton et al. 2011). The per capita supply of fishery products from aquaculture and capture fisheries is $18.9 \mathrm{~kg}$ in Bangladesh (FAO 2012a).

\section{Cambodia}

Key ecosystems and ecosystem services underpinning aquatic agricultural systems. The Mekong River and Tonle Sap Lake catchments create a vast open-water system in Cambodia's lowlands. In the wet season (July-February), the floodwaters occupy around $60 \%$ of the territory, with Tonle Sap Lake covering between 2,700 and $12,000 \mathrm{~km}^{2}$, depending on the season. During this period, inundated rice fields become open access fishing grounds. However, increasing fisher competition, upstream hydropower development, and climate variability are affecting these natural resources and driving the expansion of agriculture and aquaculture. The productivity of the Mekong and Tonle Sap floodplain also supports intensive rice cropping (CGIAR 2012a), and beyond the Tonle Sap floodplain is a mixed-crop residential zone that sustains rain-fed lowland rice and cash crops, fish culture, livestock production, and firewood collection (Hap et al. 2006). Three regions in Cambodia where increases in AAS productivity are considered to have potential for improving the livelihoods of poor and vulnerable households are the Tonle Sap floodplain, the lowland floodplains, and the Mekong floodplain (CGIAR 2012a). These three regions are initial areas of focus for the AAS program.

Current population and poverty rate. In Cambodia, 35\% of the 14.3 million people live below the national poverty line, and 15-20\% live in extreme poverty (Grant 2010; The World Bank 2012b). Due to high population densities, $80 \%$ of this poverty occurs in the floodplain areas and the Tonle Sap region, which have poor infrastructure and few livelihood opportunities (Ballard et al. 2007). The average person in the Tonle Sap region lives on US\$373 per year, just above US\$1 per day (Hall \& Bouapao 2010). A key characteristic of poverty in Cambodia is undernutrition, with $28 \%$ of children under five being underweight, $14 \%$ being severely stunted, and $11 \%$ being wasted (National Institute of Statistics \& Directorate General for Health 2011). Chronic malnutrition is particularly prevalent in the Mekong floodplain (CGIAR 2012a). In 2007, the situation in Cambodia was categorized as "alarming" according to the Global Hunger Index (World Food Programme 2007).

Household demographics and assets. Households around Tonle Sap Lake have poor living conditions and limited access to basic amenities such as drinking water. Asset ownership and the incidence of debt differ between household types with different livelihood strategies. For example, some fishing households build their houses on boats, cages, and stilts over water; they own $25 \%$ less land and the value of their houses is lower than those owned by people in farming households (Hap et al. 2006). Fishing households have higher expenditures than farming households because they require boats and engines for fishing and transportation, generators for fish processing, and mobile phones for communication. Fishing households also incur more expenses for consumables, and consequently have greater debt than households where livelihood strategies include both fishing and farming (Hap et al. 2006).

Livelihood and food security strategies. Between $74 \%$ and $80 \%$ of the Cambodian population are directly dependent on aquatic agricultural systems for all or part of their livelihoods (Joffre et al. 2010; Joffre et al. 2012). Freshwater fish are central to both food security and livelihood strategies and are cultured or caught in rice fields, rivers, streams, natural lakes, and community ponds (Horlte 2007; Joffre et al. 2010; Joffre et al. 2012). In these systems, $0.30-0.45$ million metric tons of fish are produced, providing approximately $33.8 \mathrm{~kg}$ per person per year (Horlte 2007; Joffre et al. 2010; FAO 2012a). Rice fields alone yield an estimated 50-100 $\mathrm{kg}$ of fish per ha per year for Cambodian farmers (Guttman 1999). Aquaculture represents approximately $11 \%$ of total inland fishery production in Cambodia, and the total aquaculture production reached 39,025 metric tons in 2008 (So \& Haing 2007). Of this, approximately $70-80 \%$ of Cambodia's aquaculture production comes from inland cage culture, with the remainder from pond-based production systems (Joffre et al. 2010). Marketoriented aquaculture uses semi-intensive and intensive culture systems, with higher-value species. These production systems require substantial capital investment and access to inputs and markets, and are generally not accessible to the rural poor (So et al. 2005). In small-scale aquaculture systems in provinces adjacent to the Tonle Sap region (a focus region for the AAS program), pond production is generally less than $200 \mathrm{~kg}$ per household per year (So 2009). Despite production being low, 
small-scale aquaculture is reported to provide nutrition and income for some rural households and is considered to have the potential to grow further (Joffre et al. 2010). Major productivity constraints include reliance on wild feed and seed and limited access to financial, land, and water resources. Improvements to farm infrastructure and technology are also key to improving productivity. Rice farming is also a core activity for many households. Rice production has doubled in the last decade, producing a surplus of 4.3 million metric tons at the national level. However, some farmers are still unable to produce enough rice to satisfy household-level consumption and income because the average plot size is only $1.4 \mathrm{ha}$, and yields are typically low due to expensive and poorly regulated inputs (CDRI 2013). As a result, income from fish, poultry, livestock, crops, and wage labor contribute where income from rice production is not sufficient (Hori et al. 2006). In addition, up to $50 \%$ of households in the floodplain region have at least one member who migrates to Phnom Penh or Thailand during the dry season to supplement household income with wage labor (Joffre \& Sheriff 2011).

\section{Coral Triangle}

\section{Solomon Islands}

Key ecosystems and ecosystem services underpinning aquatic agricultural systems. Solomon Islands has a large expanse of oceanic waters that support commercial and small-scale pelagic fisheries, mangrove areas that are used to supply wood and support the production of mangrove fruit, fish and shellfish for consumption, and highly biodiverse coral reefs supporting subsistence and commercial fisheries. Land on fertile coastal plains and in mountainous areas supports forestry activities and logging, and both subsistence and commercial agriculture that produces locally consumed and exported food (Annex 1).

Current population and poverty rate. Solomon Islands is a low-tomiddle-income country with a population of around 500,000. Eighty percent of the population resides in rural and coastal areas where the population density is relatively low; in coastal areas, for example, the population density is between $10-50$ people per $\mathrm{km}^{2}$ (Foale et al. 2011). Civil unrest in Solomon Islands has adversely impacted economic development and social wellbeing, and poverty levels are projected to continue increasing in the future (Lightfoot et al. 2003; Yari 2003). Poverty is not abject; however, a considerable portion of the population is deprived of opportunities to change or improve their living situations (Lightfoot et al. 2003). Due to a rapidly growing population, developing markets, and environmental degradation (associated with domestic pollution, logging, and climate change), there are increasing concerns about future food security. For example, projections suggest that without significant increases in production, there will be a substantial shortage of marine products to meet people's needs, posing a threat to nutritional and food security (Bell et al. 2009; Weeratunge et al. 2011). Further, nutritional security in Solomon Islands is influenced by the introduction of cheap processed foods with high fat and sugar contents (Andersen et al. 2013). Changing diets, related to diminishing natural resources and increased accessibility of processed foods, have resulted in $25 \%$ of women and $30 \%$ of men being overweight or obese (Andersen et al. 2013). One third of children are also stunted, which further indicates dietary micronutrient deficiencies (Andersen et al. 2013).

Household demographics and assets. While around $84 \%$ of Solomon Islanders are literate (i.e., at least able to write a simple sentence) and have some formal schooling (Solomon Islands Government 2009), functional literacy rates can be as low as 7-17\% in some provinces (The World Bank 2012a). This situation has implications for sustainable adoption of productivity interventions and the ability of farmers to innovate and tailor interventions to local conditions. Farmer confidence is often low among poorly educated groups in the Pacific, and extension material must be verbally conveyed (Baynes et al. 2011). Given that rural households produce $60 \%$ of their own food (compared to only $10-15 \%$ in semi-urban and urban areas), innovation around food production technologies is crucial to meeting rural consumption demands in a country with one of the fastest growing populations among Pacific nations (Solomon Islands National Statistics Office \& UNDP Pacific Centre 2008; SPC 2011). Families are relatively large, comprising on average five people, and $53 \%$ of the population is younger than 20 (National Statistics Office et al. 2007).

Key livelihood and food security strategies. The majority of the population are dependent on agriculture, fisheries, and forestry, with $75 \%$ being subsistence-oriented smallholder farmers and fishers (CIA 2012; The World Bank 2012d). Small-scale subsistence cultivation (shifting cultivation and homestead gardening) produces locally consumed food and export commodities, such as copra and cacao, and therefore provides an important livelihood activity where other opportunities for income generation are limited (Mertz et al. 2012). For example, production of fruits and vegetables makes up approximately $25 \%$ of the total "mixed cultivated area," with crops such as sweet potato, cassava, taro, and watermelon (Siliota et al. 2008) providing 43-64\% of the annual income for households in rural areas (HIES 2006). Also, $50 \%$ of the women and $90 \%$ of the men participate in small-scale fishing, and the majority of households have at least one member who fishes for home consumption and supplementary income (Gillett \& Lightfoot 2001; Weeratunge et al. 2011). Subsistence and artisanal fishers largely harvest fish, mollusks, and crustaceans from coastal areas (mangroves, reefs, lagoons) and fish from nearshore pelagic waters and sometimes inland waters. Inland aquaculture is in its infancy and provides an (as yet largely untested) opportunity for development of land-based production systems, with native milkfish (Chanos chanos) and exotic tilapia (Oreochromis mossambicus) being explored (WorldFish 2011b).

\section{Philippines}

Key ecosystems and ecosystem services underpinning aquatic agricultural systems. Aquatic agricultural systems in the Philippines are located either in coastal lowlands, along the $36,289 \mathrm{~km}$ of coastline, or in the uplands that border the narrow coastlines. Marine resources such as coral reefs, mangrove forests, and seagrass beds also play a critical role for AAS productivity through habitat provision, coastal protection, and nutrient entrapment and cycling.

Current population and poverty rate. The population of the Philippines is 94.8 million. The poverty rate is $26.5 \%$ (The World Bank 2012e), with $71 \%$ of this poverty being in rural areas. Nationally, the Philippines has a diverse economy with less poverty than any of the other AAS countries: Bangladesh, Cambodia, Solomon Islands, and Zambia (FIES 2006; WorldFish 2011 b). However, the poverty rate worsened from 2003 to 2009 , with the number of people below the poverty line increasing from 20 million to 23 million in this period. In 2009, 1.5 million Filipino households could not fulfill their subsistencelevel food requirements (NSCB 2012). ARMM (Autonomous Region of Muslim Mindanao), Caraga, Bicol, Eastern Visayas, and Zamboanga are the poorest regions in the Philippines, with a poverty rate of $45 \%$ (FIES 2006). Caraga, Visayas, and Zamboanga are the initial areas of focus for the AAS program. In the province of Bohol within the Visayas hub, over $60 \%$ of the coastal inhabitants live below the poverty line (Christie et al. 2006). Average daily household income is approximately US\$3-4 per day in rural areas (Cedamon et al. 2005; Christie et al. 2006). Malnutrition $^{2}$ is high, with $30 \%$ of preschool children who are under five years old being malnourished (Christie et al. 2006). 
Household demographics and assets. Average farm sizes vary from 0.8 ha to 2.9 ha depending on the region, but only $40 \%$ of households own their houses or farms (Cedamon et al. 2005; WFP 2010). The population is dense around coastal areas, with poor families living in households with five or more members, so having access to fishing assets such as boats is often as important as having access to farming land (Christie et al. 2006; WFP 2010). At the national level, households are comprised of relatively few members, averaging five to six people, and typically consist of extended families (Cedamon et al. 2005; Magcale-Macandog et al. 2010). Despite only $60 \%$ of household heads attending or finishing primary school in the province of Bohol (Christie et al. 2006), there are areas where the literacy and education rates are high. In Mindanao, the literacy rate is 95\% (Magcale-Macandog et al. 2010), and in Leyte, $50 \%$ of households had one member who had completed high school, and a further $15 \%$ of households had a member who had completed college (Cedamon et al. 2005). This infers that farmers in Mindanao have the capacity to innovate and tailor productivity technologies and management practices to local conditions because educated farmers are more confident than farmers with low literacy rates (Baynes et al. 2011).

Key livelihood and food security strategies. Among the poor, 59\% work in agriculture, $55 \%$ belong to families whose head works in the informal sector (activities that are neither taxed nor monitored), and $66 \%$ belong to families whose head did not reach high school (FIES 2006). In the Philippines, the poverty rate is correlated to underemployment (rather than unemployment) and is high among households headed by individuals without education (The World Bank 2010). Domestic remittances contribute significantly to poverty reduction (The World Bank 2010). The major livelihood strategies include agriculture, fisheries, wholesale agricultural trade, forestry, and hunting (WFP 2010). The lowland areas are predominantly cultivated with rice, maize, tobacco, coconut, and other cash crops. The upland areas bordering the coastlines in AAS target hubs are dominated by coconut plantations, and subsequent production of copra is common (Cabili \& Cuevas 2010). Coconut plantations exist as either mono-crops or integrated crops with intercrops consisting of fruit trees, root crops, or vegetables such as eggplant, squash, and pepper (Cabili \& Cuevas 2010). Fish are particularly important for animal protein provision, with approximately 90 million Filipinos consuming $38 \mathrm{~kg}$ per person per year (Perez et al. 2012).

\section{African inland floodplains}

\section{Zambia}

Key ecosystems and ecosystem services underpinning aquatic agricultural systems. Forty percent of southern Africa's surface freshwater resources are located in Zambia. Seasonally, almost $20 \%$ of the country $\left(150,000 \mathrm{~km}^{2}\right)$ is inundated by rivers, lakes, and wetlands, which support freshwater fisheries and grazing lands for zebra, antelope, and more than 450 species of birds (Annex 1). A range of field types are supported by these AAS ecosystems, including raised gardens (Lizulu), rain-fed village gardens (Litongo), seepage gardens (wet Litongo), drained seepage gardens (Sishango), lagoon gardens (Sitapa), and riverbank gardens (Litunda; (IUCN 2003). The AAS program in Zambia has started operations in the Barotse floodplain, with plans to scale out in other regions dominated by aquatic agricultural systems, such as the Kafue flats and Luapula-Chambeshi system.

Current population and poverty rate. Of the 13.5 million people living in Zambia, 64\% are living in poverty and face food insecurity and malnutrition (UNDP 2007). While productive, the households within the three regions targeted by the AAS program face higher than national averages of poverty, with $73-83 \%$ of people below the poverty line as defined by household income (Longley \& Thilsted 2012). High incidences of child stunting and gender inequity, as well as significant HIV prevalence, are also development concerns. HIV prevalence in Western Province, where the Barotse floodplain is located, is $12.6 \%$. Within Western Province, some districts have rates much higher than the average; Mongu, for example, has a prevalence rate of $22.2 \%$ (UNDP 2007). Data collected by Concern Worldwide Zambia indicate higher levels of poverty in Mongu and Senanga districts (which are adjacent to the floodplain) than in Kaoma District, which is located away from the floodplain. Nearly $50 \%$ of households in the Mongu and Senanga regions face at least five months of food insecurity or have incomes of less than US\$1.9 per day per adult equivalent in the household (Concern Worldwide Zambia 2012; Longley \& Thilsted 2012).

Household demographics and assets. The households surveyed by Concern Worldwide Zambia (2012) indicated relatively low levels of social capital, measured in terms of group membership and the sharing of food or money as a coping mechanism to meet essential needs in times of crisis, with many households currently receiving substantial government or NGO assistance. Asset ownership, the value of assets, and the average income are lower for female-headed households than male-headed households (Concern Worldwide Zambia 2012). In addition, female-headed households typically support an average of three orphans each, compared to male-headed households, who support no orphans or one orphan (UNDP 2007). Women have limited access to formal support mechanisms, and existing mechanisms and policies generally do not meet the needs of women (Kent \& MacRae 2010).

Key livelihood and food security strategies. Extensive agriculture, fisheries, and livestock production contribute directly to the livelihoods of approximately 3 million people in Zambia. Livelihood strategies of the rural poor are largely subsistence-oriented (IUCN 2003), and are linked closely with the seasonal flooding of the river, which usually occurs once between December and March (IUCN 2003). Marketed products include fish, crops, rice, and livestock, which contribute $6.1 \%$ of the nation's GDP (Phiri 2006). Agroecological diversity allows for a variety of crops, including maize, rice, cassava, sweet potato, sugar cane, fruits, and vegetables (IUCN 2003). The main food products are maize, millet, cassava, beef, small livestock, rice, sorghum, fish, and groundnuts. An estimated 400,000 households also derive all or part of their income from the fisheries sector, and $40 \%$ of animal-source food comes from fish (Mundenda et al. 2005). During the dry season (May-October), the majority of local agricultural production, economic activities, and settlement occur in the floodplain area. The main crop-growing season in the floodplain is between November and April. Cattle are managed under a system of transhumance and usually spend January to July in the floodplain and the remainder of the year in the uplands (IUCN 2003). Fishing activity intensifies from May until November, at which time heavy rains cause fishing activities to cease (IUCN 2003). In recent years, there has also been the implementation of a nation-wide closed season for fisheries, extending throughout December-March. The lean months are November to January or February, when incomes are lowest, food expenditures are high, and locally produced food is limited. Within the three proposed AAS regions, livelihood strategies differ according to access to and availability of natural resources, as well as differences in the type of natural resources, such as woodlands, grasslands, and fishing sites (Kent \& MacRae 2010). Livelihood strategies are also influenced by market access, with communities located close to markets selling a wider variety of products, including fish, milk, and vegetables such as sindambi (sour hibiscus), pumpkin leaves, grape, and okra (Nyirenda et al. 2007). The population in the Barotse floodplain system depends on a mixed livelihood strategy that combines crop farming, livestock production, fishing, and natural resource exploitation (IUCN 2003), but the recent visits made as part of the AAS program community visioning exercise revealed that some communities rely only on fishing, while others have very limited access to fishing sites (Longley \& Thilsted 2012). Likewise, not all communities have equal access to the range of natural resources or field types supported by the Barotse floodplain system. Those that do have access to natural resources and are able to cultivate crops or graze livestock are faced with variable climate and changing 
seasons. Other livelihood strategies adopted by women to secure extra income include beer brewing, carpentry, house construction, pole making, hunting wild animals, the sale of wild fruits (when in season), and charcoal making (UNDP 2007). Crafts provide an important source of income for poorer women, and include reed mats, baskets, and brooms. Fish drying and smoking, which accounts for up to $75 \%$ of all fish sold in markets, and trading, also offer important employment opportunities, especially for women (Longley et al. unpublished). In Kalabo District, women reported that income from crafts sales exceeded that of traditional cassava trading, which requires walking long distances to markets. In general, men have access to a greater range of income-earning activities than women (Kent \& MacRae 2010), and of the small amount of proceeds that women do generate, $90 \%$ is controlled by men (Kwashimbisa 2012). Laboring work or "piecework" is an important coping strategy for poorer households and is usually undertaken on other people's farms. It is primarily done by women, but in the poorest households, women, men, and children take part (Kent \& MacRae 2010). Children who engage in piecework are typically obliged to miss school, and piecework undertaken by women conflicts with child care, potentially impacting children's nutrition (Kent \& MacRae 2010). Cassava is commonly used as payment for piecework, and the amount traded is generally just enough to provide food for a day. Reliance on piecework is an indication of household poverty, with destitute households almost completely reliant on piecework for food security (Kent \& MacRae 2010). To reduce reliance on piecework, there is potential for increases in AAS productivity, particularly in the beef sector. A Zambian Beef (ZAMBEEF) representative at the June 2012 stakeholder consultation in Mongu highlighted that livestock in Western Province were getting low prices due to diseases, with most of the internal organs discarded, as they were not fit for human consumption. In addition, goats can potentially make significant contribution to poor women and men, especially given their tolerance to harsh, dry conditions (Homann et al. 2007). Improved crop management through training and knowledge sharing, complemented by new, innovative technologies and improved market access, has the potential to enhance productivity and development outcomes and reduce the reliance on piecework in Zambia (Lewis et al. 2011).

\section{Review of selected productivity interventions in aquatic agricultural systems}

As described above, literature searches using various combinations of the words productivity, yield, household, homestead, food security, nutrition, income, agriculture, aquaculture, integration, natural resource management, food production, poverty, fish, crops, livestock, Bangladesh, Cambodia, Solomon Islands, Philippines, and Zambia returned approximately 450 studies that appeared relevant to the present review based on their titles. After these 450 studies were screened to discard studies that did not address any of the research questions, the remaining 75 studies were critically analyzed and given a score based on the degree to which they addressed the research questions (Annex 2). Of these 75 studies, $67 \%$ gave quantitative evidence of the effect of an intervention on productivity or yield. Forty-nine percent presented empirical evidence of the impact of an intervention on household income. Twenty-seven percent of the 75 studies addressed food security, although about half of these presented only qualitative evidence. Only $7 \%$ addressed improved nutrition, and the majority of these offered only qualitative evidence. These results are in accordance with Masset et al. (2011), who demonstrated very limited quantitative evidence of the impact of productivity interventions on household nutrition. Seventy percent of the cases considered environmental sustainability in relation to farm integration and/or ecosystem functions thought quantitative assessment data were often lacking.

Annex 2 gives the extended list of the 75 studies with further details of the research questions addressed in each publication. This annex may be used as a resource for AAS program participants and others to guide further insights about a wider range of published productivity interventions.

\section{Case Studies}

From the 75 studies analyzed, two to five interventions were selected from each focal country as case studies. We preferentially selected case studies that demonstrated evidence of relations between interventions and development outcomes. The selection of the cases does not represent a de facto selection of the productivity intervention for inclusion in the AAS program. Rather, cases were selected on the basis of the evidence presented and the learning available regarding productivity interventions in aquatic agricultural systems.

\section{Bangladesh}

In Bangladesh, five interventions were selected for review (Table 2), involving integrating fish into rice-based systems and polyculture ponds, implementing gher and floating garden systems, introducing high-yielding, stress-tolerant rice varieties, and improving rice management techniques. The interventions and key references are summarized below.

Table 2. An overview of the selected productivity reviews in Bangladesh.

\begin{tabular}{|c|c|c|}
\hline Intervention & $\begin{array}{l}\text { Aquatic agricultural } \\
\text { system }\end{array}$ & Key references \\
\hline $\begin{array}{l}\text { Integrating fish } \\
\text { into rice-based } \\
\text { systems }\end{array}$ & $\begin{array}{l}\text { Rain-fed, flooded } \\
\text { farming system }\end{array}$ & $\begin{array}{l}\text { Ahmed \& Garnett } \\
\text { 2011; Dey et al. } \\
\text { 2013;Frei et al. 2007; } \\
\text { Haque et al. 2010; } \\
\text { Jahan \& Pemsl 2011; } \\
\text { Oehme et al. } 2007\end{array}$ \\
\hline Gher systems & $\begin{array}{l}\text { Rain-fed, flooded } \\
\text { farming system }\end{array}$ & $\begin{array}{l}\text { Ahmed et al. 2010; } \\
\text { Karim et al. 2011; } \\
\text { Rahman \& Barmon } \\
\text { 2012; Rahman et al. } \\
\text { 2011; Alam et al. } 2007\end{array}$ \\
\hline $\begin{array}{l}\text { Integrating small } \\
\text { indigenous fish } \\
\text { species into } \\
\text { polyculture ponds } \\
\text { and optimizing } \\
\text { stocking density } \\
\text { and ratio }\end{array}$ & $\begin{array}{l}\text { Irrigated, rain-fed } \\
\text { farming system }\end{array}$ & $\begin{array}{l}\text { Jahan et al. 2008; } \\
\text { Kadir et al. 2006; } \\
\text { Milstein et al. 2009; } \\
\text { Roos et al. } 2007\end{array}$ \\
\hline $\begin{array}{l}\text { High-yielding, } \\
\text { stress-tolerant } \\
\text { rice varieties } \\
\text { and improved } \\
\text { management }\end{array}$ & $\begin{array}{l}\text { Irrigated, rain-fed, } \\
\& \text { flooded farming } \\
\text { system }\end{array}$ & $\begin{array}{l}\text { Amin 2001; Hossain } \\
\text { 1996; Hossain et al. } \\
\text { 2006; Hossain et al. } \\
\text { 2007; Howlader \& } \\
\text { Biswas 2009; Mackill et } \\
\text { al. 2012; Molden } 2007 ; \\
\text { Rahaman et al. } 2011 \\
\end{array}$ \\
\hline Floating gardens & $\begin{array}{l}\text { Floodplains, } \\
\text { wetlands, \& rivers }\end{array}$ & $\begin{array}{l}\text { Irfanullah et al. 2008; } \\
\text { Irfanullah et al. 2011; } \\
\text { Ullah et al. } 2009\end{array}$ \\
\hline
\end{tabular}

Integrating fish into rice-based systems. There are two broad strategies of rice-fish integration: 1) seasonally alternating management, wherein wet season fish culture is followed by integrated dry season (boro) rice and fish culture, and 2) yearround fully integrated rice and fish systems. Here we review a case study whereby three systems are compared: i) seasonally alternating rice-fish, ii) year-round fully integrated rice-fish, and iii) rice monoculture. Evidence was reviewed from farmer field trials of the impact on productivity of implementing each of these three systems. There was no significant difference in boro rice yield in any of these three systems. Monsoon rice (aman) was cultured in both the fully integrated system and the monoculture rice system. Yield was significantly higher in fully integrated ricefish systems at 5,261 $\pm 312 \mathrm{~kg}$ per ha per year, compared to 4,702 $\pm 305 \mathrm{~kg}$ per ha per year in monoculture rice systems (Ahmed 
\& Garnett 2011). Overall, fully integrated farming achieved the highest rice productivity out of the three systems. Fish yield in the alternating and integrated systems was 1,108 \pm 217 and $259 \pm 98$ kg per ha per year, respectively (Ahmed \& Garnett 2011). In terms of development outcomes, farmers participating in integrated culture consumed significantly more fresh fish (Ahmed \& Garnett 2011). Although changes in nutrition were not quantified, higher levels of fish consumption could have improved food and nutrition security. No information was available on intrahousehold distribution of fish consumed.

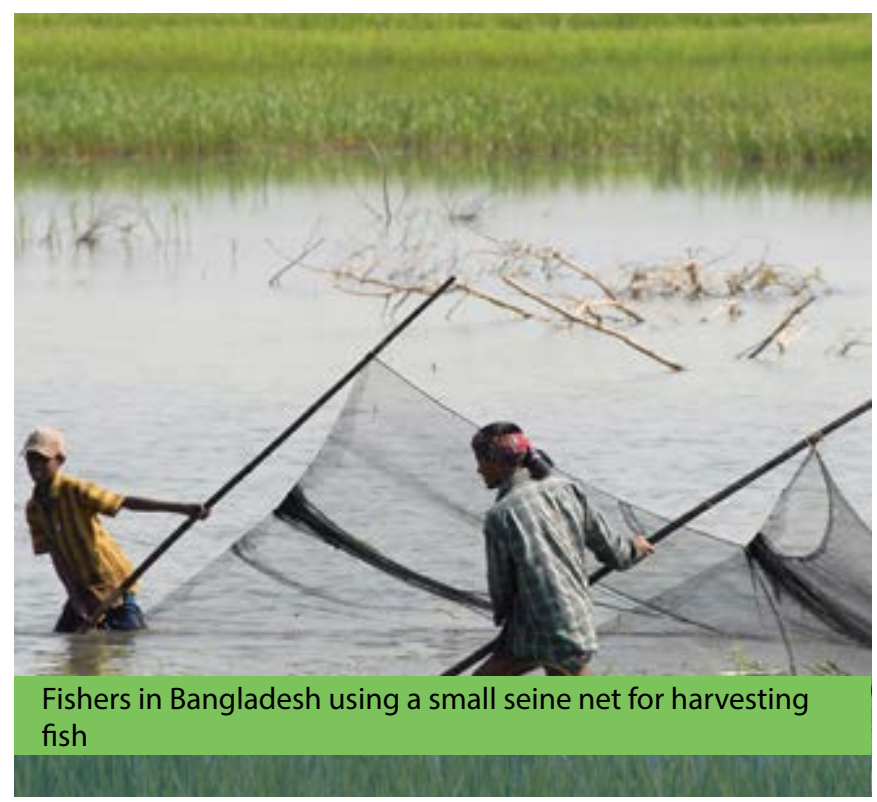

Outcomes varied between farming strategies. For example, farmers who practiced full rice-fish integration considered fish as the secondary cash crop, consuming $40 \%$ of their fish and selling the remaining $60 \%$, whereas alternating farmers considered fish as the primary cash crop, consuming only $15 \%$ of their fish and selling the remaining 85\% (Ahmed \& Garnett 2011). In addition, household income improved as a result of the integration of rice-fish culture but varied between farming strategies (Ahmed \& Garnett 2011). For example, farmers practicing integrated culture made an annual net income of US\$633 per household, compared to an annual net income of US\$508 from rice monoculture and US\$368 per household from alternating farming systems (Ahmed \& Garnett 2011). This difference is attributable to differences in variable costs between system types, with the highest costs incurred in alternating farming, at US\$731 per ha (Ahmed et al. 2011). A subsequent study estimated that an alternating system under collective management (i.e., a group of farmers) can generate net income of up to US\$2,634 per ha per year (Dey et al. 2013). Households targeted by this intervention needed a substantial asset and labor base, including access to a reasonable amount of land $(0.97 \pm 1.08$ ha per household) and adequate inputs such as fingerlings and rice seed (Haque et al. 2010), which would have restricted poorer farmers from the benefits of such systems. Although training and information were provided to support farmers in the adoption of rice-fish cultivation, farmers with some prior knowledge of fish culture were more suited to rice-fish farming, because good water management is essential for rice-fish culture and takes many years to learn (Jahan \& Pemsl 2011). The participation of women in rice-fish cultivation was not widespread; however, where women were involved (usually in feeding and general husbandry of fish), this seems to have been facilitated by their inclusion in training courses (Haque et al. 2010; Dey et al. 2013).
The productivity and environmental sustainability benefits from improving the integration of rice and fish production are suggested to be important, but not well quantified. Positive outcomes included improved nutrient-use efficiency because nitrogen uptake by rice is enhanced in the presence of fish (Oehme et al. 2007). Further, the swimming action of fish releases organic nutrients from the sediments, and fish excretions and feeding have a fertilizing effect on the rice (Oehme et al. 2007; Ahmed \& Garnett 2011). Nutrient assimilation by rice from rural wastewater also reduces the eutrophication potential of a system (Li et al. 2009). In Bangladesh, stem borer insects cause rice yield losses of $20-40 \%$ in the Khulna region (Mondal et al. 2010), and an additional potential gain of integrating rice and fish is that fish may act as a natural pest management system. However, a detailed understanding of local predator-prey interactions is required to ensure pest management is effective (Quoc et al. 2012). Integrating fish into rice-based systems may also have implications for climate change, as rice-fish systems significantly increased methane emissions, from $20 \mathrm{mg}$ per $\mathrm{m}^{2}$ per hour in rice monoculture to $34 \mathrm{mg}$ per $\mathrm{m}^{2}$ per hour when fish were integrated into the production system (Frei et al. 2007). However, methane emissions were not compared to systems where only fish were cultured, and there was no indication as to the wider implications should this technology be scaled out.

To date, widespread uptake and sustainable adoption has not occurred, and the dissemination of rice-fish farming techniques appears to be constrained by various factors, including access to training (Ahmed \& Garnett 2011). Sustainable adoption of rice-fish technology requires competent crop and aquaculture management skills. Managing water quality is particularly complex. Dissolved oxygen and $\mathrm{pH}$ significantly decrease in rice-fish systems, while chlorophyll a (a proxy for phytoplankton) and particulate inorganic matter significantly increase compared to monoculture rice plots (Frei et al. 2007). Farmers need to be technically skilled to ensure optimal pond conditions for both the rice and the fish. Additional management options include varying fertilizer and feeding regimes, varying pond design, producing seed in ponds or beneath covered nursery structures, and sourcing good quality fry from traders. Jahan and Pemsl (2011) recommend long-term (three-year) training programs and extension support to improve uptake and adoption of rice-fish technology.

Despite suggestions in some of the literature we reviewed that rice-fish systems improve livelihoods, evidence is weak, and it appears this technology is not overly suitable for asset-poor and unskilled farmers. Farmer innovation is required to adapt this technology into a system that is easily managed and is flexible enough to endure erratic weather patterns. Gender aspects of the technology also need to be better understood, particularly given that rice is often farmed in field plots away from the homestead, a physical separation from the household that in itself will restrict the possibilities for participation by women.

Gher systems. The traditional agricultural system in southwestern Bangladesh was dominated by the cultivation of rain-fed summer rice. This system was transformed by the introduction of black tiger shrimp (Penaeus monodon) farming in coastal areas during the late 1970s (Rahman et al. 2006). Most culture activities are carried out in paddy fields converted to make them suitable for shrimp culture by constructing peripheral trenches, which provide shelter for the stocked shrimp, and building dikes to prevent flooding or escape. These are referred to as ghers (Belton et al. 2011). In areas close to the coast where salinity levels preclude terrestrial agriculture, shrimp and fish are grown year round. Shrimp and fish farming also occurs year round in some inland polders where salinization caused by shrimp culture or changes in local hydrology have made it impossible to cultivate rice. In other areas, ghers may involve wet season cropping of rice. Gher systems are typically between 0.06 and 1.00 ha in size and have some similarities to the rice-fish systems described above. 


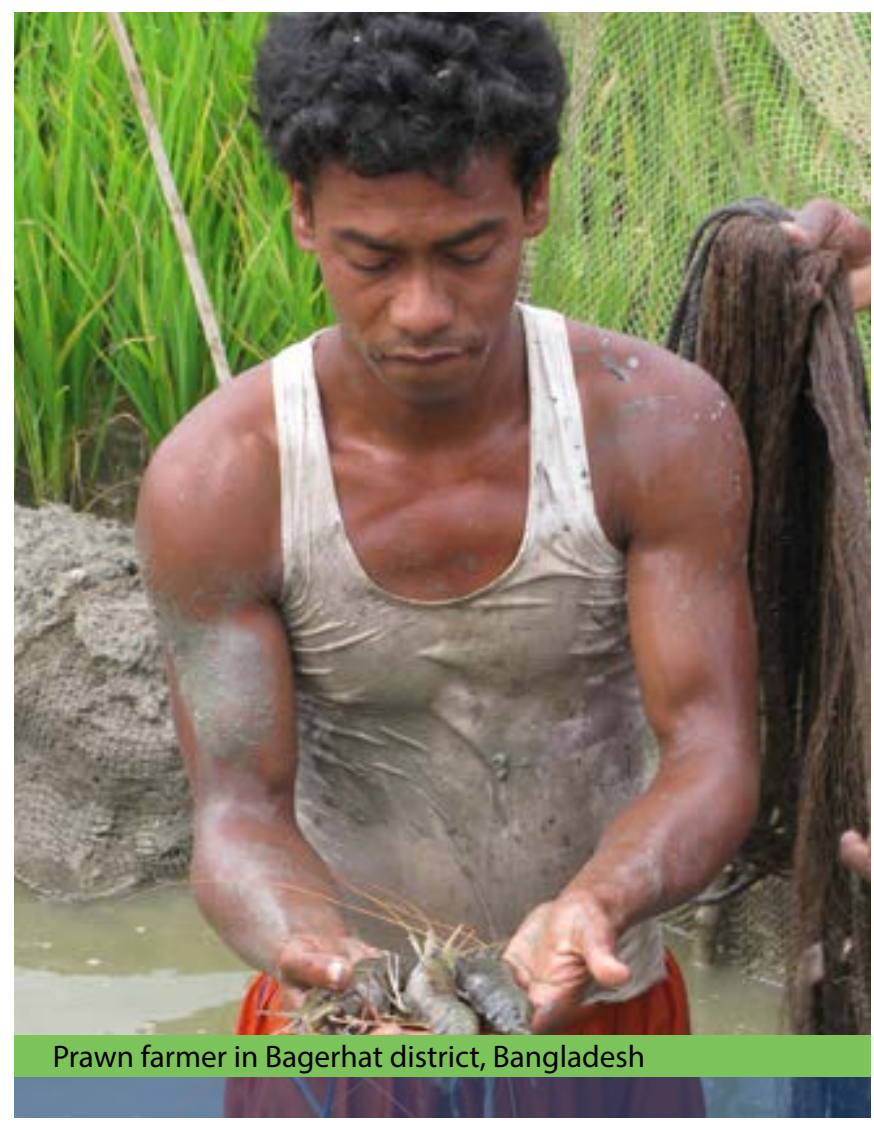

Here we describe a case whereby production in traditional rice ghers is compared to production in improved gher systems, through better management, diversification of aquaculture to shrimp and fish, and cropping of vegetables on raised pond dikes. The total annual production in improved gher systems is usually higher than that in traditional gher systems, and the commodities produced are more varied and valuable (Table 3; Hossain et al. 2006; Ahmed et al. 2010; Wahab et al. 2012). Average shrimp production in improved ghers is $1411 \pm 926 \mathrm{~kg}$ per ha, while in traditional rice ghers it is $169 \pm 118 \mathrm{~kg}$ per ha (mean \pm standard deviation; Karim et al. 2012). Vegetables are cultivated on the dikes that separate the canals, adding another dimension to the system of particular importance for income.

The impact of ghers on household food security and nutrition has not been elucidated, and reports to date suggest mixed results. For example, there are claims that prawn farming in ghers has substantially improved the food security of some people living below the poverty line (i.e., via increased and more varied food intake). Conversely, food security is reported to have been harmed in some cases where smallholder farmers lost entire crops due to floods and did not plant enough rice to feed their families because they had converted the land to dikes and canals (Ahmed et al. 2010). Reports of net profit from gher technology are also variable, with estimates between US\$141-1,180 per ha in one study (Alam et al. 2007), and US\$1,470-3,145 per ha in a different study (Karim et al. 2012). This technology appears to benefit from economies of scale, with farmers with larger landholdings ( $>0.4 \mathrm{ha}$ ) earning US\$1,132 per household per year, compared to smallholder farmers with $<0.2$ ha earning only US\$476 per household per year (Ahmed et al. 2010). Reports from key informants state that the net situation of smallholder farmers has been improved since the introduction of gher technology (Ahmed 2012). Reportedly, the livelihoods of those who partake in fry collection and day laboring (including women and children) have been improved due to demand for their products and employment opportunities with wealthier gher farmers (Ahmed et al. 2010). This author also notes that landless women can now find laboring jobs, including feeding, dike cropping, harvesting, and post-harvest handling (Ahmed et al. 2010).
Table 3. Outcomes from traditional and improved gher production from Ahmed et al. (2010), Hossain et al. (2006), Paul and Vogl (2011), Karim et al. (2012), and Wahab et al. (2012).

\begin{tabular}{|c|c|c|}
\hline & Traditional gher & Improved gher \\
\hline Total yield $\left(\mathrm{kg} \mathrm{ha}^{-1} \mathrm{yr}^{-1}\right)$ & $\begin{array}{l}3,000 \text { and } 6,000 \\
\text { with traditional } \\
\text { and high- } \\
\text { yielding varieties, } \\
\text { respectively }\end{array}$ & 3,710 \\
\hline Shrimp (kg ha-1 $\mathrm{yr}^{-1}$ ) & $100-500$ & $600-15,000$ \\
\hline Fish $\left(\mathrm{kg} \mathrm{ha}^{-1} \mathrm{yr}^{-1}\right)$ & No & $986-2,209$ \\
\hline Rice $\left(\mathrm{kg} \mathrm{ha}^{-1} \mathrm{yr}^{-1}\right)$ & $3,000-6,000$ & 2,257 \\
\hline Vegetables (yes/no) & No & Yes \\
\hline Net profit (US\$ ha-1 $\mathrm{yr}^{-1}$ ) & $651 \pm 1065$ & $141-3,145$ \\
\hline
\end{tabular}

Operating a gher system facilitates integration of production commodities and has the potential to enhance the environmental sustainability of the system. For example, integrating freshwater prawns into gher systems raises the required energy, labor, and variety of feed ingredients (Rahman \& Barmon 2012). However, the system is still considered environmentally sustainable because of the large positive energy balance $(80,820 \mathrm{Mj}$ per ha) from the rice component, which is improved in the presence of fish and prawns due to the fertilizing effect of excess feed and feces (Rahman \& Barmon 2012). The situation is likely similar for shrimp ghers. In addition, the water stored in the canals can be used to irrigate rice during the dry season, reducing pressure on groundwater resources (Rahman \& Barmon 2012). Overall, the net energy balance of the gher is $18,510 \mathrm{Mj}$ per ha (Rahman \& Barmon 2012). However, the environmental sustainability of this intervention hinges on hatchery rearing, because collection of wild post larvae and the associated bycatch is suggested to have impacts on coastal fisheries and biodiversity (Ahmed et al. 2010). A sustainable supply of feed ingredients is also paramount, because production of high-protein feeds contributes significantly to global warming potential, acidification potential, and eutrophication (VGREEN 2012).

Gher technology that was largely disseminated through farmerto-farmer interaction is now being facilitated further by NGOs and extension agents, including WorldFish projects in the region. Gher technology was reported by Ahmed et al. (2011) to be founded by a local innovator in 1987, and adoption has been widespread, particularly in Bagerhat District. Dissemination appears to have occurred horizontally, with farmers witnessing the success of their neighbors and converting their own rice fields to integrated gher systems (Ahmed et al. 2010).

The review of gher literature indicates that high production costs are commonly reported by gher farmers as the biggest limitation, particularly for smallholder farmers (Ahmed et al. 2010). There is still a lack of information about the development outcomes and impact of gher technology on household food, nutrition, and income security. In particular, the question remains whether this is a beneficial technology for marginal groups, particularly those with limited land.

Integrating small indigenous fish species (SIS) into polyculture ponds. Here we review a productivity intervention whereby SIS are integrated into polyculture systems with rohu (Labeo rohita), catla (Catla catla), common carp (Cyprinus carpio), and silver carp (Hypophthalmichthys molitrix). It was found that the yield of the cash crop (carp) is unaffected, and the additional crop of SIS contributes to increased consumption of the small nutrition-rich fish species by members of the household. Stocking density can be optimized to achieve high yields $\left(20.3 \mathrm{~kg}\right.$ per $100 \mathrm{~m}^{2}$ per 155 days) and a low food conversion ratio (Milstein et al. 2009). The 
addition of silver carp to this system is particularly important for enhancing productivity, and results in total yield increases from approximately $4,025 \mathrm{~kg}$ per ha per year to $6,039 \mathrm{~kg}$ per ha year (Kadir et al. 2006). Further, it was found that $2,800 \pm 800 \mathrm{~kg}$ per ha per season of SIS fish can be cultured in polyculture systems, of which $47 \%$ is consumed by the farming household (Roos et al. 2007). This addition to diets has the potential to improve nutrition security, as SIS are rich in vitamin A, calcium, iron, and zinc (Kadir et al. 2006; Roos et al. 2007). Income may also be raised due to sale of small fish, which sometimes have high value. In an integrated polyculture-SIS system, the gross income was estimated at US\$1,692 per ha, compared to the control treatment (i.e., where no SIS were added), which generated an estimated US\$1,384 per ha (Kadir et al. 2006). This technology is suitable for farmers with small landholdings; the mean farm size of project farmers was $0.8 \pm 0.5$ ha (Jahan et al. 2008). It is therefore likely that this technology is suitable to homestead ponds for which women tend to play a significant role. Gender disaggregated data are required to determine the impact on and roles of women and men in households adopting integrated polyculture-SIS systems.

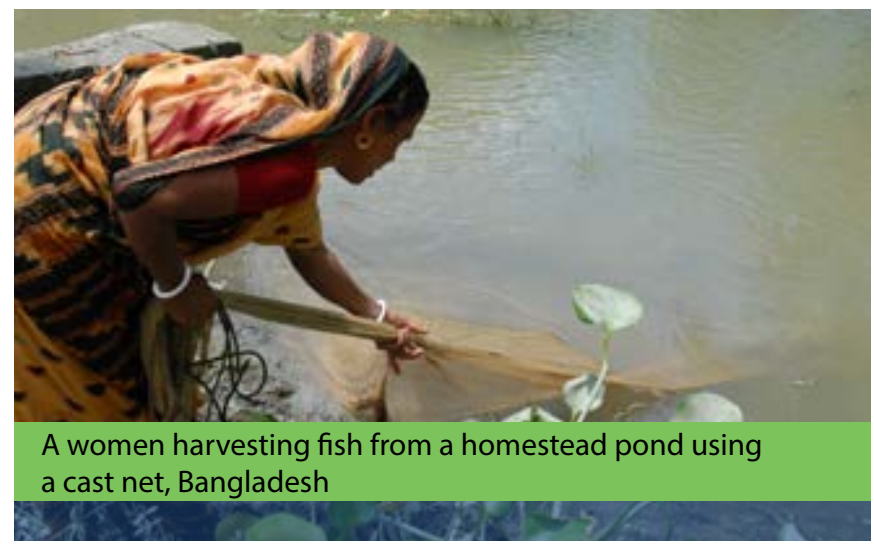

The environmental sustainability of integrated polyculture-SIS systems has not been assessed despite their reliance on external inputs such as fertilizers. For example, at 10-day intervals, urea, triple super phosphate, and lime are applied at a rate of $1 \mathrm{~kg}$ per $100 \mathrm{~m}^{2}$ per pond, and manure is applied at a rate of $6.5 \mathrm{~kg}$ per $100 \mathrm{~m}^{2}$ per pond (Kadir et al. 2006). Nevertheless, by integrating fish species that occupy different ecological niches (such as filter feeding herbivores and benthophagous fish) in the same pond, nutrient resources are likely to be used efficiently, and environmental impact is potentially lessened compared to monoculture fish systems. A further gain attributed to integration of these species is the instrumental role that common carp play in releasing nutrients and lime from the pond sediments while feeding, which stimulates phytoplankton growth and enhances the efficiency of liming (Milstein et al. 2002).

Dissemination of integrated polyculture-SIS technology requires long-term, regular training, as demonstrated by Jahan et al. (2008), who trained 225 farmers fortnightly through formal and informal training sessions over a period of three years. Although this study only focused on carp polyculture, and not the inclusion of SIS, it presents an effective training model which could be used to disseminate SIS technology, provided there were sufficient funding and resources available to apply the model on a wider scale. There is evidence that polyculture technology has led to improvements in pond productivity and household development outcomes. Out-scaling this technology presents a significant opportunity for rural households, but out-scaling should occur hand in hand with a simple monitoring and evaluation scheme conducted through participatory action research to ensure the impact of this intervention can be measured. In addition, farmer innovations should be encouraged and documented to ensure the system continues to adapt to changing socioeconomic and environmental conditions.
High-yielding, stress-tolerant rice varieties and improved management. Here we review improved management and cultivation of high-yielding rice varieties (HYV) as an intervention for improving productivity in traditional rice systems. HYV have been selectively bred for characteristics that confer resistance to a range of biotic and abiotic stresses. These characteristics include non-photosensitivity, shorter growth cycles, resistance to various diseases, and tolerance to salinity (Saltol gene), submergence (Sub1 gene), and drought. Improved varieties reduce the risk associated with climate change and variability by surviving in unfavorable conditions. For example, salt-tolerant varieties demonstrate $50 \%$ yield increases over traditional varieties in conditions of high salinity, and some improved varieties can survive submergence for up to 14 days (Molden 2007). HYV enhance the productivity of farming systems by $1-3$ metric tons per ha compared with local varieties (Mackill et al. 2012). Between the 1969-1970 season and the 2001-2002 season, the average rice yield increased from 1.7 to 3.5 metric tons per ha due to the introduction of HYV across Bangladesh (Hossain et al. 2006). The productivity of rice plantations with improved varieties can be further enhanced through rigorous management. In a study conducted in Khulna District, earlier planting (November 7-15) with improved boro varieties of rice (BRRI dhan28 or PVS B8) reduced the risk of crop loss due to cold weather, and planting in early to midNovember ensured that there was adequate water available through irrigation and natural rainfall (Mondal et al. 2010). Additionally, under these conditions crops yielded 4-5 metric tons per ha, and an additional $14 \%$ of net cultivable area could be irrigated if rice were planted between November 7 and 15 (Mondal et al. 2010).

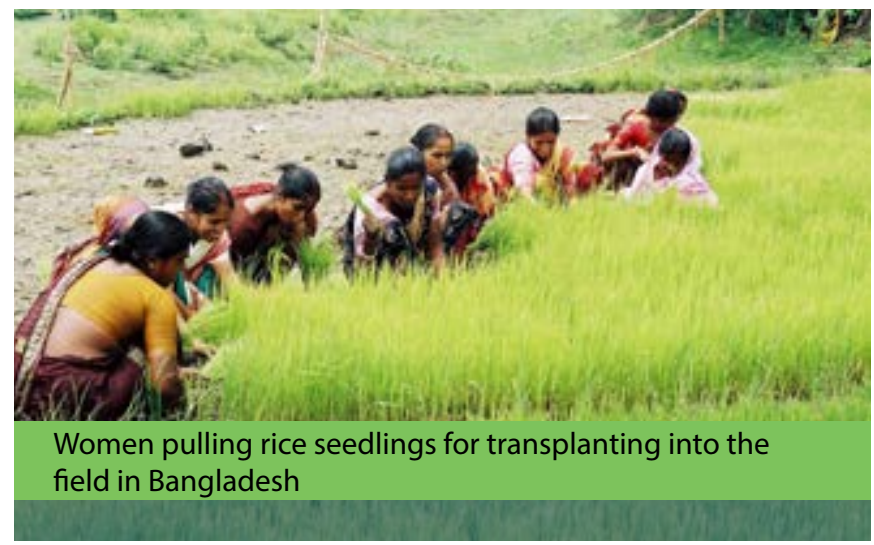

The increases in productivity achieved by planting HYV and by improving farming practices have led to tangible development outcomes. For example, in 2000 the gross monetary value attained by cultivating improved varieties of rice was US\$519 per ha, compared to traditional varieties, which fetched a gross value of US\$326 per ha (Hossain et al. 2006). These income benefits were accessible both to relatively wealthier farmers and to small and marginal farmers, because markets for water and fertilizer were competitive, keeping the prices for these inputs low (Hossain 1996; Hossain et al. 2007). Concerns regarding the nutritional quality of HYV have been raised, as HYV are typically a good source of starch (energy) but contain very limited protein, minerals, and vitamins. For households consuming HYV, it is important that additional foods are available to diversify diets in order to obtain the missing minerals and vitamins. The improved variety BRRI Dhan-29, which is widely cultivated as a HYV, is of poor nutritional value in terms of the Glycemic Index (>70) and low protein content $(5.8 \pm 0.13 \%$ compared to BR-26, which has $8.8 \pm 0.18 \%$ protein; Howlader \& Biswas 2009). Instead of BRRI Dhan-29, the varieties BR-16 or Pajam are recommended due to their superior nutritional qualities (Howlader \& Biswas 2009), although rigorous testing has not been conducted. Often there is a tradeoff between high-yielding properties and nutritional value. Testing and improving the productivity of other HYV that have better nutritional value (e.g., high vitamin A levels) is an important area of ongoing research (Howlader \& Biswas 2009). 
As with the introduction of any modified variety, there are concerns about environmental impacts. For example, there is potential for reductions in agro-biodiversity due to the substitution of one or two improved varieties for a range of traditional varieties and the concomitant use of pesticide and fertilizers with HYV. This concern is particularly imminent for rice varieties in Bangladesh, where the introduction of HYV has resulted in fewer than 100 varieties of rice being cultivated, compared to approximately 8,000 varieties 30 years ago (Amin 2001; Rahaman et al. 2011). A loss of biodiversity makes a system vulnerable to environmental challenges, such as disease outbreaks, which are predicted to be more erratic due to the impacts of climate change (Chapin et al. 2000; Thornton \& Cramer 2012). To redress biodiversity loss, the scientific rice-breeding community preserves each variety of rice (traditional and improved) in a seed bank, which ensures that seeds with different characteristics are preserved and always available.

The International Rice Research Institute (IRRI) has disseminated improved rice varieties, Swarna-Sub1 and BR11-Sub1, through the Stress-Tolerant Rice for Poor Farmers in Africa and South Asia (STRASA) program. To determine the strain of HYV to disseminate, the program conducted participatory varietal selection, which highlighted the preferences and reasons for these preferences of both women and men (Mackill et al. 2012). The two improved rice varieties released by IRRI were planted by 25,000 farmers in Bangladesh and reached $65 \%$ of rice-growing regions through training and extension facilitated largely by the Bangladesh Rice Research Institute, which worked to inform farmers about the benefits of improved management and timely planting (Hossain et al. 2006; Mackill et al. 2012). Adoption was initially constrained due to lack of irrigation infrastructure, which hampered rice production in the dry season (Hossain et al. 2006). In the 1980s, the market for irrigation services was developed when the government removed a ban on private sector imports of agricultural machinery (Hossain et al. 2006). The private sector was instrumental in promoting shallow tubewells, which improved irrigation facilities and enhanced uptake of HYV (Hossain et al. 2006).

There are many lessons and intricacies relating to the introduction of HYV that must be considered and carefully managed. Introduction of improved varieties of rice has implications relating to cultural and social norms, and it is important to understand the underlying cultural and social dimensions which determine the end use of the rice. For example, some households may sell the improved variety of rice to buy local varieties because of the status, preferred flavor, and grain shape associated with traditional varieties. Therefore, linking development outcomes to the introduction of HYV is complex, and must be accounted for in monitoring and evaluation strategies. In addition, the introduction of HYV requires efficient and timely water management, a scenario which also applies to rice-fish integration, gher systems, and many other productivity interventions for Bangladesh. Bangladesh is an interesting case because human-made polders were constructed around most districts in the coastal zone, initially to reduce the intrusion of saline water into productive farming systems. However, with the introduction of brackish water shrimp farming, many conflicts over water management have arisen, often resulting in the relatively better-off members of the community deciding how to manage water entrainment into the polder. Systems to ensure equitable and efficient water management have not been implemented but are crucial to the success of farming interventions. Productivity constraints can only be addressed through efficient and collective community-based water management, awareness of environmental issues, training, and local policy reform to ensure water quality remains suitable for all users.

Floating gardens. The construction of floating gardens is a productivity intervention which has the potential to harness stagnant floodwater to culture vegetables (e.g., ginger, cowpea, eggplant, snake gourd) under hydroponic conditions. Large floating beds are constructed using aquatic flora, typically the prolific weed water hyacinth (Irfanullah et al. 2008; Ullah et al. 2009; Irfanullah et al. 2011). Vegetable seedlings are subsequently transplanted from the homestead production system to the floating bed as monsoon floodwaters rise (Irfanullah et al. 2008). A project was initiated in northeast Bangladesh by the World Conservation Union and CARE Bangladesh that targeted 21 families who were landless and illiterate (Irfanullah et al. 2008). Twenty meetings were organized to share information regarding floating gardening, and one formal training session was held before the monsoon season when floating gardens are constructed (Irfanullah et al. 2008). The majority of the five to eight vegetable varieties cultured on a single bed are consumed by the household, contributing to food and nutrition security over the monsoon season (Irfanullah et al. 2008). The combined mean income from a $7-\mathrm{m}^{2}$ floating bed and a $120-\mathrm{m}^{2}$ winter garden plot is US\$10 (range: US\$7-20) in 150 days (Irfanullah et al. 2008), suggesting the technology has limited scope for poverty reduction. Floating gardens might be adopted by asset-poor households to provide income and food, which is especially important for the resilience of households whose land becomes submerged during the wet season (Ullah et al. 2009), but further improvements are necessary. Experiences from NGO projects to date suggest that women are particularly interested in this technology, with over $70 \%$ of approximately 200 attendees at initial awareness meetings in Habiganj District being women (Irfanullah et al. 2008). A gender balance was encouraged for the duration of the project, and husbands responded positively towards their wives' participation (Irfanullah et al. 2008), but no other information on sustained gender outcomes was available.

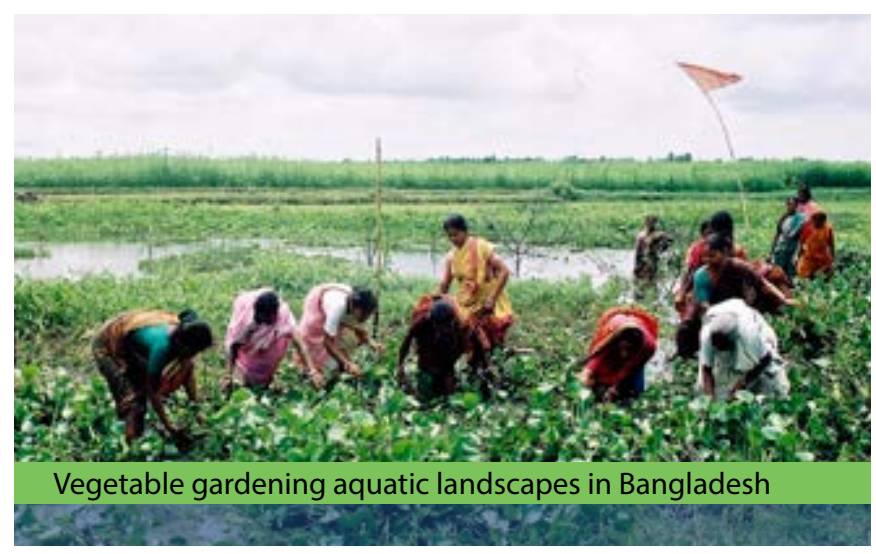

The environmental sustainability of these systems has not been quantified, although external fertilizers, irrigation, and additional land are not required. In terms of environmental sustainability, collecting large amounts of aquatic flora has both advantages and disadvantages. In cases where aquatic weeds such as water hyacinth are used to build the floating bed, then floating gardens present an opportunity for weed control; however, where large amounts of aquatic weed are not available, collection of aquatic plants may threaten some native species. Hydroponic gardening enhances nutrient cycling by providing compost for winter gardens once the floodwaters have subsided. In addition, there are reports that vermicompost technology (growing worms within the compost for natural fertilizer), is being developed using the degrading floating garden bed, and that vermicompost can be sold for almost US\$19 per kg (Rezaul Haque, A. H. M. Pers. Comm. DFID-SHREE project). From a $2.0 \times 0.5-\mathrm{m}$ plot, reports suggest that farmers sell $25 \mathrm{~kg}$ of vermicompost per annum and use a small portion for their own gardens (Rezaul Haque, A. H. M. Pers. Comm. DFID-SHREE project).

Lessons from the literature suggest that supporting new farmers to visit existing farms is a successful training technique; however, this approach may not be scalable with financial resources (Irfanullah et al. 2008). This technology has the potential to create opportunities for women who were not already involved in income-generating activities and also provides access to fresh vegetables for marginalized households whose land becomes submerged during the monsoon season (Irfanullah et al. 2008). 


\section{Cambodia}

Five productivity interventions were reviewed that are relevant to aquatic agricultural systems in Cambodia (Table 4). These include implementing community fish refuges to provide habitat for fish over the dry season, integrated rice-fish systems, multi-purpose farming systems, and forage-based production systems to produce on-farm livestock feed.

Table 4. An overview of the selected case studies in Cambodia.

\begin{tabular}{|c|c|c|}
\hline Intervention & $\begin{array}{l}\text { Aquatic agricultural } \\
\text { system }\end{array}$ & Key references \\
\hline $\begin{array}{l}\text { Community fish } \\
\text { refuges }\end{array}$ & $\begin{array}{l}\text { Seasonal floodplain } \\
\text { rice field fisheries }\end{array}$ & $\begin{array}{l}\text { Doma \& } \\
\text { Yakupitiyage 2011; } \\
\text { Joffre et al. 2012; } \\
\text { Horlte et al. 2008; } \\
\text { Viseth et al. 2008 }\end{array}$ \\
\hline $\begin{array}{l}\text { Integrated rice-fish } \\
\text { systems }\end{array}$ & Rice field fisheries & $\begin{array}{l}\text { Halwart \& Gupta } \\
\text { 2004; Joffre et al. } \\
\text { 2010; Soviet } 2007\end{array}$ \\
\hline $\begin{array}{l}\text { System of rice } \\
\text { intensification }\end{array}$ & Rice fields & $\begin{array}{l}\text { Anas et al. 2011; } \\
\text { Anthofer 2004; } \\
\text { CEDAC 2008; } \\
\text { Dobermann 2004; } \\
\text { Ly et al. 2012; } \\
\text { Resurreccion et al. } \\
\text { 2008; Roger 1996; } \\
\text { SRI-Rice 2012; } \\
\text { Suryavanshi et al. } \\
\text { 2013; Uphoff et al. } \\
2011 \text {; WASSAN } 2006\end{array}$ \\
\hline $\begin{array}{l}\text { Multi-Purpose } \\
\text { Farm }\end{array}$ & $\begin{array}{l}\text { Mixed-crop } \\
\text { residential zone with } \\
\text { rain-fed lowland rice } \\
\text { and cash crops }\end{array}$ & $\begin{array}{l}\text { IFAD 2010; } \\
\text { Soviet 2007; } \\
\text { Wijeratna } 2012\end{array}$ \\
\hline $\begin{array}{l}\text { Forage crop-based } \\
\text { production system } \\
\text { or forage banks }\end{array}$ & $\begin{array}{l}\text { Rain-fed lowland } \\
\text { aquatic agricultural } \\
\text { systems }\end{array}$ & $\begin{array}{l}\text { Maxwell et al. 2012; } \\
\text { Stür et al. } 2002\end{array}$ \\
\hline
\end{tabular}

Community fish refuges (CFRs). CFRs management is implemented for fisheries conservation and for improving the productivity of rice field fisheries (Joffre et al. 2012). Refuge ponds are confined water bodies which retain water throughout the year and may be either human-made or occur naturally. During the wet season, the fish migrate into the seasonally flooded rice fields. In the dry season, CFRs provide habitat for indigenous and introduced fish species, including snakeheads (Channa striata), catfish (Clarias batrachus), climbing perch (Anabas testudineus), and gouramis (Trichogaster spp). Occasionally, hatchery-raised juvenile silver barb, Barboides gonionotus, are also stocked in the CFRs (Joffre et al. 2012). The impact on productivity and development outcomes was investigated by the Freshwater Aquaculture Improvement and Extension Project supported by JICA. Survey data were collected regarding four fish refuge ponds of different sizes (0.15-80 ha) that were located in Takeo, Kampong Speu, Kampot, and Prey Veng provinces (Viseth et al. 2008). Annual catch of fish and aquatic animals in these CFRs was estimated to be 86-684 $\mathrm{kg}$ per household, with per capita consumption of $17.4-47.8 \mathrm{~kg}$ (Viseth et al. 2008), although the study does not elucidate how the fish were shared within the household. According to the survey findings, the increase in the fish catch rate after establishment of fish refuge ponds was $20-50 \%$ (Viseth et al. 2008). Similar reports were made by Thuok (2009), who surveyed 291 fishers and found that mean fish catch rate was six times greater in the presence of CFRs, doubling household income and bringing the mean fish catch up to $348 \mathrm{~kg}$ per person per year. In a separate study, the Aquaculture and Aquatic Resources Management (AARM) project stocked 750-10,000 juvenile fish per ha into CFRs in central and southern Cambodia. The authors claim that this increased the productivity of the system beyond the productivity of rice fisheries without CFRs, which yielded $119 \pm 25 \mathrm{~kg}$ per ha per season, though the productivity of systems with CFRs has not been quantified (Horlte et al. 2008; Joffre et al. 2012).

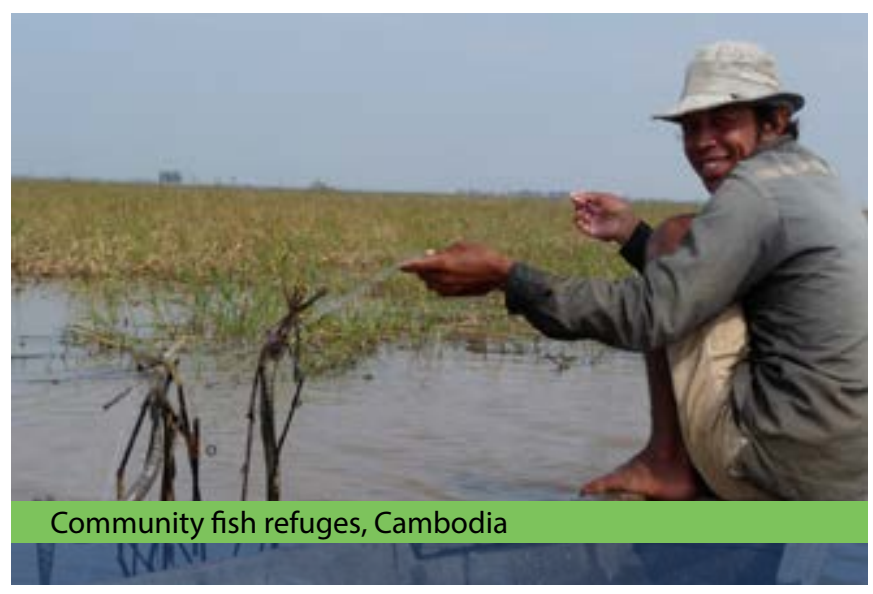

Approximately 7.2 million people participate in rain-fed rice field fishery each year (Horlte et al. 2008), so it is suggested that establishing a CFRs in a village has a positive impact on local livelihoods, especially for those dependent on open access fisheries (typically the landless poor); however, direct links have not been made. With the marketing values of target commodities being US\$1.5 per kg for fin fishes, US\$0.75 per $\mathrm{kg}$ for shrimp, US\$1.5 per kg for frog, US\$0.75 per kg for snail, and US\$0.6 per $\mathrm{kg}$ for crab, the economic benefit of the fish refuge ponds was estimated to be between US\$2,300 and US\$35,500 in the 2006-2007 fishing season (Viseth et al. 2008). Using the maximum number of households participating in fishing activities during the wet season, this equates to economic benefit due to CFRs of US\$18 per household for Samrang village, US\$45 per household for Piry village, US\$29 per household for D.T. Khang Cheung village, and US\$378 per household for Prey Kdouck village (Viseth et al. 2008).

Dissemination and adoption of this intervention has been reasonably widespread. Refuge ponds were first introduced to Cambodia in 1995 through the AARM project supported by AIT (Joffre et al. 2012). The Cambodian government, through the Fisheries Administration (FiA), has encouraged implementation of CFRs, and between 1998 and 2004, a total of 16 CFRs were set up in the seasonal floodplain region. As of July 2011, a total of approximately 670 CFRs were recorded nationally by the FiA, with a geographic concentration in the southeastern provinces (Joffre et al. 2012). Dissemination and implementation of CFRs to benefit smallholder farmers is complex, because CFRs are typically not privately owned, as the connecting rice fields become open access when inundated. Access to such fishing grounds and resources therefore needs to be managed collectively, and dissemination of the technology needs to be targeted at entire communities (Doma \& Yakupitiyage 2011). Hence using CFRs to enhance rice field fisheries requires a community-based approach rather than individual, household, or private sector initiatives. Through knowledge dissemination and training, communities can agree collectively on a combination of regulations needed to manage the water bodies and the resources. Examples of such regulations include banning certain fish equipment, having closure periods, or establishing monitoring and surveillance programs.

There are three key aspects of CFRs that need further investigation. First, an innovative monitoring and evaluation scheme is required to attribute changes in the density and species diversity of fish to CFRs and different interventions within CFRs. Fish abundance is site-specific and difficult to measure due to differences in the natural productivity of different CFRs, the dispersal of fish during the wet season, differing hydrology regimes, distance from 
permanent water bodies, unregulated fishing pressure, and pollution emissions. Examining the impact of different interventions within CFRs, such as brush parks and water quality management, would add rigor to the design and understanding of CFRs implementation. Second, the effect of the CFRs on rice and agricultural productivity in associated fields has not been quantified, and changes in herbicide or pesticide use may affect fish productivity in CFRs. Conflicts may also arise between farmers practicing the system of rice intensification (SRI) and those implementing CFRs. Alternate wetting and drying cycles are an integral practice for SRI farmers and may restrict flooded areas, which are required to facilitate fish migration in agro-ecosystems with CFRs. Third, governance issues, power relations, and who gets access to and makes decisions about CFRs, as well as how CFRs affect the most marginalized groups and women and children, have not been elucidated. Understanding and resolving governance issues are critical for CFRs success, since beneficiaries of this intervention are numerous and not well identified, and fish migration covers large areas, particularly in the floodplain. CFRs in one region may benefit communities in another region, resulting in little incentive for a single community to manage a CFR. Finding successful, sustainable, and replicable models of collective action in Cambodia is a challenge (Joffre \& Sheriff 2011). Implementing CFRs is complex, as a result of the technological, marketing network, and institutional challenges, such as changes in access rights and water management (Joffre et al. 2012). Therefore, while the current initiative of the Cambodian government to develop CFRs ponds represents an important step towards building capacity and infrastructure for fisheries and aquaculture development, further research and testing is needed to improve productivity and sustainability, and to ensure equity of these systems (Sheriff et al. 2010).

Integrated rice-fish systems. In rice-fish culture systems in Cambodia, pangasius catfish (Pangasius conchophilus), silver barb (Barbanymus gonionotus), tilapia (Oreochromis niloticus), or common carp (Cyprinus carpio) are raised between rice crops while rice fields are flooded. Fish yields of between $100-300 \mathrm{~kg}$ per ha can be achieved under stocking regimes of $0.03-0.45$ individual per $\mathrm{m}^{2}$ (Joffre et al. 2010). Halwart and Gupta (2004) analyzed rice-fish yield data published between 1977 to 1992 in five other countries in Asia (China, India, Indonesia, the Philippines, and Thailand), and revealed that growing fish in rice fields also increases rice yields in most instances. The analysis demonstrated that despite the area for rice cultivation being decreased in rice-fish culture, in $80 \%$ of cases the introduction of fish in rice fields resulted in slightly higher yields (>2.5\%) compared to growing rice without fish (Halwart \& Gupta 2004). The impact of higher yields on development outcomes is not well understood, and there is a paucity of literature regarding cost-benefit analyses and household gains from rice-fish systems in Cambodia. However, in Bangladesh, the Philippines, and Indonesia, rice-fish systems offer financial gains over rice monoculture, with 51$208 \%$ increases in net returns (Halwart \& Gupta 2004). It is assumed that household food security and nutrition will be improved through the concurrent production of carbohydrates and animal protein in rice-fish systems; however, this assumption has not been tested in Cambodia, and information regarding nutrition impacts is also limited elsewhere (Halwart \& Gupta 2004; Masset et al. 2011).

Rice yield increases are attributed to increased inputs and better management due to the presence of the fish, which compensates for the loss in rice production area (Halwart \& Gupta 2004). In addition, the fish forage for feed in the rice field, consuming worms, insects, and grass seeds and thereby increasing rice productivity. The fish also re-suspend sediment particles while swimming, which oxygenates particles and facilitates aerobic mineralization and release of dissolved nutrients. Deposited fish feces further enrich soil organic matter (Soviet 2007). Farmers may use fertilizers to increase the naturally occurring food organisms in the rice field and supplements to feed the fish directly. The use of supplemental feeds is required if a certain degree of intensification is desired, since the natural food in a rice field is probably not adequate to support a higher biomass of fish. Feed supplements such as duckweed, termites, earthworms, and rice bran may be used (Gregory 1997).

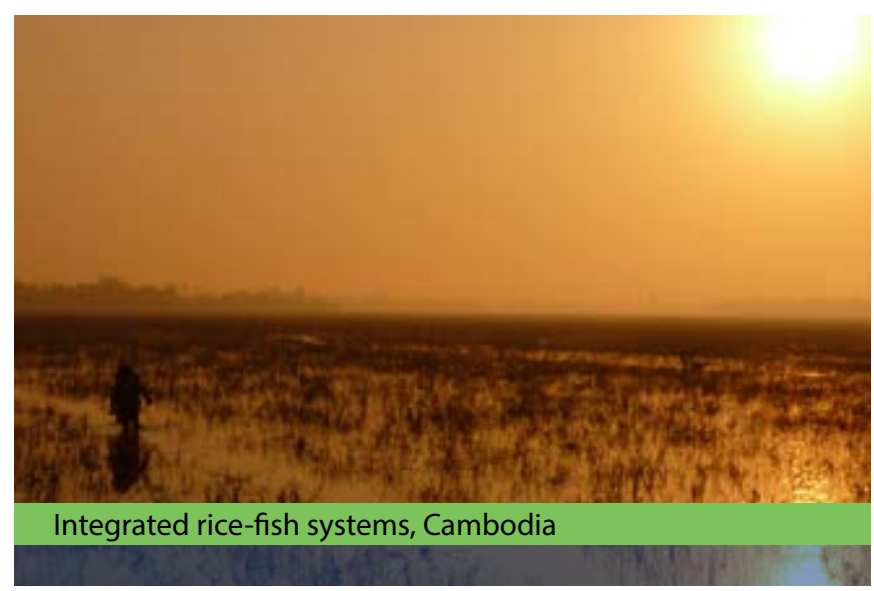

Theft is a prominent issue in rice-fish culture in Cambodia, with the only solution being 24-hour monitoring of systems, particularly before fish harvest. Monitoring is logistically difficult, especially if systems are located far from households, which is especially a concern for women. Alternative low-cost solutions could be identified and tested as part of the AAS program, and land tenure models that are conducive to reducing fish theft should be explored. In addition, the drivers of low adoption of rice-fish technology in Cambodia should be better understood to determine the suitability of rice-fish systems for the AAS target households.

System of rice intensification (SRI). SRI is an intervention comprising a set of eight management practices, developed through participatory action, to increase the productivity of mono-crop rice-based systems. Examples of the management practices include early transplanting of strong seedlings at wide spacing $(25 \times 25 \mathrm{~cm}$ to $50 \times 50 \mathrm{~cm})$ to allow for manual weeding, alternating flood-dry cycles, and application of organic fertilizers (Anthofer 2004). Farmers are now classified as SRI participants if they practice four of the eight principles of SRI. In theory, the management practices provide optimal conditions for individual rice seedlings to grow deep, dense roots into the soil to access water and nutrients. This increases resilience to drought and enhances rice seedling survival in unfertile soils. In Cambodia, rice yield under SRI regimes significantly improved, from 2026-2296 $\mathrm{kg}$ per household in conventionally managed rice systems to 2934-3275 kg per household in SRI over the 2009-2010 cropping season (Ly et al. 2012). The size of the rice fields in this study varied from $0.75-1.91$ ha and was not significantly different between farms managed under conventional regimes and those managed under SRI regimes (Ly et al. 2012). Anthofer (2004) demonstrated similar yield increases, from $1629 \mathrm{~kg}$ per ha to 2289 $\mathrm{kg}$ per ha, due to adoption of SRI technology. These yield increases occur despite a reduction in the quantity of seeds used, suggesting system productivity increases. In areas where water resources are limited, employing SRI reduces the need for continuous flooding and significantly increases water productivity to $3.56 \mathrm{~kg}$ per ha per $\mathrm{mm}$ compared to conventional transplanting and double transplanting at $2.61 \mathrm{~kg}$ per ha per $\mathrm{mm}$ and $2.87 \mathrm{~kg}$ per ha per $\mathrm{mm}$, respectively (Suryavanshi et al. 2013). There is debate surrounding the impact of converting to SRI on labor productivity and whether SRI increases labor requirements, making it unsuitable for resourcepoor farmers. Dobermann (2004) reported that SRI is labor intensive compared to conventional systems. However, Anthofer (2004) reported that land and labor productivity were increased under SRI management in Cambodia, with labor reduced by 10 man-days per ha during uprooting and transplanting periods. Labor demand for weeding increased, but labor is more readily available during weeding periods (Anthofer 2004). 


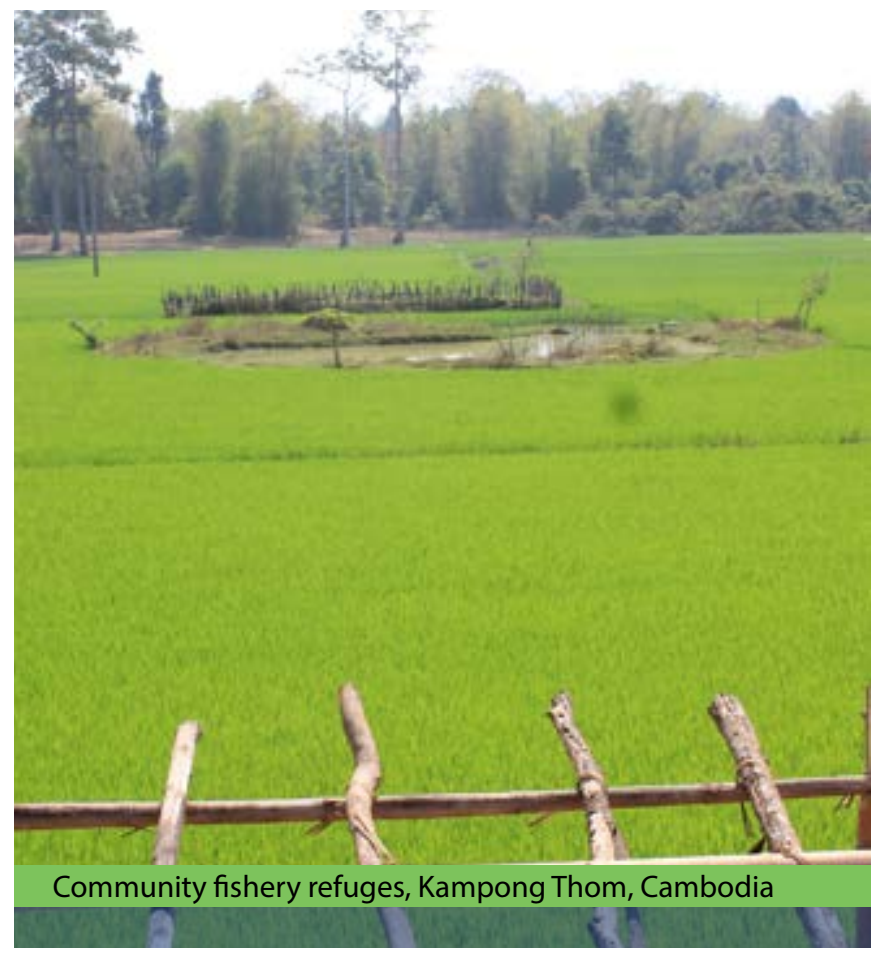

Reported development outcomes include increased income and improved social situation (CEDAC 2008). In the five provinces of Kandal, Kampong Thom, Kampot, Takeo, and Prey Veng, gross profit margin increased from US\$120 per ha to US\$209 per ha for farmers who adopted SRI (Anthofer 2004). In these villages, if farmers converted $21 \%$ and $42 \%$ of their rice land to SRI (from conventional practices) then the marginal profit supplied 2.2 and 4.6 months of a household's rice supply, respectively (Anthofer 2004). In Kampong Speu, Kampot, and Takeo provinces, the social status of SRI-adopter farmers was improved above that of non-adopter farmers through farmers joining savings groups, farmer associations, and organic producer groups (CEDAC 2008). This reportedly enhanced collaboration and knowledge sharing among farmers (CEDAC 2008). In addition, income increased in these provinces from US\$103 \pm 2 per household per year in non-SRI adopters to US\$153 \pm 8 per household per year in SRI adopters (CEDAC 2008). SRI technology is suitable for small-scale $(\sim 1 \mathrm{ha})$, resource-poor farmers who cultivate rice under water scarcity regimes (Dobermann 2004). It is particularly suitable for farmers who have limited financial assets for fertilizers, seeds, and pesticides (CEDAC 2008). Women's participation is similar in SRI farming and conventional farming, and women usually take part in seedling preparation, uprooting, transplanting, weeding, and harvesting (Resurreccion et al. 2008). In some cases, women's participation in labor tasks such as uprooting, seedling preparation, and land preparation have lightened because the labor has become more intensive and is therefore conducted by men (Resurreccion et al. 2008). This has left women with more time for domestic work and income-generating homestead activities (Resurreccion et al. 2008). However, female-headed households who rely on male labor to complete the more intensive labor tasks under SRI regimes are left disadvantaged due to limited access to male labor (Resurreccion et al. 2008).

Research on SRI suggests gains from diversifying the farming system. Although SRI applies to rice mono-cropping systems, smallholder farmers practicing SRI typically have a diverse farming system adjacent to the SRI plot, and crop rotation and multi-cropping are common. Potential environmental benefits from SRI include reductions in the utilization of herbicides and inorganic fertilizers. While reductions in inorganic fertilizer use due to increases in the use of organic composts were demonstrated in Cambodia, changes to herbicide use have not been quantified (Anthofer 2004). There are suggestions that herbicide use actually increases under SRI regimes because limited shading and competition from wide rice plant spacing enables weeds to proliferate, and manual weeding is labor intensive (Dobermann 2004). However, utilizing mechanical weeders, such as the cono weeder, harnesses the organic matter resource within weeds by digging them back into the soil and simultaneously aerating the soil, stimulating microbial activity and micronutrient release (WASSAN 2006). Further environmental gains are suggested through reductions in methane emissions. In experimental plots in India, cumulative methane emissions were lowest in SRI treatments at 19.93 ka per ha, compared to conventional transplanting and double transplanting at 32.33 and 29.30 ka per ha, respectively (Suryavanshi et al. 2013).

Though converting from conventional best management practices to SRI can be risky in optimal lowland rice-growing areas where water is not limited and the soil is clayey and fertile (Dobermann 2004), in suboptimal conditions SRI can help mitigate the effects of some soil nutrient toxicities and enhance soil microbial activity. In particular, some soils are prone to a buildup of the reduced compounds of ferrous iron $\left(\mathrm{Fe}^{2+}\right)$ or hydrogen sulfide $\left(\mathrm{H}_{2} \mathrm{~S}\right)$, which can accumulate to toxic levels (Roger 1996; Dobermann 2004). Farmers who cultivate rice under these conditions will benefit from periodic drying, implemented during SRI, to ensure that the root systems are oxygenated (Roger 1996; Uphoff et al. 2011). Older studies state that if farmers have ample water resources, rice fields should be flooded to enhance biological activity and $N_{2}$ fixation, mobilize nutrients, and stimulate primary productivity (Roger 1996). However, recent studies on soil microbial activity in SRI in India and Indonesia reported higher levels of enzyme activity attributed to increased availability of nitrogen and phosphorus and increased soil microbial carbon and nitrogen pools accessible for both microbes and rice plants (Anas et al. 2011).

Dissemination of SRI technology in Cambodia has predominantly been facilitated through NGOs; in particular, Centre d'Etude et de Development Agricole Cambodian (CEDAC) and the GTZsupported Rural Development Program have been instrumental for the scaling up of this technology (SRI-Rice 2012). SRI was first introduced to 28 farmers in Cambodia in 2000 (Anthofer 2004). Reports suggest that by 2008 , approximately 100,000 rice farmers were practicing SRI (CEDAC 2008). However, elsewhere SRI has been adopted during periods of extension support with high subsequent disadoption rates, and where adoption was sustainable, it took farmers extended periods of training and extension visits to be confident with using SRI practices (Dobermann 2004).

Some important lessons come to light from the review of SRI literature. First, as with many cropping systems, dissemination and training should not focus narrowly on SRI, but rather should include training on a complementary set of skills encompassing employment rights, entrepreneurial skills, and other livelihood activities such as poultry, vegetable, and fish production (Resurreccion et al. 2008). Second, evidence for or against SRI technology is still mixed, and there are very distinct schools of thought both strongly in favor of and against the introduction of SRI. At this stage, the success of SRI appears largely dependent on the suitability of local conditions, and the AAS program potentially provides a platform to establish environmental and socioeconomic conditions under which SRI would, if at all, increase system productivity and lead to development outcomes. SRI should be conducted only in areas proven ecologically suitable for this technology, and implementation of SRI technology should be used as a learning tool to gradually improve the management of rice fields without compromising product quality or production. 
Multi-purpose farm through farmer association (MPF-FA). To increase agricultural productivity, some smallholders in Cambodia use high-input chemical fertilizers and pesticides, which are prohibitively expensive and negatively affect people's health, soil quality, and the wider agro-ecosystem (Wijeratna 2012). In response, CEDAC introduced the MPF-FA initiative in 2003 (Wijeratna 2012). The aim of Multi-Purpose Farm technology (MPF) is to increase productivity through better integration of production components without increased external inputs. MPF includes the production of rice, fruit trees, multi-purpose trees, perennial crops, seasonal crops, vegetables, farm animals, and fish (Soviet 2007). One of the focuses of MPF is to use local knowledge, seeds, and varieties, and it emphasizes the initiative being farmer-led and farmer-propagated. In MPF, farmers retain around $50 \%$ of their land area for their rice field, while other spaces are transformed into ponds for storing water and aquaculture production (Soviet 2007). The excavated soil from the ponds is typically laid out adjacent to the ponds, providing a fertile resource on which to create the upper fields (Soviet 2007). In the upper fields, mixed crops and fruit trees are grown (Soviet 2007). A recent survey of 107 farmers who adopted the low-input MPF indicated that rice yields increased by $61 \%$, and the amount of costly rice seeds used was reduced by $53 \%$, while the use of chemical fertilizers dropped by $72 \%$ (Wijeratna 2012). Additional research over the last decade showed an increase in rice yields of 30-150\% (IFAD 2010; Wijeratna 2012).

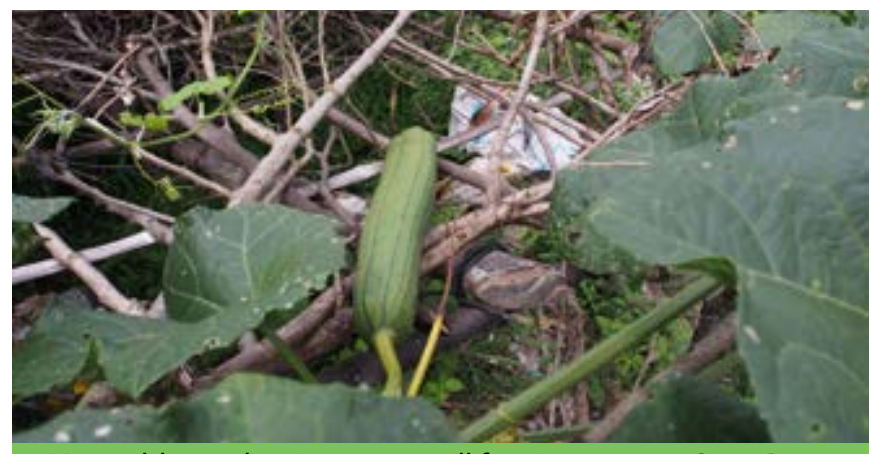

Vegetable production on a small farming system, Siem Reap

Reports suggest that under certain conditions MPF provides higher rice yields (with SRI), in addition to producing vegetables, fruit, other crops, fish, firewood, fodder, and green manure, and providing food and shelter for livestock. There is also potential to optimize MPF to provide year-round profitable work opportunities for households reliant on off-farm labor, though this requires further investigation to optimize system components towards employment generation. Yield increases have the potential to lead to development outcomes, with application of MPF on an area of approximately $0.7 \mathrm{ha}$, increasing income from around US\$190 per year to US\$600 per year (Wijeratna 2012). Other reports claim increases in farm profits by $300 \%$ (IFAD 2010; Wijeratna 2012), though the data were not provided. The average sum of money invested for developing MPF is approximately US\$300 per year (Soviet 2007). According to Soviet (2007), increases in agricultural productivity also lead to improved family food security due to household consumption of diverse products, including meat, fish, fruit, and vegetables, which also potentially improves nutrition and health. However, no specific empirical evidence was presented, and there is no indication as to how the products are distributed among family members. MPF is targeted at smallholder farmers whose land assets range from 0.2 to $0.6 \mathrm{ha}$, and who cannot produce enough to feed their families (Wijeratna 2012). The benefits and adaptations of MPF are diverse and are therefore suited to households with varying household strategies and asset bases (Soviet 2007). There is potential for year-round food production with optimal combinations of produce, which is particularly inviting for households subjected to food and income shortages during the dry season when seasonal crops are difficult to grow.
The environmental sustainability of MPF is suggested to be high and attributed to diversified and integrated farming practices that improve soil quality, eliminate the use of chemical fertilizers, and protect against soil erosion, making greener landscapes (Soviet 2007). In theory, crop rotation to maintain soil fertility is practiced by alternating summer wet season rice production with vegetables or legumes during the dryer winter season (Soviet 2007), though the impacts of this practice have not been tested. The cultivation of perennial and semi-perennial trees in the upper fields is likely to enhance soil structure in the long term, albeit initial disruption of soil structure will occur during the construction stage when converting from traditional rice cultivation to MPF.

Dissemination of this technology has occurred, with approximately 50,000 initial adopters of MPF-FA across Cambodia under the direct support of CEDAC, plus the spin-off Farmer and Nature Network (FNN; Wijeratna 2012). However, effective resourcespresumably manuals, extension agents, and farmer field schools-are limited, and a lack of farmer knowledge has resulted in farmers failing in their attempt to implement MPF (Soviet 2007). Soviet (2007) compiled case studies from five successful MPF farmers to create a manual for farmers wishing to adopt MPF. Farmer innovation and adaptation to local conditions are the cornerstones of successful MPF systems but are yet to be utilized to their full potential.

The sustained adoption of MPF by smallholders in the AAS hubs of the Tonle Sap plain and lower floodplain is dubious and not widespread, likely because rice cultivation is a historical paradigm, and converting traditional systems to multifaceted systems requires acquisition of new skills and outlay of resources. The factors driving adoption in different regions need further assessment. In regions where adoption of MPF is likely, this intervention has potential to enhance equitable gender relations through the integrated and varied activities encouraged by this intervention. Social messaging appropriate to the hub context could be included in AAS dissemination programs to address gender inequalities that may hinder household well-being and development outcomes. This intervention provides a potential opening to implement gender-transformative approaches within productivity enhancement interventions.

Forage banks to improve livestock (cattle) feeding. Livestock are an important part of most smallholder farming systems in Cambodia. Cattle are used as draught animals and provide meat and milk for home consumption, manure for fertilizer and cooking, and cash income. They are typically the most important asset or capital that can be readily converted to cash when the need arises (Stür et al. 2002). Forage crop-based production systems (FCP), or forage banks, are suggested as an intervention to improve the productivity of small-scale livestock production in Cambodia (Maxwell et al. 2012; Weeratunge et al. 2012). Forage banks are plots of grasses and legumes cultured close to the homestead. Empirical data demonstrating the effect of forage banks on livestock productivity are currently not available; however, qualitative data suggest that forage banks fatten livestock, ensure cattle calve earlier, and provide feed during the months when feed is scarce (Purcell et al. 2000; Maxwell et al. 2012). 


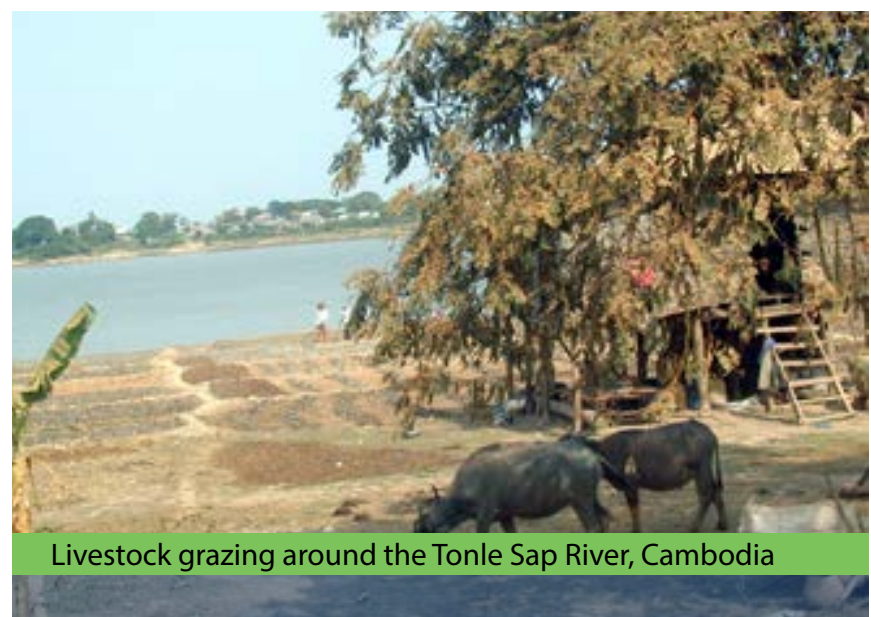

Given the lack of evidence linking forage banks to improvements in productivity, empirical links to development outcomes are also lacking. There are reports that in systems where forage banks have been introduced, there is a reduction in the time spent collecting food for livestock. Previously farmers (primarily women and children) who engaged in "cut and carry" of wild forage to provide food for tethered animals had to travel long distances, with up to eight hours per day being dedicated to gathering fodder (Maxwell et al. 2012). FCP adoption therefore leads to benefits for children, because children participating in fodder collection sacrifice their attendance at school (Maxwell et al. 2012). The average hours spent cutting and carrying are reduced from 12.8 child hours per week per family pre-FCP to 0.5 child hours per week per family post-FCP (Maxwell et al. 2012).

The environmental benefits of implementing forage banks include the production of legumes, which are beneficial for fixing nitrogen and improving soil fertility; they also have a high protein content, so are nutritious for livestock (Sumberg 2002). Farmers who adopted forage bank technology were able to diversify their farming systems and integrate other small livestock, legumes, and grasses, although the direct impacts of this integration are unclear. More obscure, albeit environmentally beneficial, was the installation of biodigesters by farmers who had more time, since they did not have to collect fodder (Maxwell et al. 2012). The biodigesters were fuelled with cow manure, which produced biogas for household cooking (Maxwell et al. 2012). This allowed households to cease cutting firewood, which was both beneficial for the environment and saved more time (Maxwell et al. 2012).

CIAT and ACIAR have been instrumental in disseminating livestock forage bank technology in Cambodia (Harding et al. 2007; CIAT 2008). Statistics regarding the rate of adoption and scaling out of FCP in the Tonle Sap region are not readily available. However, Cambodia DAHP, DA Kampong Cham, and RUA (with funding from ACIAR and UNE) have been working to integrate forages into smallholder systems throughout Cambodia through information and knowledge-sharing tools such as the SoFT website titled "Tropical forages: An interactive selection tool" (www.tropicalforages.info), which is targeted at researchers and educational institutions to facilitate and inform forage germplasm distribution and to filter knowledge down to farmer training (CIAT 2008).

Studies to date have not confirmed whether forage banks can improve livestock productivity and lead to improved nutrition, food security, and income. A monitoring and evaluation system that provides empirical evidence for or against these links is imperative before resources are invested in implementing this intervention.

\section{Solomon Islands}

Two productivity interventions were reviewed in Solomon Islands and are summarized, along with the key references, in Table 5: community-based resource management of coastal ecosystems and low external input sustainable agriculture.

Table 5. An overview of the selected case studies in Solomon Islands.

\begin{tabular}{|c|c|c|}
\hline Intervention & $\begin{array}{l}\text { Aquatic agricultural } \\
\text { system }\end{array}$ & Key references \\
\hline $\begin{array}{l}\text { Community-based } \\
\text { marine resource } \\
\text { management }\end{array}$ & $\begin{array}{l}\text { Coastal coral reef } \\
\text { systems }\end{array}$ & $\begin{array}{l}\text { Albert et al. 2012; } \\
\text { Albert et al. 2013; } \\
\text { Bell et al. 2009; } \\
\text { Boso et al. 2010; } \\
\text { Cinner et al. 2006; } \\
\text { Cohen \& Alexander } \\
\text { 2013; Cohen \& } \\
\text { Foale 2013; Cohen } \\
\text { et al. 2013; Foale \& } \\
\text { Manele 2004; } \\
\text { Govan 2009; } \\
\text { Schwarz et al. 2009; } \\
\text { Schwarz et al. 2012; } \\
\text { Williams et al. 2006 }\end{array}$ \\
\hline $\begin{array}{l}\text { Low external } \\
\text { input sustainable } \\
\text { agriculture }\end{array}$ & $\begin{array}{l}\text { Gardens \& estate } \\
\text { crop land }\end{array}$ & $\begin{array}{l}\text { Grayson 2002; } \\
\text { Grayson 2005; } \\
\text { Jansen et al. 2006; } \\
\text { Sechrest 2008; } \\
\text { Siliota et al. } 2008\end{array}$ \\
\hline
\end{tabular}

Community-based marine resource management (CBRM). As one response to redress declining productivity of coastal areas, CBRM initiatives are common and proliferating in the Coral Triangle region (Govan 2009). CBRM is community-led adaptive management of natural resources that combines scientific information and conventional approaches to management with customary and local institutions and knowledge; management arrangements are negotiated, adapted, and governed at the community (in this case, the village) level (Schwarz et al. 2012). In many cases, there is some level of support provided by the government, NGOs, or research agencies. We report such a case where WorldFish supported the implementation of CBRM with a cluster of five communities (Schwarz et al. 2009). By definition, the goals of CBRM were defined by the communities themselves, and in this case included the objective of maintaining or increasing the productivity of degraded coastal fisheries systems to support subsistence needs.

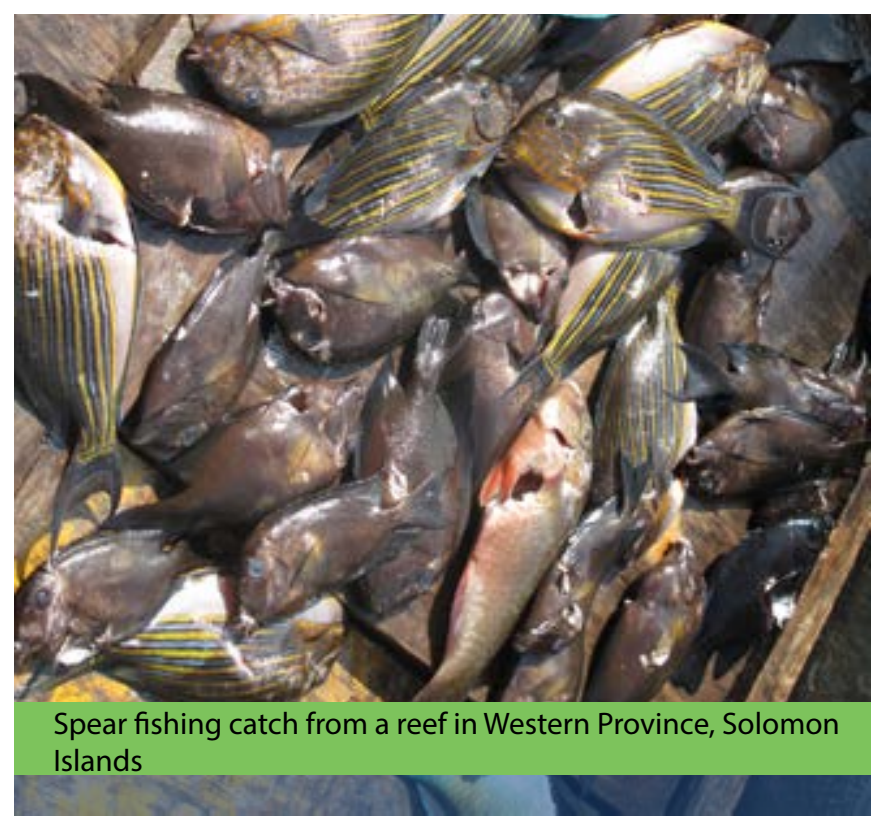


Management arrangements in these communities were devised following awareness raising and planning processes that were facilitated by WorldFish. Through their partnership with WorldFish, the communities were linked to a national network of CBRM practitioners, expertise, and experiences (Cohen et al. 2012); for example, community representatives were supported by WorldFish to participate in national-level meetings and workshops (Schwarz et al. 2012). Immediate development benefits from this CBRM initiative were reported to be community empowerment and capacity building, with the implicit outcome that communities were more informed and able to make, implement, and adapt sound management decisions (Schwarz et al. 2009; Schwarz et al. 2012). These decisions were formalized in a management plan that detailed a commitment to management measures, including size limits, gear restrictions, bans on harvesting spawning aggregations, and periodic closures of reefs and mangroves. In practice, the principal measure employed was the non-permanent closure of small areas of reef-in these cases, reef areas were closed to harvesting for 11 months and opened for one month each year (Cohen et al. 2013). This measure was intended to alleviate fishing pressure on these areas and to therefore enhance their productivity by allowing for and maintaining increases in abundance (i.e., more fish and invertebrates) and growth (i.e., bigger fish and invertebrates).

In this case, periodically - harvested closures appeared to have had some effect on productivity, as well as on when that productivity was harnessed. When periodically harvested closures were opened to harvesting, catch rates for invertebrates were higher than from reefs continuously open to fishing $(2.17 \pm 0.43$ compared to $1.03 \pm 0.24 \mathrm{~kg}$ per fisher per hour), suggesting that the period of closure was adequate for populations to replenish and build to some extent (Cohen \& Alexander 2013). Fishers perceived financial benefits from the periodic-harvesting management regime, as indicated by this quote from a fisher speaking at a community meeting:

"Before, only 5 or 10 [kg of trochus] you could catch; now when we opened the reef I counted how many trochus came off. In 2010 we collected $200 \mathrm{~kg}$ of trochus valued at $\$ 4000$. This was due to an increase in our trochus. Then in 2011 we caught $211 \mathrm{~kg}$ of trochus valued at $\$ 4220$."

However, catch rates for finfish were no different for spear fishing (1.27 \pm 0.22 compared to $1.42 \pm 0.44 \mathrm{~kg}$ per fisher per hour on open reefs) or for line fishing ( $0.91 \pm 0.40$ compared to $0.67 \pm 0.09 \mathrm{~kg}$ per fisher per hour on open reefs). Yet, some species of fish were slightly larger from periodically - harvested closures than from open reefs (Cohen \& Alexander 2013). While enhanced catch rates and larger fish represent short - term benefits to fishers, it is not yet clear whether total productivity of those reefs was enhanced or whether harvesting patterns were more sustainable in the longer term. The way in which reef productivity was harnessed was altered by the implementation of periodically - harvested closures, in that closures represented a minor, temporary reduction in accessible fishing grounds (i.e., at most $5 \%$ of the total reef area observed to be fished; Cohen et al. 2013). Opening areas to harvesting during the 11 months that they were closed was somewhat flexible, however, and openings occurred in response to elevated social and economic needs; that is, productivity was saved for times when needs were highest (Cohen et al. 2013).

Most reefs that were examined as part of this study, including the three that were periodically harvested closures, were harvested to a level below finfish yields that previous studies have suggested might be sustainable (5-10 metric tons per $\mathrm{km}^{2}$ of reef per year; Cohen et al. 2013). Quantitative data showed that over a full year, the amounts of non-finfish harvested from periodically harvested closures were low to moderate compared to yields from reefs continuously open to fishing. However, there are no multi-species estimates for maximum sustainable yield to indicate whether the levels of harvest were sustainable or not. For communities, retaining the flexibility to open periodically - harvested closures according to needs fits well with meeting social objectives, but in some situations socially or economically driven decisions to harvest these areas may not, in practice, coincide with sufficient increases in abundance and growth of some species. A suite of strategies and management measures will be required to enhance or maintain productivity of coastal systems and fisheries within the Coral Triangle, but periodically harvested closures, raised community awareness, and enhanced capacity provide useful foundations on which to further build such strategies.

At a national level, CBRM initiatives are directly supported by several NGOs and research agencies in practice and indirectly supported by the national government in policy and higherlevel processes. CBRM is spread across Solomon Islands via direct engagements of partner NGOs and research agencies, with new communities (as in this case) or via more passive processes where communities initiate and implement management alone, with information resources as the only form of external support (Govan et al. 2011). A national network of CBRM practitioners, called SILMMA, was established by the national fisheries agency and NGOs to promote collaboration, learning, and coordination among CBRM stakeholders, including NGOs, the government, and communities (Cohen et al. 2012). SILMMA provides one mechanism to disseminate information that supports and improves CBRM, and via its role in increasing coordination, can potentially support the dissemination of CBRM itself.

Experiences of CBRM in Solomon Islands offer increased understanding of the factors that enhance the success of the management process, such as inclusion of resource owners and users in decision making, raising awareness of resource related issues and the reasons for management, and increasing community-level capacity for decision making, negotiation, and monitoring (Boso et al. 2010). In terms of management measures applied, periodically - harvested closures or small reserves have been found to be particularly conducive to community-level implementation due to similarities with customary practice (Williams et al. 2006). The practice maintains fishers' ability to access and exploit resources in the area (Foale \& Manele 2004), and the community is able to observe stock replenishment or increased catchability after closures are lifted (Cinner et al. 2006). The results of the case described above and others suggest that these closures may result, however, in only modest gains in productivity in many situations. Productivity gains are more likely for fast-growing and highly fecund species and less likely for slower-growing species that have few successful offspring or have been heavily depleted by fishing (Cohen \& Foale 2013). In recognition of the ultimate limits to productivity of coastal fisheries systems and increasing demands on those systems, CBRM often incorporates other strategies that are designed to alleviate pressure on coastal areas by supporting fishers to source food or income elsewhere. For example, Fish Aggregating Devices (FADs) are commonly employed alongside CBRM to shift effort from nearshore to offshore areas and to assist small-scale fishers to harness currently less utilized pelagic productivity. For example, in this case reef fishing represented $73 \%$ of trips,mangrove/lagoon zones $8 \%$, and pelagic zones $17 \%$, with $2 \%$ of trips in more than one zone or in rivers. In this case a FAD was deployed but sank shortly after deployment (Schwarz et al. 2012). Yet, data from other cases suggest that FAD deployment can increase fisher income, household fish consumption, and household resilience while decreasing fishing pressure on coastal areas (Albert et al. 2012; Albert et al. 2013). At a national scale, CBRM approaches are commonly promoted and developed alongside other strategies, such as aquaculture, to deal with the predicted shortfall between coastal fisheries production and demand (Bell et al. 2009). 
Low external input sustainable agriculture (LEISA). LEISA is an intervention based on sustainable management practices, locally available inputs, and traditional knowledge. These management practices include on-farm breeding of vegetables with nonhybrid strains so that seed can be collected and used the following year, increased diversity of fruit and vegetables using traditional species, the use of biological sprays and pesticides of plant-based origin, integrated pest management, and the use of locally manufactured tools (Grayson 2002). The productivity impacts of this intervention have not been quantified; however, some qualitative evidence of the development outcomes is available. Small homestead gardens, or "sup sup" gardens, follow the principals of LEISA and represent an important source of food, nutrition, and income for many Solomon Islanders. Sup sup technology was integrated into a primary health care program focusing on nutritional education and monitoring through a link with a doctor at the Sasamunga Hospital (Grayson 2002). During her educational sessions, the doctor stressed the relationship between sup sup productivity and diversity, accessibility to diverse family meals, and health improvements (Grayson 2002). Between 1994 and 1997, the rate of underweight children decreased from 25\% to 15\% (Grayson 2002). This improvement was not exclusively attributed to the sup sup innovation and integrated primary health care program, but it does suggest that programs which focus on both agricultural and nutritional advice bolster success for development outcomes.

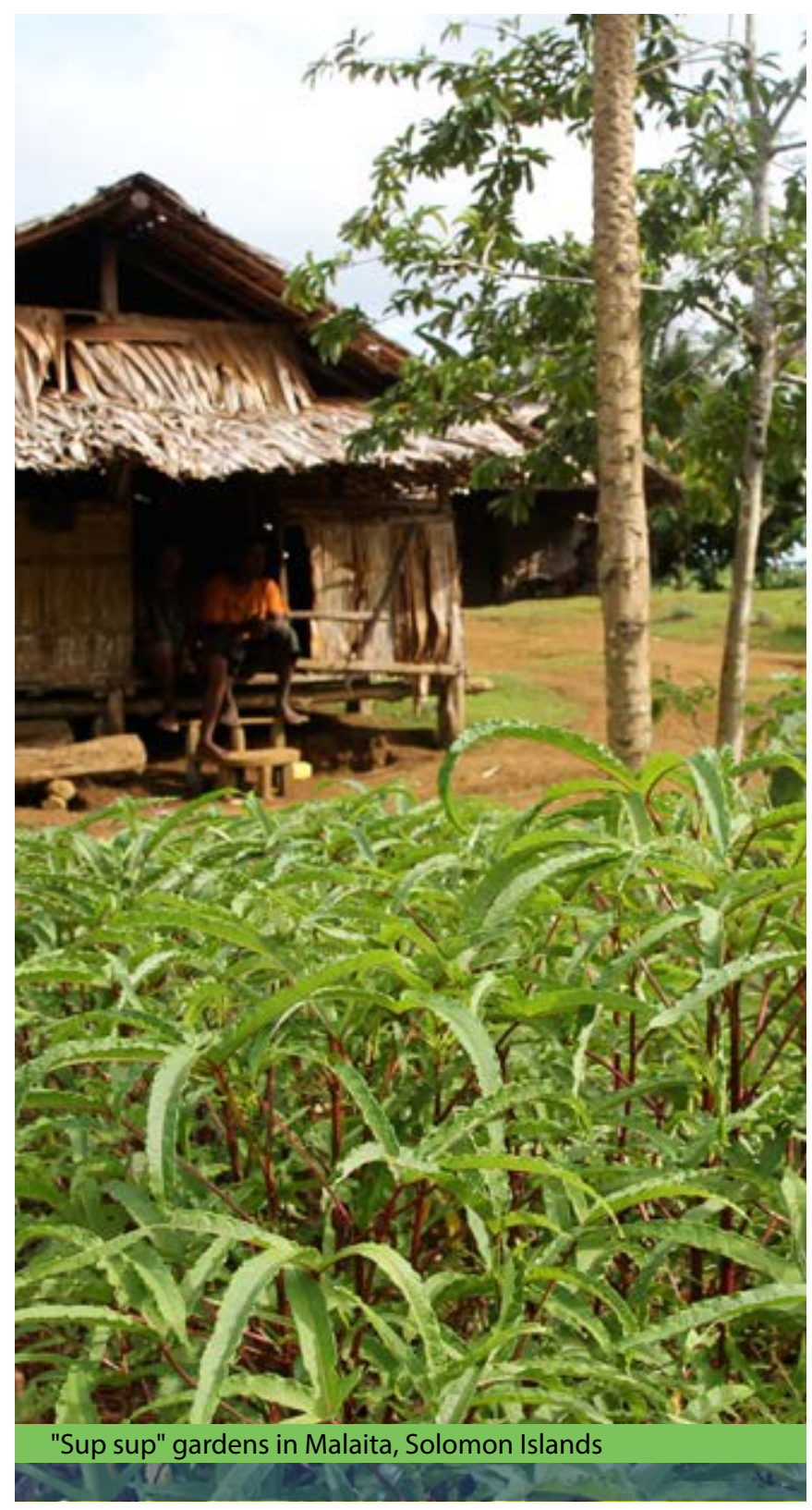

Integration of production components is an integral part of the LEISA intervention. An extensive range of fruits and vegetables (eggplant, taro, pawpaw, shallot, tomato, sweet pepper, cucumber, slippery and Chinese cabbage, yard-long bean, pumpkin, pak choi) are cultured together, and mulching with excess household organic waste (instead of practicing slash-and-burn agriculture) is encouraged to improve nutrient-use efficiency.

The training and participatory research techniques used to disseminate LEISA technology appear successful, and it is suggested that adoption of sup sup gardens was more widespread than previous interventions (Grayson 2002). This suggestion supports Sechrest (2008), who demonstrated high rates of kitchen garden adoption, as kitchen gardens are considered an accessible and convenient source of leafy vegetables for children. Fencing around home gardens is essential to prevent gardens from being destroyed by pigs and chickens and to ensure that adoption is sustainable (Grayson 2002). Techniques which enhanced adoption of LEISA were regular, informal conversations regarding farmer experimentation in their gardens, limiting the number of concepts introduced at one time, and having trainers set up their own sup sup garden to demonstrate their belief in the system (Grayson 2002). The adoption rate of the home gardening technologies of terracing, intercropping, reducing burning, green manure, contouring, fire ash, woodlot, kitchen garden, and new crop varieties was analyzed in women farmers (Sechrest 2008). Among these technologies, which were introduced by Peace Corps volunteers, intercropping had the highest adoption rate (61\%) because similar technologies were traditionally practiced (Sechrest 2008). Those with coconut plantations showed a high adoption rate to intercropping compared to those planting cocoa (Sechrest 2008). Additional technologies with high adoption rates were kitchen gardens (46\%) and green manure fertilization (41\%; Sechrest 2008). High adoption in both target and non-target participants was attributed to the gardens being very close to the homestead and therefore easily accessible for women. Woodlots, which are tree plantations with the purpose of providing fuel for the household, were least adopted (2\%), because women still found plenty of firewood in their area (Sechrest 2008). This is despite the fact that men identified accessing firewood for processing copra among the key problems.

Some important lessons were derived from this review. Despite the apparent success of the LEISA program, dissemination of knowledge regarding productivity interventions among smallholders in Solomon Islands has been a significant challenge for many gardening and cultivation programs (Grayson 2005; Jansen et al. 2006; Sechrest 2008; Siliota et al. 2008). Training from external organizations is not widespread, and available training has often targeted and been conducted by men (Siliota et al. 2008). Women are often intimidated by and will not seek advice from male extension workers (Sechrest 2008). Home gardening was traditionally conducted by both men and women, but is increasingly conducted by women. Men participate in land preparation, but men and women play different roles in farming, with some evidence that knowledge sharing between men and women is limited (Sechrest 2008). The adoption of gardening techniques was higher in the community where the Peace Corps volunteers lived in the community, joined the normal activities of the community members, and taught by demonstrating to the participants (Sechrest 2008). The second community, where the Peace Corps volunteers lived outside the community and only visited the community regularly, had lower adoption rates. Overall, the study, although limited in scope, highlighted a number of factors that may play a role in the adoption of LEISA technology, including who introduced the technology (male or female extension workers, live-in versus visiting volunteers), the farmer's assets and wealth, and the expectation of additional income (Sechrest 2008). 


\section{Philippines}

Five productivity interventions were reviewed from the Philippines (Table 6), spanning coastal mangrove ecosystems (rehabilitation and restocking), lowland rice-based systems (diversification), and coastal upland hilly systems (agroforestry).

Table 6. An overview of selected case studies in the Philippines.

\begin{tabular}{|l|l|l|}
\hline Intervention & $\begin{array}{l}\text { Aquatic agricultural } \\
\text { system }\end{array}$ & Key references \\
\hline $\begin{array}{l}\text { Improved } \\
\text { management } \\
\text { in agroforestry } \\
\text { systems }\end{array}$ & $\begin{array}{l}\text { Hilly upland coastal } \\
\text { system }\end{array}$ & $\begin{array}{l}\text { Baynes et al. 2011; } \\
\text { Bertomeu 2012; } \\
\text { Magcale-Macandog } \\
\text { et al. 2010; Newby \& } \\
\text { Cramb 2012; Snelder et } \\
\text { al. 2007 }\end{array}$ \\
\hline $\begin{array}{l}\text { Coconut } \\
\text { intercropping }\end{array}$ & $\begin{array}{l}\text { Hilly upland coastal } \\
\text { system or low-lying } \\
\text { coastal system }\end{array}$ & $\begin{array}{l}\text { Cabili \& Cuevas 2010; } \\
\text { Magat 2009; Magat } \\
\text { et al. 2007; Magat } \\
\text { \& Secretaria 2007; } \\
\text { Philippine Coconut } \\
\text { Authority 2004 }\end{array}$ \\
\hline $\begin{array}{l}\text { Mangrove } \\
\text { rehabilitation }\end{array}$ & $\begin{array}{l}\text { Mangrove } \\
\text { ecosystems }\end{array}$ & $\begin{array}{l}\text { Salmo \& Duke 2010; } \\
\text { Triño \& Rodriguez 2002; } \\
\text { Walton et al. 2006 }\end{array}$ \\
\hline $\begin{array}{l}\text { Restocking } \\
\text { mud crabs into } \\
\text { mangrove } \\
\text { systems }\end{array}$ & $\begin{array}{l}\text { Mangrove } \\
\text { ecosystems }\end{array}$ & $\begin{array}{l}\text { Braithwaite \& } \\
\text { Salvanes 2010; Lebata } \\
\text { et al. 2009; Lebata et al. } \\
\text { 2012; Lorenzen 2008 }\end{array}$ \\
\hline $\begin{array}{l}\text { Integrated } \\
\text { rice-based } \\
\text { systems and } \\
\text { location-specific } \\
\text { technology }\end{array}$ & $\begin{array}{l}\text { Irrigated and rain- } \\
\text { fed farming systems } \\
\text { for crops, livestock }\end{array}$ & $\begin{array}{l}\text { Abrogena et al. 2006; } \\
\text { Casimero 2010; } \\
\text { Philippine Rice Research } \\
\text { Inst. 2005; Romanillos et } \\
\text { al. 2012 }\end{array}$ \\
\hline
\end{tabular}

\section{Improved management in agroforestry systems. Since the} mid-1990s, the International Center for Research in Agroforestry (ICRAF) has been implementing the Landcare program to elicit social mobilization and encourage farming practices that conserve soil and water resources (Mercado et al. 2001). This productivity intervention encourages farmers to establish tree and shrub plantations (or natural vegetative filter strips) along contours around steep coastal hills in order to stabilize soils that are threatened by erosion and have poor soil fertility and water productivity (Magcale-Macandog et al. 2010; Newby \& Cramb 2012). The tree plantations typically comprise functionally important timber, rubber, legume, and fruit trees and are intercropped between cash crops of maize, rice, corn, or vegetables (Magcale-Macandog et al. 2010; Mercado et al. 2010; Mercado et al. 2012). Recently, improved management to enhance tree species selection and tree spacing has been tested to optimize the productivity of both intercrops and traditional cash crops (Bertomeu 2012). A four-year study in the uplands that border the coastal regions in Northern Mindanao compared hedgerow planting, where trees were spaced at $1 \times 10 \mathrm{~m}(1000$ stems per ha), with block planting, where trees were spaced at $2 \times 2.5 \mathrm{~m}$ (2000 stems per ha). In addition, the study determined maize productivity when intercropped with the legume trees bagras (Eucalyptus deglupta Blume) or gmelina (Gmelina arborea R. $\mathrm{Br}$.) within each planting design (hedgerow or block). Maize yield was higher using intercrops of bagras in hedgerow plantations (24.8 metric tons per ha) compared to block plantations (10.4 metric tons per ha; (Bertomeu 2012). Maize yield in control monocrop treatment was 30.6 metric tons per ha (Bertomeu 2012). Gmelina trees caused higher reductions in maize yields and lower estimated timber yields of $60-110 \mathrm{~m}^{3}$ per ha, compared to bagras timber yields of $146-185 \mathrm{~m}^{3}$ per ha (Bertomeu 2012).

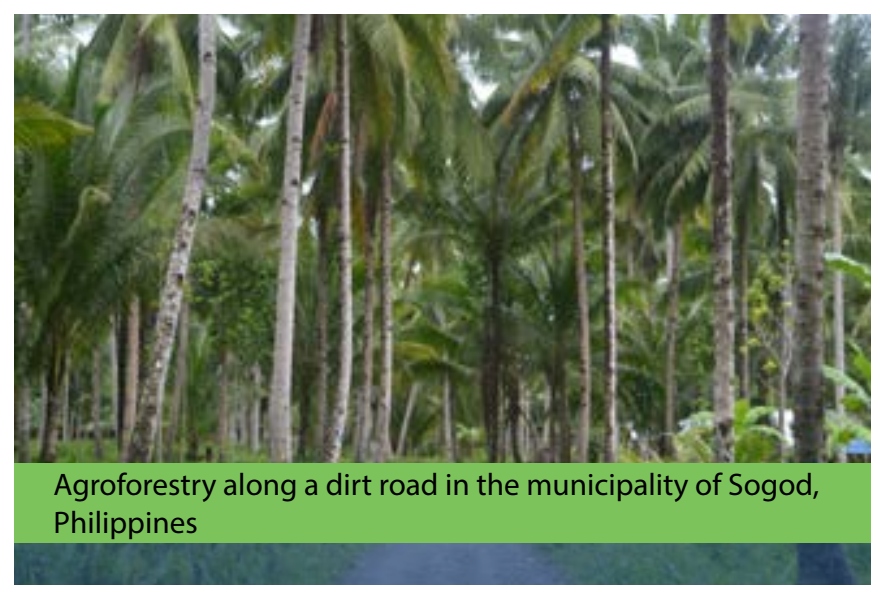

Agroforestry can increase food security and income for rural households. An estimated $25-50 \%$ of household food supply for subsistence farmers comes from trees in agroforestry systems, particularly from jackfruit, coconut, marang, mango, and avocado, which supply nutritious food during the lean months (MagcaleMacandog et al. 2010). In Claveria, once hedgerow agroforestry systems were established, income generation reached US\$2,463 per annum, compared to US\$1,037 in mono-crop systems (Magcale-Macandog et al. 2010). Fruit tree plantations in particular are perceived as long-term investments which supplement cash crops and provide regular and sustained cash flow without reinvestment (Snelder et al. 2007). However, initial investment in agroforestry systems is high, as fertilizer inputs and labor for planting, weeding, and pruning are necessary (Snelder et al. 2007). This technology is therefore suitable for farmers with land and capital assets (Snelder et al. 2007). The roles of men and women appear segregated in agroforestry, with women participating in marketing produce, managing household budgets, and cooking for the family (Magcale-Macandog et al. 2010). According to Magcale-Macandog et al. (2010), men manage farms and decide what trees should be planted and how they should be managed; however, the authors do not analyze how women and men actually relate, cooperate, make decisions, or resolve conflict, and the underlying power relations are not elucidated.

Intercropping with trees and shrubs increases the environmental sustainability in hilly upland coastal systems. This is evidenced by reductions in soil loss after heavy rainfall in Laguna from 100-200 metric tons per ha per year in traditional farm management systems to just 5 metric tons per ha per year in agroforestry systems (Paningbatan et al. 1995). Starapple, mango (Indian variety), jackfruit, pummel (Citrus maxima), and santol (Sandoricum koetijape) are particularly suitable for reducing erosion and also provide a source of food to rural households (Snelder et al. 2007). An additional environmental benefit is carbon sequestration, with $2.7 \mathrm{Mt}$ of carbon being sequestered annually in Filipino agroforestry systems (Lasco et al. 2010). Nitrogen cycling is also enhanced under agroforestry regimes. In systems with timber hedgerow intercropping, $\mathrm{N}_{2}$ fixation is estimated to range between $61 \mathrm{~kg}$ per ha in fouryear-old plantations to $250 \mathrm{~kg}$ per ha in 12-year-old plantations, contributing approximately $42 \%$ more soil nitrogen than in maize mono-cropping systems (Mercado 2007). Neighboring farmers who are asset poor and unable to access agroforestry technology may also benefit if ecosystem scale gains such as increased soil stability and fertility have flow-on effects to surrounding farms. 
Agroforestry plantations cover approximately half a million hectares in the Philippines, so knowledge dissemination and adoption of this technology have been reasonably successful (Lasco et al. 2010). Organizations such as the World Neighbors, IRRI, and the Philippine Department of Agriculture have facilitated a farmer-to-farmer extension program aided by manuals, which has accelerated the adoption of agroforestry (Lapar \& Ehui 2004).

In the Philippines, knowledge dissemination is more effective if manuals are accompanied by verbal explanations and training, because $38 \%$ of farmers have difficulty reading and comprehending written material, and the content is often misconstrued (Baynes et al. 2011). Also, 35\% of farmers lack confidence in learning situations (Baynes et al. 2011). This hinders technology adaptation and troubleshooting capacities (Baynes et al. 2011) and is an area where the AAS program could make a significant contribution. Dissemination of technical nursery information and information regarding harvesting legislation is also important for enhancing and sustaining adoption of agroforestry (Baynes et al. 2011).

Coconut intercropping. Interventions applicable to coconut mono-crop systems to improve productivity include introduction of livestock, soil amelioration with salt, improved fertilization (multi-nutrient fertilizer), utilizing high-yielding local varieties, and intercropping (Magat et al. 2007; Magat \& Secretaria 2007; Kruijssen 2009; Philippine Coconut Authority 2011). Intercrops comprising peanuts, garlic, tobacco, pineapple, corn, cassava, legumes, and citrus are being adopted in many regions (Philippine Coconut Authority 2004). In this section, we review intercropping with cacao, which is a high-value, sweet bean crop that increases the productivity of the farming system above that of a coconut monocrop. Reports indicate that 1.5 metric tons per ha of dried cacao beans can be produced on the approximately $78 \%$ of land between the coconut rows that is not utilized in coconut mono-crop systems (Magat \& Secretaria 2007; Rodriguez et al. 2007). In addition, the productivity of the coconut system is largely unaffected if coconut and cacao are cultivated at optimal densities based on local rainfall and soil regimes (Magat \& Secretaria 2007). Similarly, copra yields can be as high as 2 metric tons per ha (or 8000 nuts per ha) in intercropped systems (Magat \& Secretaria 2007).

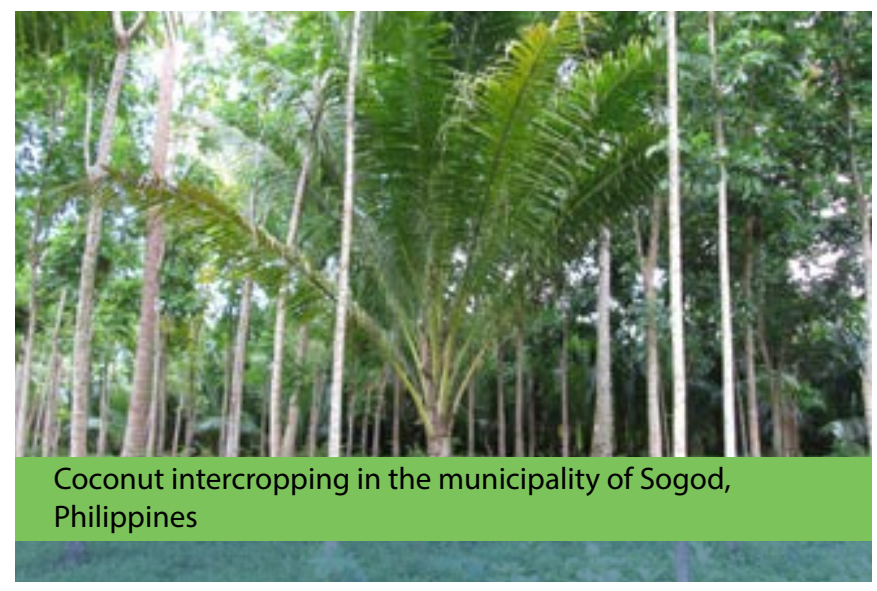

Generally, the program increased annual household income by US\$200-400 and decreased the poverty rate of participant farmers from $58 \%$ to $12 \%$ (Rodriguez et al. 2007). For nonparticipant farmers, the poverty rate was $39 \%$ before the program and increased to $52 \%$ after the program (Rodriguez et al. 2007). Magat and Secretaria (2007) also demonstrate the economic gains of intercropping coconut and cacao trees compared to mono-crop coconuts, with the annual net income five years after establishment of the cacao plantation being US\$2,858 and US\$518 per ha, respectively. Despite the increase in income, no quantitative link was made between increased food security or household nutrition and intercropping with cacao. In $2004,60 \%$ of coconut farms, or 2 million ha, were still mono-crop systems; therefore, there is potential to improve the annual net income of thousands of poor and vulnerable coconut farmers through conversion to intercropping systems (Philippine Coconut Authority 2004). Women do not typically play a major role in coconut production (FAO 2005), so crop diversification through intercropping may provide an avenue for women to participate in coconut production systems if they choose to do so (Scheewe 2003). The impact of converting from mono-crop systems to intercropped systems on women's well-being and livelihood activities and the changes in power relations between men and women after converting to intercropping systems should be determined.

Integrating cacao and coconut crops provides shade for cacao trees and is beneficial for cacao growth (Osei-Bonsu et al. 2002). Coconut and cacao trees more or less compete for nutrient and water resources, so tree spacing must be optimized and fertilization regimes increased to allow for optimal production of both crops (Magat \& Secretaria 2007). The environmental impact of increases in fertilization rates has not been quantified but is important given the close proximity of many coconut farms to coastal ecosystems that sustain fishing livelihoods and could be affected by run-off. In addition, the already significant carbon sequestration capacity of a coconut mono-crop system, which stands at approximately 24 metric tons of carbon per ha over 3.2 million ha, can be enhanced by integrating cacao trees into coconut mono-crops (Magat 2009). To date, sediment run-off from coconut farms in Northern Samar has proven minimal as indicated by the presence of Cymodocea seagrass and healthy fish productivity and diversity in adjacent coastal ecosystems (Cabili \& Cuevas 2010).

A model for dissemination of improved coconut farming in the Philippines is the MAUNLAD program, which is a comprehensive participatory program comprising access to credit, training services, and farmer-led monitoring and evaluation of coconut interventions such as integrated livestock and intercropping (Rodriguez et al. 2007). We recommend that a participatory program such as MAUNLAD be used to disseminate intercropping technology.

Three important lessons arise from this review. First, the amount of credit used and the total coconut area cultivated appear to be important factors determining farmers' participation in coconut intervention programs (Rodriguez et al. 2007), and these barriers should be addressed to allow poor farmers access to this technology. Second, further research is needed to determine the reasons that women do not actively participate in coconut production, and training programs should address these reasons and seek opportunities for women to participate in coconut farming. Third, in regions directly adjacent to the coast where farming activity or fertilizer use is intensified, environmental monitoring using the presence of Cymodocea seagrass as an environmental indicator should be conducted.

Mangrove rehabilitation. Mangrove ecosystem services have an estimated value of US\$60 per ha per year (Janssen \& Padilla 1999). In coastal Filipino communities, 1.3 million metric tons of mud crabs, gastropods, and fish provide essential food security and income (Janssen \& Padilla 1999; Perez et al. 2012). However, mangroves are suffering environmental degradation, leading to the loss of vital ecosystem goods and services. Mangrove rehabilitation is utilized as an intervention to preserve natural resources and to mitigate further environmental degradation. For example, the productivity and habitat functionality of a rehabilitated mangrove in Lingayen Gulf in the northwestern Philippines increased, as evidenced by 11 species of mollusks re-colonizing the area (Salmo \& Duke 2010). Mollusk abundance varied significantly with the age of the rehabilitated forest, and abundances of $1834 \pm 154$ and $352 \pm 108$ individuals per square meter were recorded in six- and 18-year-old forests, respectively (Salmo \& Duke 2010). The trend of initial colonization and high 
abundances of mollusks and then a slow decrease in abundance likely mirrors the mangrove tree density, which is initially high and subsequently decreases as the forest matures (Salmo \& Duke 2010). In a separate study of a rehabilitated mangrove in the Aklan province of Western Visayas, the productivity of the rehabilitated mangrove fisheries was estimated at $2204 \mathrm{~kg}$ per ha per year, compared to an estimated productivity of $1065 \mathrm{~kg}$ per ha per year had this area been converted to brackish water shrimp production ponds (Walton et al. 2006).

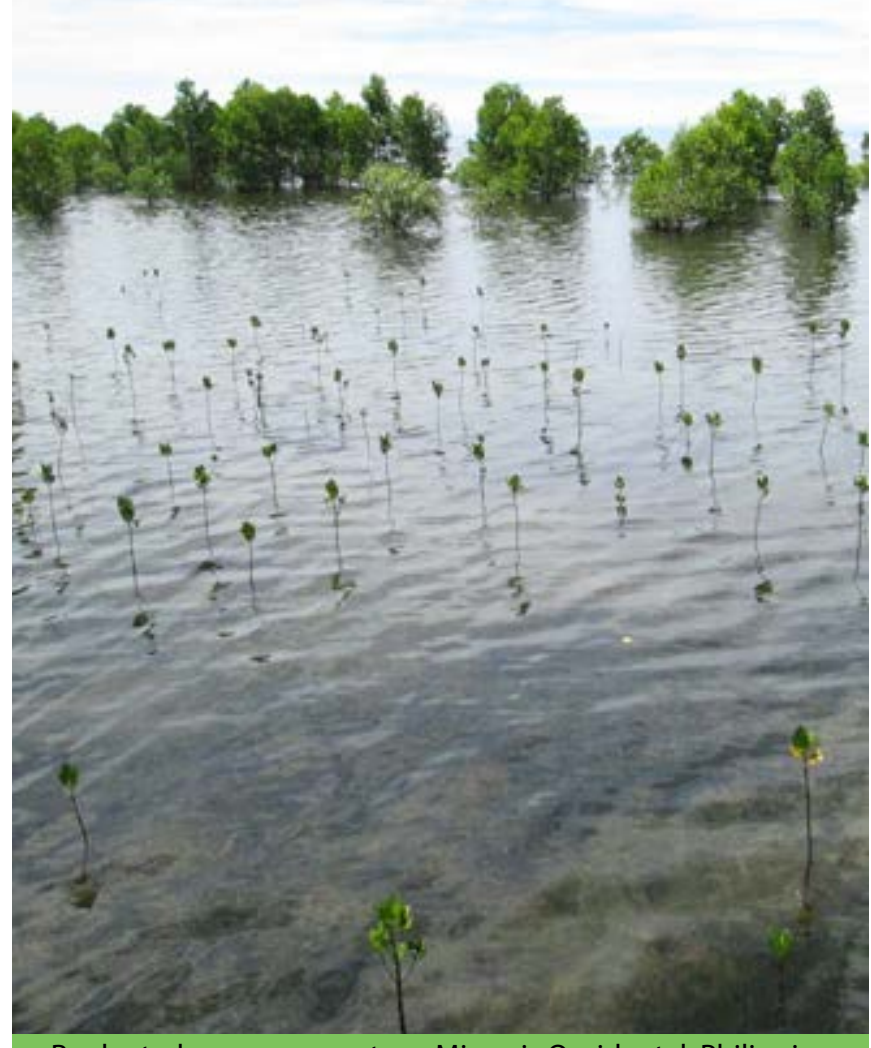

Replanted mangrove system, Misamis Occidental, Philippines

Research suggests that development outcomes result from the mangrove rehabilitation intervention and that marginalized, asset-poor groups might benefit from this intervention. Mangrove rehabilitation is an integrated approach, targeting multiple components of coastal ecosystems, which provide income andfood security for poor coastal communities. These components include fish, crabs, mollusks, timber, and tourism commodities, while enhancing coastal resilience against storms and offshore sediment and pollution runoff. In the Aklan province of Western Visayas, a plot that was rehabilitated by planting mangrove saplings in 1990 provided supplementary income and food to fishing families through fishing or gleaning (Walton et al. 2006). Landings of the mud crab, Scylla spp., were worth an estimated US\$100 per ha per year (Walton et al. 2006), and it is likely that these landings benefited marginalized coastal inhabitants due to their reliance on and access to mangrove habitats (Triño \& Rodriguez 2002). Total landings (inclusive of crabs, prawns, fish, and mollusks) in the rehabilitated mangrove in Aklan were 294 $\mathrm{kg}$ per ha per year; half of this was sold, and the remainder was consumed (Walton et al. 2006). Since there were 241 fishing families, comprising 465 people, responsible for these landings from the 75.5-ha plot, the produce remaining after sale equates to $24 \mathrm{~kg}$ available for consumption per person per year, which potentially contributed to food security and household nutrition. Indicators used to measure increases in productivity and habitat functionality of mangrove ecosystems attributed to rehabilitation projects include changes in forest structure and biomass, fish recruitment, and species composition and biomass of mangroveassociated fauna, such as crabs and mollusks (Salmo \& Duke 2010).
These or variations of these indicators could be applied should stakeholders in the AAS program decide mangrove rehabilitation would be beneficial for their community. Successful tools for dissemination need to be developed, and the gaps in the literature regarding the impact of landings from rehabilitated mangroves on food security and household nutrition, as well as how these landings were distributed among different members of the household, need to be elucidated. In addition, the roles of men and women in mangrove rehabilitation and the impact of these roles on improved fishery productivity are unclear.

Restocking mud crabs in mangrove systems. To ensure the success of mangrove rehabilitation programs, income-generating activities that specifically rely on the health of the mangrove ecosystem may be implemented to support livelihoods and motivate communities to nurture rehabilitated mangroves. One such intervention involves the stocking of hatchery-reared juvenile mud crabs into mangrove systems. Mud crabs are highly valued by Filipinos for their taste, texture, and nutritional value, and mud crab aquaculture and fisheries are important livelihood strategies (Triño \& Rodriguez 2002). However, loss of mangrove habitats and overfishing are resulting in declining populations of these crabs.

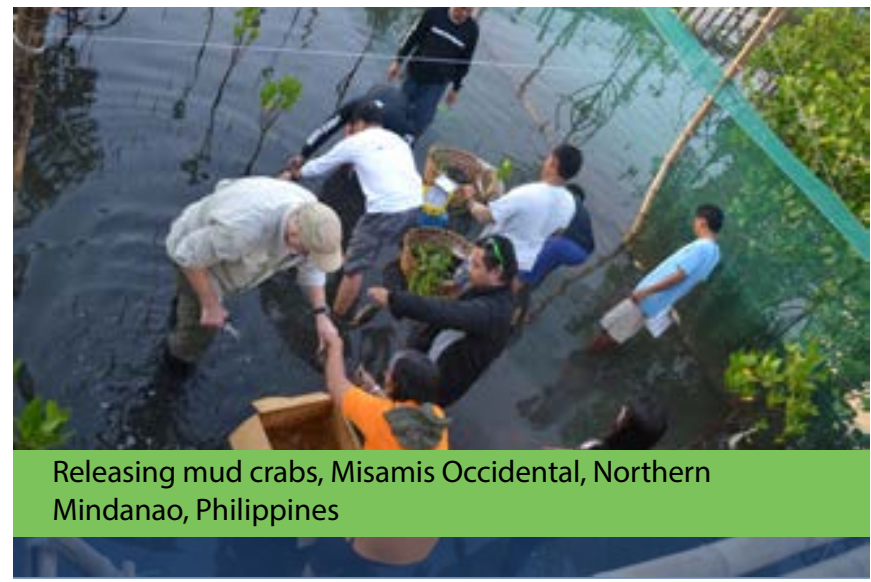

Preliminary investigations demonstrate that restocking with juvenile mud crabs (Scylla olivacea and S. serrata) increases fishery productivity by $46 \%$, from $48 \pm 3$ g per gear per day for wild crabs to $68 \pm 3 \mathrm{~g}$ per gear per day for total wild and restocked crabs (Lebata et al. 2009). Mean recapture rates range from $35-42 \%$, highlighting the benefits of releasing juveniles for both long-term stock improvement (more than $50 \%$ of released crabs remain un-captured, although some likely suffer mortality) and seasonal improvement in fishery productivity (Lebata et al. 2009; Lebata et al. 2012).

Fisheries enhancement programs can threaten environmental sustainability if they are not explicitly managed (Braithwaite \& Salvanes 2010). Wild populations of mud crabs will be affected through genetic and ecological interaction with hatcheryreared animals that have been exposed to different selection pressures and genetic lineages (Philippart 1995; Lorenzen 2008). The process of selecting brood stock with similar genetic diversity, phenotypic and life history traits, biological attributes, exposure to environmental conditions (burrowing habitats, fluctuating salinity), and intraspecific competition (feeding habits in aquaculture can cause aggressive behavior) is a complex but vital step to ensuring the environmental sustainability of the restocking program (Braithwaite \& Salvanes 2010). The environmental impacts will also be a product of the community's actions and initiatives to manage the program (Lorenzen 2008). 
Lorenzen (2008) presents a framework for disseminating, implementing, and managing an enhancement program which has four broad steps: 1) form stakeholder groups by engaging members of the community who are already participating or who have a genuine interest in the fishery; 2 ) understand the enhancement fisheries system and what the development outcomes might be; 3 ) qualitatively analyze the fisheries system attributes, fish population, fishing gears, and how they relate to fishing regulations and habitat management; and 4) initiate collective management and monitoring. Stakeholder participation and innovation are pertinent to the emergence and sustainability of mud crab fishery enhancement; however, limited physical, human, and financial assets of stakeholders can limit fisheries enhancement programs because optimizing post-release performance and minimizing impact to natural populations is expensive and requires substantive knowledge (Lorenzen 2008).

The lessons relating to this intervention span technical, institutional, and socioeconomic spheres. Technical factors affecting productivity increases attributed to this intervention include survival of hatchery-reared crabs, which can be improved with pond conditioning prior to release, and growth rates of different species, which were highest for S. olivacea at $11.7 \mathrm{~mm}$ per month, compared to $3.7 \mathrm{~mm}$ per month for S. serrata (Lebata et al. 2009). Site selection for stock enhancement programs is also critical for insuring the success of the program (Lorenzen 2008). Lebata et al. (2012) demonstrated that the lbajay mangrove system in the Philippines was suitable for mud crab release because food supply and dietary composition were sufficient, as indicated by high specific growth rates of released crabs. The system was also relatively closed, which excluded predatory sharks and macaques, and the initial wild crab density was low (12-33 per crabs ha) compared to similar systems, demonstrating that the system was likely to be below carrying capacity and that the opportunity for stock enhancement was significant (Lebata et al. 2012). As the development of this technology in the Philippines is still rudimentary, the effects on income, food security, and nutrition have not been tested.

\section{Institutional arrangements, particularly those pertaining to} harvesting and access rights, are essential to the socioeconomic and ecological success of restocking programs. The AAS program could play a key role in determining ways to address barriers and encouraging innovation from all social groups, including women and marginalized groups. Property rights are currently undefined in the Philippines but are the cornerstone to ensuring enhancement projects result in equitable access to mud crabs without resulting in unsustainable harvesting (Lorenzen 2008; Perez et al. 2012). Importantly, the role of women in mangrove crab meat processing has been demonstrated elsewhere, and women are likely to play a similar role in the Philippines, as women participate in post-processing of fisheries products (D'Agnes et al. 2005; Magalhães et al. 2007).

\section{Integrated rice-based systems and location-specific crop} management. Mono-crop rice-based systems in the Philippines are being converted to highly diversified and fully integrated rice-based farming systems, which include livestock, vegetable, fish, and fruit tree production components (Philippine Rice Research Inst. 2005; Abrogena et al. 2006; Casimero 2010). This system modification includes improved location-specific management techniques, such as only applying nitrogen fertilizer when needed, guided by a low-cost, easy-to-use leaf color chart, and determining the most limiting soil nutrients using the "minus one element technique" (MOET). These techniques have been advocated through two interventions: 1) the integrated rice-based farming Palayamanan approach; and 2) communitybased "Give Me Five Rice" (GM5: 5 metric tons per ha yield target) projects (Abrogena et al. 2006; Romanillos et al. 2012). Through both of these interventions farmers were recommended to divide a 1-ha block into a residential area, a field crop production area, and a small farm reservoir area at a ratio of approximately 0.05 , 0.75 , and 0.20 ha, respectively (Philippine Rice Research Inst. 2005). The residential area would include the homestead, nursery, vegetable garden, animal production area, and a waste recycling area. The crop production area would include rice and cash crop production and rice-fish culture, andthe reservoir area would include water storage and catchment, fish culture, and fruit tree plantations (Philippine Rice Research Inst. 2005).

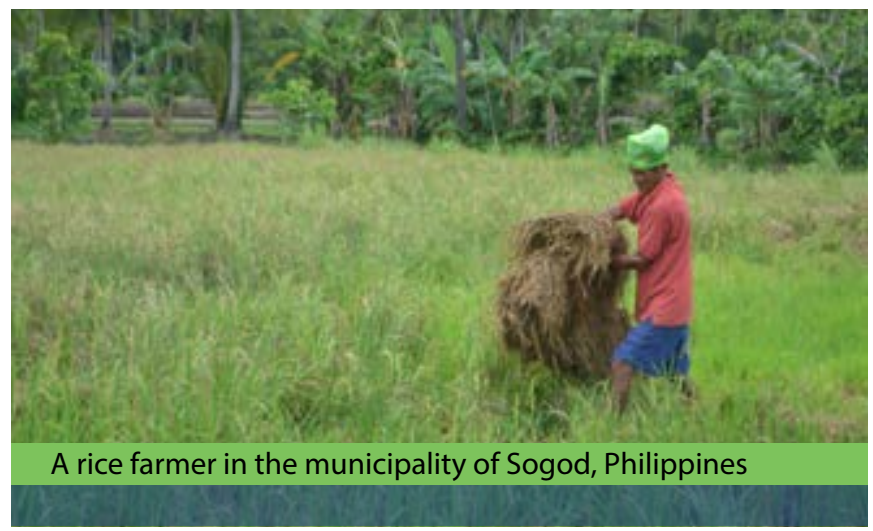

By optimizing fertilizer regimes (using leaf color charts and MOET) and by using improved seed varieties under the GM5 intervention, the mean rice yield was increased by 1.1 metric tons per ha in the first season and increased significantly again in the second season to result in a mean yield of 3.4 metric tons per ha, with a range of 1.5-6.2 metric tons per ha (Romanillos et al. 2012). Similarly, the Palayamanan project resulted in rice yield increases of 2.9-8.0 metric tons per ha in participant farmers, compared to 2.6-5.1 metric tons per ha in non-participant farmers (Abrogena et al. 2006). In northwestern Luzon, integrated rice-based farming has been introduced in 22 sites, largely through expansion of the Palayamanan project (Abrogena et al. 2006).

There is evidence of development outcomes attributed to the rice diversification intervention, albeit the evidence is incomefocused and does not include quantification of changes to food and nutrition security. Net income from rice produced in the wet season for farmers participating in Palayamanan trials was US\$237-994 per ha, compared to non-participant farmers who earned US\$12-549 per ha (Abrogena et al. 2006). Palayamanan is suitable for smallholder farmers with landholdings of approximately 1 ha of dryland or rain-fed rice fields (Abrogena et al. 2006; Casimero 2010). Implementation of the GM5 project resulted in significant increases in net income, from US\$62 to US\$296 per ha (Romanillos et al. 2012). A 1-ha integrated ricebased farming system can provide the majority of a farming family's daily food needs (vegetables, livestock, and fish) and generate considerable income (Abrogena et al. 2006).

Research also suggests gains from better integrating rice and other production commodities. The cornerstone of this intervention is integrating different components of the system by conducting crop rotation with rice-legume-rice crops, by planting taro around the perimeter of the rice area and beans, okra, eggplant, and peppers along the bunds, or by fertilizing raised vegetable plots with carbonized rice hull, compost, and animal manure (Philippine Rice Research Inst. 2005).

The GM5 project implemented the Community Participation and Intervention Framework (CPIF) to ensure dissemination of these principles. The CPIF provided an effective knowledge dissemination tool because the rice farmers, $33 \%$ of whom were women, participated in decision processes that led to the adoption and adaptation of the technological interventions that were location-specific and innovated by the farmer. The Philippine Rice Research Inst. (2005) presents a simple Palayamanan manual 
for improved, integrated rice-based systems. Palayamanan has been adopted by the Department of Agriculture as a component of the National Rice Program since 2008, which has accelerated the adoption of diversified rice systems. Several internationally funded projects also incorporate Palayamanan (e.g., JICA Technical Cooperation Project for ARMM, USAID CocoPal project) as part of their anti-poverty strategies.

Integrating rice-based systems with other food production systems and improving management practices provides a platform for farmer innovation, an opportunity which has not yet been fully harnessed. Fostering an environment for farmer innovation in combination with participatory action research to quantify the environmental outcomes of this intervention would strengthen the current knowledge of these systems and encourage scaling out of this technology.

\section{Zambia}

Three productivity interventions were reviewed from Zambia and are summarized, along with their key references, in Table 7. These included agricultural cultivation in dambo wetland systems, livestock improvement through disease control, and improved feeding and seasonal fish production in aquaculture ponds.

Table 7. An overview of selected case studies in Zambia.

\begin{tabular}{|c|c|c|}
\hline Intervention & $\begin{array}{l}\text { Aquatic agricultural } \\
\text { system }\end{array}$ & Key references \\
\hline $\begin{array}{l}\text { Dambo aquatic } \\
\text { agricultural } \\
\text { systems }\end{array}$ & $\begin{array}{l}\text { Seasonal wetlands } \\
\text { that flood in the wet } \\
\text { season, preventing } \\
\text { tree growth, and } \\
\text { retain moisture } \\
\text { throughout the dry } \\
\text { season }\end{array}$ & $\begin{array}{l}\text { Kuntashula et al. } \\
\text { 2006; Mabeza \& } \\
\text { Mawere 2012; } \\
\text { Sampa } 2007\end{array}$ \\
\hline $\begin{array}{l}\text { Livestock } \\
\text { improvement }\end{array}$ & Floodplain & $\begin{array}{l}\text { Baars \& Ottens } \\
\text { 2001; Cardoso 2012; } \\
\text { Chisembele 2005; } \\
\text { FAO 1997; } \\
\text { Grace et al. 2008; } \\
\text { Muma et al. 2009; } \\
\text { Nampanya et al. } \\
\text { 2012; Phiri 2006; } \\
\text { Sumberg 2002; } \\
\text { The World Bank \& } \\
\text { UKAID 2011; } \\
\text { Tittonell et al. 2009; } \\
\text { Vatta et al. 2011; } \\
\text { Windsor } 2006\end{array}$ \\
\hline Aquaculture & $\begin{array}{l}\text { Seasonal wetlands } \\
\text { that flood in the wet } \\
\text { season }\end{array}$ & $\begin{array}{l}\text { Kaggwa 2006; } \\
\text { Kipkemboi et al. } \\
\text { 2007; Kipkemboi et } \\
\text { al. 2010; Musumali } \\
\text { et al. } 2009\end{array}$ \\
\hline
\end{tabular}

Dambo aquatic agricultural systems. Dambos are natural wetland depressions that are flooded in the wet season, preventing tree growth, and retain moisture throughout the dry season, providing a valuable resource for cropping that is accessible to poor farmers in Zambia (Sampa 2007). They are estimated to cover approximately $10-15 \%$ of the country and are particularly prevalent in the Luapula-Chambeshi region (Chidumayo 1992). Crop and vegetable production has taken place in dambos for several decades despite some productivity limitations attributed to poor soil fertility (Kuntashula et al. 2006). We review an intervention to optimize management practices that enhance soil fertility. Gliricidia sepium, a readily available legume with high nitrogen content, can be used as an organic fertilizer to improve soil fertility through rapid release of nutrients when applied to the cultivation area (Mafongoya et al. 1997). Integration of G. sepium with other agricultural systems is a proven intervention (Ajayi et al. 2011), and according to Kuntashula et al. (2006) has potential to improve dambo productivity. Fertilization with G. sepium at a rate of 8 metric tons per ha improved dry season vegetable yield (Kuntashula et al. 2006). In the control treatment, cabbage yield was 19 metric tons per ha, compared to 51 metric tons per ha in the treatment where $G$. sepium was applied, and 49 metric tons per ha where commercial fertilizer was applied (Kuntashula et al. 2006). Although these data were collected during farmer field trials and were not statistically analyzed, the results concur with a controlled experiment where total cabbage yield was significantly lower in the control treatment, at 32 metric tons per ha, compared to 60 metric tons per ha in the treatment where G. sepium was applied (Kuntashula et al. 2006). However, in the treatment where commercial fertilizer was applied, yield was significantly higher, at 81 metric tons per ha, than either the control or the organic fertilizer treatments (Kuntashula et al. 2006).

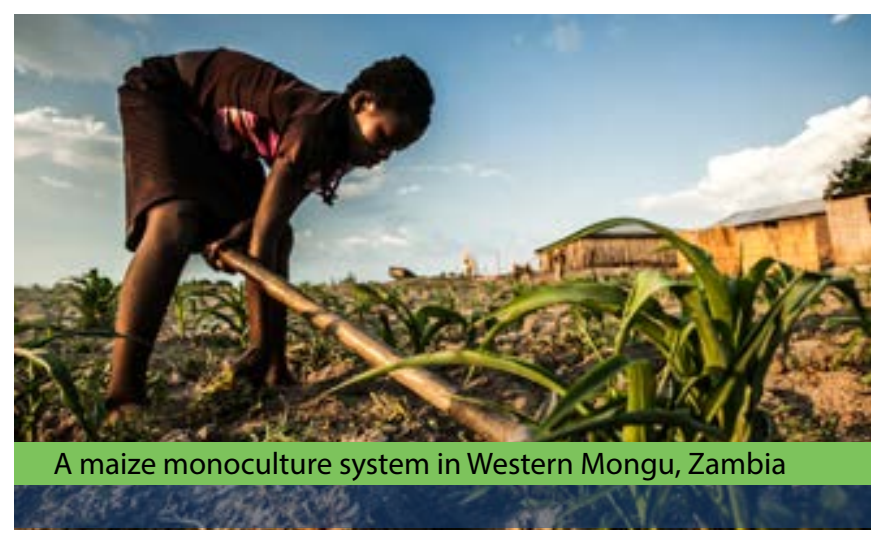

There are suggestions of development outcomes attributed to the improved dambo management, and the social groups which benefit from this intervention appear to be among the most marginalized. In Mpika District, a single woman raising four children and struggling to support her family by working as a farm laborer began cultivating vegetables in an adjacent dambo (Sampa 2007). She used improved management practices, was able to earn US\$200 in one year, and could thereby afford school fees for her four children (Sampa 2007). From the profit the following year, she diversified by investing in chickens, which increased her income to US\$900 per annum (Sampa 2007). Her household was food secure, and her social network improved, as she was elected secretary of the community school (Sampa 2007). To date, the effects of dambo cultivation on household nutrition have not been tested, but the scope for optimizing the combination of vegetables, fish, and cash crops to improve household nutrition is potentially large. Dambos are accessible to people with very limited assets and poor livelihood strategies, such as piece workers or migrant laborers, and it is suggested that dambos have the potential to significantly contribute to the livelihoods for rural households through the provision of grazing land and water for livestock, fishing grounds, grass for thatching, and small-scale cultivation of onions, tomatoes, potatoes, utunkomankoma (pumpkin), kanjele (maize), squash, beans, and sweet potatoes (Sampa 2007).

The environmental sustainability of this intervention was not specifically tested, although it was speculated that using the organic fertilizer tree would offer environmental benefits over using the recommended $800 \mathrm{~kg}$ per ha of basal dressing fertilizer and a further $250 \mathrm{~kg}$ per ha of urea as a top dressing fertilizer (Kuntashula et al. 2006). As dambos are also used for fish production and livestock watering in the wet season, it is suggested that leaching and run-off from inorganic fertilizers could have detrimental effects on fish, livestock, and downstream ecosystems (Kuntashula et al. 2006). The long-term availability of $G$. sepium and the associated environmental impact of 
intensive cultivation of $G$. sepium require further investigation. Environmental degradation can result from soil erosion and downstream sedimentation in adjacent water bodies (Sampa 2007; Mabeza \& Mawere 2012). To prevent soil erosion and sedimentation, ridges on which vegetables are planted should be constructed on an angle slightly across the slope (Sampa 2007), and optimal planting arrangements of G. sepium should be investigated to further reduce soil erosion. Potential environmental gains derived from integrating G. sepium and vegetable cultivation also include improved nutrient-use efficiency (Kuntashula et al. 2006).

Dissemination of dambo cultivation technology occurred through local extension agents and programs such as the North Luangwa Wildlife Conservation and Community Development Program (Sampa 2007), although dissemination of improved management with $G$. sepium fertilization appears less widespread.

There are a number of unknowns relating to dambo cultivation. The impact of growing and amending soils with G. sepium on the biogeochemical dynamics of dambos requires rigorous testing. Nutrient budgets should be determined for carbon, nitrogen, and phosphorus under regimes with and without fertilizer trees. Opportunities for further diversification in dambos include integrating plants, livestock, and fish, although the effects of this integration are not well documented and should also be tested. It is possible that nutrient resource flows exist between dry season vegetable cultivation and wet season fish production and livestock watering. It is unclear how the use of dambos is governed and how the resource would be accessed and shared by elite and marginalized groups if the value and yield of the produce from dambos continues to increase. As women are largely responsible for food preparation for the household, there is a need to enhance their opportunities to engage in dambo (and commercial crop) cultivation to go beyond the current focus on food security in order to address nutrition security as well. In addition, the actual contribution to and development outcomes of improved dambo cultivation for poor households have rarely been investigated and provide an opportunity for AAS research.

\section{Improved disease control and feeding for livestock} improvement. Cattle are important for both food security (milk and meat) and income for the Zambian people. Over 310,000 rural households own cattle (The World Bank \& UKAID 2011), and there is potential for cattle to play a larger role in the livelihoods of rural Zambians. Reports indicate that widespread cattle diseases, such as contagious bovine pleuropneumonia (CBPP), foot and mouth disease (FMD), and liver flukes (fascioliosis) are hampering productivity and economic returns (AAS 2012). Indeed, these reports are confirmed in the peer-reviewed literature by Muma et al. (2009), who demonstrated that the rate of cattle mortality in Zambia is 7.8\%, and Phiri (2006), who demonstrated that the rate of condemned cattle carcasses at three abattoirs in the Baroste floodplain system was a further $0.6 \%$. In this section, we review an intervention where cattle production is improved through farmer training in disease management and fodder production. The current knowledge among farmers regarding cattle diseases is low, with only $34-61 \%$ of farmers reporting any knowledge of disease symptoms and management (Chisembele 2005). Training farmers to manage disease outbreaks has the potential to enhance cattle productivity through increased body condition, increased calving rates, and decreased calving and adult mortality (The World Bank and UKAID 2011). In addition, on-farm fodder production, comprising legumes and grasses (e.g., Napier grass), has potential to improve the health and productivity of cattle, because body condition significantly declines in October when the weather is hot and dry and grazing periods are short (Baars $\&$ Ottens 2001; Sumberg 2002). Body condition also deteriorates at the end of the flood season (Baars \& Ottens 2001), so these periods represent significant opportunities in cattle feeding and management.

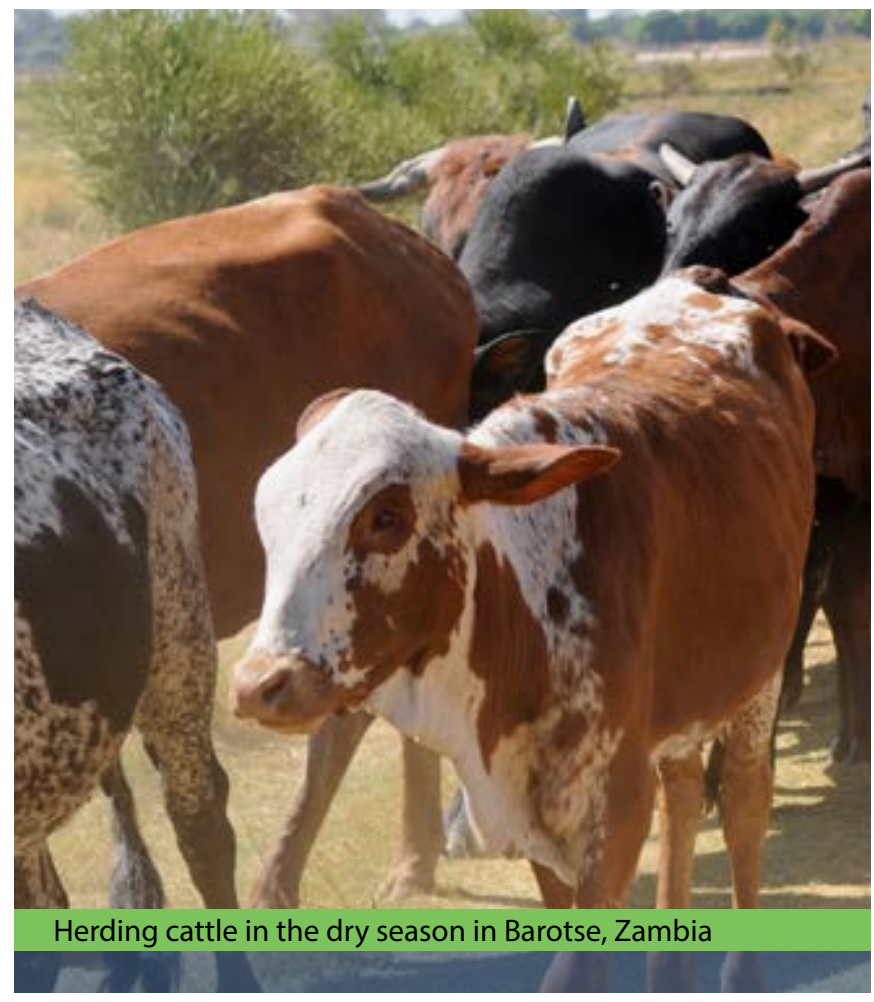

We were unable to find literature on direct links between increased awareness of diseases and enhanced cattle productivity in Africa or elsewhere. However, some indirect links were made. In south Mali, farmers were given information leaflets regarding diagnosis and treatment of trypanosomosis (an obligate parasite), which resulted in $84 \%$ of recipient farmers administering cattle treatment successfully, compared to only $73 \%$ of control farmers administering treatments successfully (Grace et al. 2008). In Southeast Asia, a 2.5-year project that included participatory field research (low intervention), on-the-job training (low and high intervention), and formal training (high intervention) reached approximately 773 households and resulted in a $0 \%$ infection rate of foot and mouth disease in villages subjected to high intervention and training programs (Nampanya et al. 2012). This was despite widespread outbreaks in surrounding villages and villages that received only low levels of intervention (Nampanya et al. 2012). The increased disease awareness likely resulted in a reduction in risk behaviors by farmers and subsequent disease spread in cattle in the high intervention group (Nampanya et al. 2012). Direct links between on-farm fodder production and cattle productivity were also unclear, although integration of cattle into a crop-livestock production system enhanced the primary productivity of the farming system up to 5 metric tons per ha per season and improved the health of cattle (Sumberg 2002; Tittonell et al. 2009). However, we were unable to elucidate any quantitative evidence of development outcomes attributed to improved cattle disease control and feeding.

Research on cattle production suggests links between environmental sustainability and improved cattle management. Reducing disease rates and enhancing the health of the existing cattle without increasing herd size helps to mitigate environmental impacts (Cardoso 2012). A smaller herd size ensures methane emissions are low and land clearance is minimized, and it potentially enhances off-take rates (sales as a percentage of stock) so that the structure of the herd is rejuvenated with more fertile stock (Cardoso 2012). In 2009 in Africa, the cattle off-take rate was $12 \%$, compared to a world average of $22 \%$ (Cardoso 2012; FAOSTAT 2012). In addition, carcass yield decreased by $2 \%$ between 1979 and 2009, while the world average increased by $8 \%$ (FAOSTAT 2012). Reducing disease outbreak to increase cattle offtake rates and carcass yield, therefore, has a positive effect on the environment and enhances productivity. 
Effective dissemination of knowledge regarding disease management in livestock has been demonstrated by Nampanya et al. (2012) in Southeast Asia through long-term, intensive training. Vatta et al. (2011) have also presented a framework for knowledge transfer for livestock owners in Africa and demonstrated that on-farm research projects, community-based workshops, and extension manuals were effective for disseminating knowledge. There are manuals available for dissemination that help farmers to identify symptoms and accurately diagnose diseased cattle (FAO 1997). Eradication of CBPP in Zambia has been proposed and requires the formation of local committees of farmers, leaders, and veterinarians, yearly vaccination campaigns, and the capacity to sustain an infection-free environment after the cessation of vaccinations (Windsor 2006). Eradication of diseases would likely secure a position for smallholder farmers to supply quality products to commercial and local markets (The World Bank 2012f), providing opportunity to generate additional income.

Our review brings some lessons to light. Research linking farmer training in disease management to increases in food security, income, and improved nutrition has not been conducted, and the AAS program provides an avenue to elucidate these links. Information regarding the role of gender in smallholder cattle production systems is scarce, although it is clear that women lack access to both livestock resources and the right to make decisions regarding livestock (Chiuta et al. 2011). Gender aspects of livestock productivity interventions are important and require further investigation.

Aquaculture. Aquaculture contributes directly to the livelihoods and food security of between 6,155 and 14,865 households, and aquaculture production in Zambia was reported as 10530 metric ton in 2011 (Musumali et al. 2009; FAO 2013), although some studies have indicated annual production figures may be $50 \%$ lower (Runnebaum et al. 2011). Aquaculture development is location-specific and governed largely by sufficient rainfall (700$1,400 \mathrm{~mm}$ per year), the infrastructure to store water, or access to markets (FAO 2013). Some households dependent on aquatic agricultural systems in Zambia are semi-nomadic, following seasonal rainfall and river flood patterns, so fish production interventions must align with the seasonal transhumance patterns practiced by local stakeholders. Here we review the use of fingerponds, which are seasonally flooded fish production ponds. We also discuss different fingerpond fertilization strategies as management practices for increasing the production of fish for marginalized semi-nomadic groups. Fingerponds are dug into the fringe of wetlands during the dry season and flooded during the wet season. The excavated soil is heaped around the edges of theponds to form raised garden beds for vegetable or fodder production. The pond and garden system is inundated during the wet season, and as floodwaters recede, fish are trapped in the ponds, providing animal-source protein that would otherwise not be available for poor households. Research in Kenya demonstrates that three species of tilapia, Oreochromis niloticus, $O$. variabilis, and $O$. leucostictus, are commonly trapped in the ponds at a density of 1 to 11 fish per $m^{2}$ (Kipkemboi et al. 2010). After floodwaters recede, pond productivity can be increased through application of readily available livestock manure and household organic waste. In ponds where manure was added at a rate of either 625 or $1,250 \mathrm{~kg}$ per ha per week, pond yield ranged between 402 and 1,069 kg per ha in 2.5 months, compared to 162 to $259 \mathrm{~kg}$ per ha in ponds with no manure (Kipkemboi et al. 2010).

Development outcomes attributed to the fingerpond intervention have been addressed in several studies (Kaggwa 2006; Kipkemboi et al. 2007). Contributions to household food security (improved supply and access) have been recorded through both vegetable and fish supply, with per capita fish supply increasing by $3 \mathrm{~kg}$ per season from a $192-\mathrm{m}^{2}$ pond adjacent to Lake Victoria in Kenya (Kipkemboi et al. 2007). The seasonal net income from a fingerpond system was US\$256 per ha, and $70 \%$ of this income

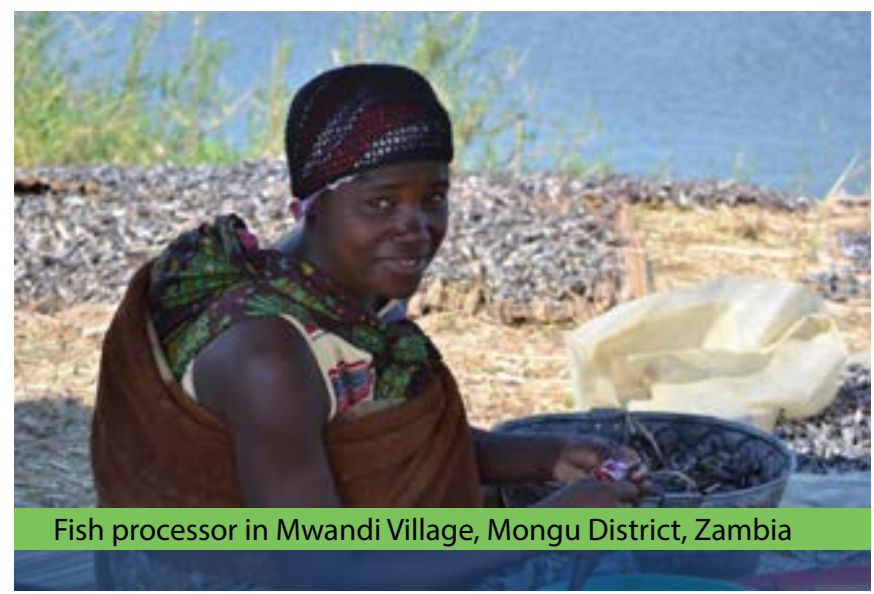

has been attributed to vegetable production (Kipkemboi et al. 2007). This estimate was generated from only one production cycle and the long-term economic viability of fingerponds has not been assessed. However, based on this estimate, fingerpond technology has the potential to offer generous economic returns when considering that the mean household income in Western Province, Mongu, and Senanga are US\$210, US\$208, and US\$126, respectively, and the national annual average is US\$347 per household. Fingerpond technology is potentially a lowinvestment and low-risk approach that can be accessed by assetpoor farmers and used to supplement livelihood strategies, which are typically comprised of papyrus plant harvesting, fishing, and seasonal crop cultivation (Kipkemboi et al. 2007). Only 5\% of the total time allocated to traditional livelihood activities is needed for fingerpond management once construction is complete, so traditional livelihood activities can still be practiced (Kipkemboi et al. 2007).

Research on fingerponds suggests gains from linking production commodities and environmental sustainability. Integration of fish and vegetable production and fertilizing ponds with livestock manure contributes to productivity of both components of the system. Nutrients mineralized from manure stimulate primary production, as evidenced by chlorophyll a concentrations, which were approximately $150 \mu \mathrm{L}$ in manured ponds, compared to approximately $30 \mu \mathrm{L}$ in unmanured ponds during field trials (Kipkemboi et al. 2010). However, adding manure to ponds must be regulated, as ammonium concentrations neared the critical level of $1.44 \mathrm{mg}$ per $L$ for fish at some stages of the trial (Kipkemboi et al. 2010). There are suggestions that fingerponds have minimal environmental impact owing to their small size (typically $200 \mathrm{~m}^{2}$ ), natural stocking, limited alteration to wetland hydrology, and low external inputs (Kipkemboi et al. 2010).

To date, fingerpond technology has not been disseminated in Zambia but has been introduced in Kenya and Uganda (Kaggwa 2006; Kipkemboi et al. 2010) on a small scale. There are no plans yet to disseminate this technology in Zambia, and factors affecting the sustainability of adoption are not well documented. Fingerpond technology is an intermediate between capture fisheries, which are traditionally practiced by Zambians, and true aquaculture. It may have a role in suitable environments, but needs further research and comparison with the pros and cons of establishing conventional pond aquaculture, which is also showing potential in some fringing areas of the Barotse floodplains. 
This review brings some lessons to light. First, the suggestion that fingerponds have limited environmental impact is not well supported, and robust indicators, as part of a monitoring and evaluation scheme, are required before fingerponds are introduced. Second, the effect of fingerponds on gender relations is not understood. Aquaculture production in Zambia is currently dominated by male farmers (grades 5-9; Mundenda et al. 2005), though women's roles in fish value chains are often more significant than formal statistics reveal (WorldFish 2010). Women are involved in mending nets and processing and selling fish in year-round aquaculture operations (Mundenda et al. 2005). Women also traditionally use wetland systems for the provision of household food (Kipkemboi et al. 2007), so introducing fingerponds into wetlands is potentially a technology that women will feel comfortable with, given their familiarity with wetland systems. Gender-specific constraints for the adoption of fingerponds by women, such as fishing being largely taboo for women, should be thoroughly assessed before this technology is disseminated (Mapedza et al. 2012). This intervention perhaps offers an avenue to develop gender-transformative approaches that address the social norms around women and fish production with the aim of giving women the choice to participate in aquaculture.

\section{Lessons and challenges}

In reviewing 20 interventions from five countries across Africa, Asia, and the Pacific, we have identified strategies such as improved management, selectively bred crops, integrated farming systems, and natural resource management that have been employed to improve the productivity of aquatic agricultural systems. The 20 cases were selected because they presented evidence of improved productivity and provided some insights on development outcomes. However, we cannot conclude that these are the most suitable interventions for increasing productivity and development impact in each of the AAS priority countries. Here we synthesize some key lessons that emerged from the cases for increasing productivity, improving sustainability, realizing outcomes for development, and enabling the sustained and widespread adoption of new technologies and management practices.

How and to what degree do interventions increase crop, fish, and livestock yield and productivity in different aquatic agricultural systems, and are these increases sustainable?

Due to growing populations and shifting diet preferences, the global demand for food will double by 2050 (Tilman et al. 2011). Increasing the productivity of current food production systems will provide a platform to meet this demand. Lessons from the Green Revolution indicate the need to ensure that increased productivity will accelerate rural development and spread the benefits to many, rather than accumulating to a few. To achieve rural development objectives through increased productivity, interventions that change practice, improve management, or introduce new technologies must consider local social and cultural contexts, including asset bases and livelihood strategies of rural households, alongside higher-level factors such as markets and national policies (Weeratunge et al. 2012; Ray et al. 2013).

Our review in developing country contexts highlights substantial opportunities to improve yields and productivity in AAS systems. Yield increases were achieved in 15 of the 20 case studies and were realized primarily through improved management, selectively bred crops, and integrated farming systems. In addition, natural resource management was employed to sustain the productivity of marine fisheries.

Improved management practices included introducing legume trees to fertilize vegetable cultivation in wetland depressions (dambos), a set of management practices collectively called the system of rice intensification (SRI), and the introduction of hydroponic methods for vegetable cultivation on floating gardens. Improved management in dambos and SRI increased crop yields by $40-70 \%$, and floating garden vegetables were produced in stagnant water bodies that were previously unproductive. Selectively bred strains of high-yielding and stresstolerant rice increased yields by over $50 \%$, and integrated farming systems such as agroforestry, gher cultivation, and community fish refuges increased yields by approximately $50-80 \%$ (Molden 2007). The magnitudes of these yield increases are in line with the broader literature. Indeed, a global assessment of yield gaps (determined by comparing landscape-level observed yields with high-yielding areas within zones of similar climate) for 17 major crops demonstrates that yield increases of $45-70 \%$ are possible with improved water and nutrient management (Mueller et al. 2013). Increased productivity provides an incentive to reduce the current trends of land clearing in poorer nations and unsustainable intensification in richer nations; these trends could result in 1 billion ha of additional cleared land and $250 \mathrm{Mt}$ per year of nitrogen use by 2050 (Tilman et al. 2011). In contrast, with a focus on improved management, selectively bred strains, and integrated farming to reduce excessive inputs in some areas and enhance inputs in areas that are plagued by soil degradation and infertility, yield gaps could be closed within $75 \%$ of attainable yields with only minor changes to global nitrogen and phosphate use (Tilman et al. 2011; Mueller et al. 2013; Tittonell \& Giller 2013).

Natural resource management by local communities was used in two cases to sustain the productivity of small-scale fisheries operating in coastal reef and mangrove areas. Community-based resource management or co-management are increasingly recognized as important strategies to manage the use of natural resources, including those utilized by fishers for food and income. However, globally there is a dearth of empirical evidence that demonstrates improvements to sustainability and productivity, let alone human development outcomes, or that elucidates how these improvements can be achieved in difference contexts (Evans et al. 2011; Gutiérrez et al. 2011). In the Solomon Islands case, there was empirical evidence that the new management regime resulted in some short-term increases in harvesting efficiency (Cohen \& Alexander 2013), and anecdotal evidence of boosted productivity and profits from invertebrate fisheries. It is well established in the global literature that effective management can improve yields and long-term productivity of fisheries systems; however, whether these improvements can be achieved through community-based management where resource reliance is high or fisheries productivity has already been reduced is still an area of some uncertainty.

Realizing sustainable development benefits from increased productivity presents an ongoing challenge, because a range of economic, social, and ecological factors must be taken into account. For example, in one case reviewed, short-term yield and productivity increases were achieved through integrating rice, prawns, and fish in a gher system in Bangladesh (Milstein et al. 2005; Ahmed et al. 2010). However, sustaining these productivity gains and ensuring that benefits reached poor and marginalized groups beyond projects appears more challenging (Ahmed \& Garnett 2010). For example, in some cases sustaining productivity required substantial and ongoing inputs that were not always accessible to poorer farmers. As a result, some farmers sold other productive assets, such as livestock and trees, to support production in ghers (Ahmed et al. 2010; Ahmed \& Garnett 2010). As with most farming systems, crops in ghers sometimes fail due to disease or unpredictable weather, the latter being a particular concern in low lying deltaic regions (Thornton \& Cramer 2012; Ahmed et al. 2013). The financial pressure of producing highvalue crops in gher systems led to increased vulnerability of poorer farmers when they sold livestock and trees, making their asset portfolios less diverse and leaving them less able to cope in the event of crop failure (Ahmed \& Garnett 2010). This situation highlights that financial and climatic vulnerability are closely linked and are key determinants of the sustainability of a system. Adaptation and risk management are integral to ensuring 
sustainable yield and productivity increases (Howden et al. 2007). Strategies to improve productivity and impact development must be financially accessible for farmers and should encourage farmers to diversify their farming systems to ensure resilience and continual access to food and income (Pretty 2008).

The cases we examined also illustrate that short-term productivity increases can be achieved within the context of subsidized projects, but that sustaining these increases is challenged by limits in social, financial, and human capital and impacted by the appropriateness and delivery of the intervention. For example, gher farmers in Bangladesh typically sustained yields while participating in the development project, but at the end of the project a lack of skills and knowledge meant that productivity decreased (Ahmed \& Garnett 2010). Similarly, sustainable productivity increases in integrated rice-fish systems were constrained by a lack of technical knowledge and training (Ahmed \& Garnett 2011). Further, technologies which were not tailored to suit local conditions resulted in unsustainable adoption and even in detrimental outcomes in some communities. For example, reducing the flooding periods under the SRI intervention led to a loss of soil fertility and reductions in long-term rice productivity (Dobermann 2004), and high labor inputs to transplant seedlings and control weeds added to the risk of adopting SRI (Moser \& Barrett 2003). These factors meant that the adoption of SRI was not sustained after the project ceased (Moser \& Barrett 2003). The sustainability of adoption of technologies or approaches that improve productivity is enhanced when interventions are selected or designed considering the priorities and constraints identified by rural communities, such as labor shortages and financial capacity (Tittonell et al. 2012). This involvement might be facilitated through adoption of a participatory action research approach (Romanillos et al. 2012).

The environmental sustainability of the majority of the interventions we reviewed was not empirically examined, albeit much of the literature claimed that environmental sustainability was enhanced. Where environmental outcomes were examined, observations were limited to experimental plots and on-farm trials (e.g., methane emissions were increased in an experimental plot of integrated rice-fish systems compared to rice mono-culture), but did not examine the broader impacts (Frei et al. 2007). Certain cases we examined (e.g., the agroforestry intervention) raised the issue of potential positive (e.g., reductions in soil erosion) and negative (e.g., increased fertilizer application) environmental outcomes at both the farm and landscape scale (Paningbatan et al. 1995; Snelder et al. 2007). However, empirical evaluations of environmental impacts resulting from productivity interventions across farm, community, and landscape scales are needed to make informed decisions about the trade-offs between the food security and environmental sustainability of development outcomes (Shepherd et al. 2013). These evaluations will require the development of a set of robust indicators for assessing the impacts on ecosystem function (Rodrigues et al. 2010; SDSN 2013). Additionally, quantifying changes in water productivity (i.e., yield per unit of water used), total factor productivity (i.e., ratio of all outputs produced to all inputs used, accounting for technological change and technical efficiency change), and nutrient- and energyuse efficiency should be critical components of implementing and adapting productivity interventions to optimize sustainability (Phiri et al. 2003; Nagabhatla et al. 2012; Asche et al. 2013). Tools such as life cycle assessment, total factor productivity, the use of planetary boundaries, risk assessment, environmental impact assessment, and environmental impact quotient may be valuable in determining the environmental implications of productivity interventions in aquatic agricultural systems across scales (Rockström et al. 2009; Renkow 2011; Henriksson et al. 2012). In circumstances where environmental perturbation is likely, payment for ecosystem service schemes may encourage innovations to reduce environmentally damaging practices (Warren-Rhodes et al. 2011), but developing schemes where distribution of costs and benefits is equitable and socially acceptable represents a significant challenge.
What gains have been realized by integrating crop, fish, and livestock production? Limited supplies of seed, fertilizer, water, land, labor, and energy mean that modern food production systems must operate efficiently to ensure sustainable expansion or intensification (Tilman et al. 2011). Integrating production components is one pathway for achieving sustainable agricultural expansion and improving resource-use efficiency. Twelve of the 20 cases that we reviewed achieved productivity improvements through the integration of crop, fish, or livestock components in a single farming system. In these cases, there were synergies between production components; for example, fish waste provided fertilizer and improved nutrient uptake by rice in integrated ricefish farming systems (Oehme et al. 2007). Such synergies were harnessed in these cases to improve both the productivity of the system and resultant yields. These synergies also led to a reduced need for external inputs, such as in the case of vegetable cultivation in wetlands (dambos) in Zambia, which were integrated with the legume Gliricidia sepium acting as an organic fertilizer (Romanillos et al. 2012). However, in five cases of integrated systems (i.e., gher system, agroforestry, coconut intercropping, and two cases of integrated rice-fish farming), external inputs, primarily feed and fertilizers, were still necessary to achieve increases in productivity. External inputs are unavoidable in some systems (i.e., in systems with low soil fertility, intensified systems, or systems culturing carnivorous fish) but can lead to detrimental environmental outcomes (e.g., eutrophication or soil degradation). The minus one element technique, a method to identify soil nutrient deficiencies, was used to guide fertilizer application and manage detrimental environmental outcomes in integrated rice-based systems in the Philippines (Abrogena et al. 2006; Romanillos et al. 2012). This technique is a form of precision agriculture which is now being recognized, especially in sub-Saharan Africa, as an approach to account for temporal and spatial variability in input requirements for food production systems (Cassman 1999; Tittonell \& Giller 2013). For example, smallholder farmers acknowledge that there are gradients of soil fertility in their fields and apply their limited fertilizers in the zones where they will be most efficiently assimilated by crops (Tittonell \& Giller 2013). Precision agriculture should be harnessed to minimize external inputs and to improve the efficiency of both integrated and mono-crop production systems.

What are the development outcomes associated with productivity interventions, and which social groups benefit from the interventions? Lessons from the Green Revolution demonstrate that investment in food production systems does not necessarily result in improvements to the livelihoods and well-being of poor people living in developing countries (Fan \& Hazell 2001; Pingali 2012). Therefore, in this review we explicitly considered where and how productivity increases have led to improved development outcomes, and in particular increased income and food security of poor rural families.

Increases in household income were observed in $50 \%$ of the interventions we reviewed, and these increases were attributed directly to a productivity intervention. However, it was unclear how the additional income was distributed and how it benefited individuals within a household or social group within a community. Additionally, in one case there were anecdotal reports of wider community development outcomes when food production shifted from the staple commodity (i.e., rice) to internationally marketable products (i.e., prawns and shrimp; Ahmed et al. 2010). Economic benefits were realized by owners and by those who were employed directly (e.g., male laborers) and indirectly (e.g., women fry collectors), and this change led to an injection of cash into the local community as benefits flowed to a range of social groups, including fruit shop and tea shop owners (Ahmed et al. 2010). However, it was noted that the intervention may have led to the exclusion of poorer farmers who had previously leased rice-farming land from richer farmers; since the intervention, rich farmers leased their land at higher prices for prawn farming, leaving land inaccessible to the poor (Ahmed et al. 2010). Similarly, four other cases (involving gher farming 
systems and integrated rice-fish cultivation) demonstrated that increased productivity may have bypassed the poor and benefited relatively richer farmers who had the resources and skills to access new technologies and management practices (Haque et al. 2010; Ahmed et al. 2011). These outcomes were attributed to unstable land tenure arrangements, inputs being inaccessible to marginalized groups, inequitable extension and training services, and development projects seeking "quick wins" by implementing interventions on already productive land, which by default was owned by relatively better-off farmers (Pingali 2012).

Quantification of increases in household food security and nutrition were less common, likely because methodologies for measuring food intake and nutrition impacts are either complex or not well defined (Masset et al. 2011). Such findings echo those of a recent review which found that links between changes in nutrition and agricultural interventions were demonstrated in only 23 out of 7000 studies (Masset et al. 2011). Even more scarce throughout the literature were socially disaggregated analyses of the benefits of productivity interventions, including gender dimensions. Determining improvements to well-being relies on disaggregated information to track changes in work loads, income management and expenditure, decision making, and food consumption (Weeratunge et al. 2012). However, it appears that this information remains deficient and therefore likely not available for guiding the design and implementation of productivity interventions.

In summary, we found limited empirical evidence linking increases in AAS productivity to increased household income, food security, and broader development outcomes. This scarcity of data calls for the establishment of a monitoring and evaluation framework and implementation process to identify technologies and management practices, and learning, which can impact development and are suitable for wider sharing and dissemination. This framework should be scientifically robust, adaptable to changing socioeconomic and ecological conditions, and easily implemented and led by those striving to improve their own livelihoods. Masset et al. (2011) recommend that interventions be complemented with well-designed studies to determine disaggregated consumption data, indicators of dietary diversity, and child height and weight. Given the limitations of human and financial resources in many development interventions, a balance between collecting data of sufficient quality and ensuring cost effectiveness should be sought; in this regard, a standardized set of proxy indicators may provide adequate data while reducing financial and labor costs (Shepherd et al. 2013). For example, the Women's Empowerment in Agriculture Index measures the role and extent of women's participation in agriculture across five domains, including decision making, access to resources, access to income, community leadership, and time investment (Feed the Future 2012; Shepherd et al. 2013). Pre-implementation social analysis examining governance structures, social relationships, and power relations will be important to help understand how interventions should proceed in a culturally and contextually appropriate manner, and may help to predict and manage the distribution of benefits.

\section{How are AAS technologies and management practices} disseminated and adopted for the benefit of smallholder producers? Where new technologies and management practices prove successful at increasing productivity, their sustained adoption will be required to make improvements to well-being and food security at broader scales (Kumar \& Quisumbing 2010; Jahan et al. 2013). Rice production, aquaculture, and fisheries are key livelihood strategies for over 55 million people in Cambodia and Bangladesh and indirectly support up to $12 \%$ of the population (Joffre \& Sheriff 2011; FAO 2012b). Therefore, if technologies to improve productivity in rice or fish systems are adopted at scale, there is the potential to create significant reductions in poverty and increases in food security. Realizing this change, however, depends in part on the widespread and effective dissemination of learning, approaches, and technologies that work, as well as an institutional environment for their sustained adoption.

Effective dissemination can be facilitated through direct engagement by research partners who have a sound understanding of the local context and can work alongside farmers, fishers, households, and other local stakeholders to facilitate knowledge exchange and learning (Hakiza et al. 2004). For example, in Solomon Islands communities learned biological principles that govern production systems and then gained the confidence and skills needed to implement and adapt garden systems towards locally available and productive inputs (Grayson 2002). Simultaneously, research partners gained an appreciation of the local context, which guided appropriate adaptations of technologies and built knowledge of challenges faced in implementation (Grayson 2002; Hakiza et al. 2004). Such processes of information exchange and knowledge building can be facilitated through more collaboration between the research community and the development community, particularly via approaches such as participatory action research (Kuntashula et al. 2006). The value of this approach is demonstrated by the success of the dissemination and uptake of forage banks for livestock fodder in Cambodia, which were facilitated by a research center that was based in-country, employed local staff, developed a sound understanding of local environmental conditions, and had strong networks with regional and district governments (Harding et al. 2007).

Along with direct engagement, dissemination of improved technologies and management practices may also occur through networks. For example, where interventions are locally appropriate (particularly where they are selected or designed through participatory action research), dissemination can occur horizontally (i.e., from farmer to farmer), without extensive input from external programs (Ahmed et al. 2010). Community-based resource management (CBRM) is proliferating throughout the Coral Triangle, in part because it is community-led, based on local and customary governance systems, and spread through community-to-community knowledge exchange (Govan 2009; Schwarz et al. 2012). CBRM is also facilitated through formal networks of CBRM support partners who explicitly seek to share information, collaborate, and coordinate to improve and disseminate CBRM approaches (Cohen et al. 2012).

The challenge of dissemination has also been tackled through engagement via markets and the private sector. For example, approaches such as the "making markets work for the poor" program (M4P) explicitly seek to overcome constraints related to scale and technology uptake. M4P assesses constraints to marketing systems and then motivates private sector actors to produce and disseminate products, technologies, and training to harness benefits of markets for the poor (M4P Hub 2010). However, even with effective dissemination mechanisms, there are ultimately limits to uptake and sustainability of adoption. New methods or technologies aimed at increasing productivity will not necessarily be suited to all the rural poor and may not remain suitable if social, economic, or environmental conditions change. Therefore, dissemination should be targeted to areas and people where specific new methods or technologies are best suited, and an understanding of the potential and limitations of productivity strategies at national scale should be built. 


\section{Conclusion}

Aquatic agricultural systems are highly productive systems, with multiple opportunities for improved productivity and the potential to lead to development impact. However, realizing increases in productivity and translating these into benefits for some of the 700 million poor and vulnerable people who depend on these systems presents a complex challenge. We reviewed 20 interventions that tackled this challenge through strategies including improved natural resource management, integration of farming systems, and the introduction of new farming methods or selectively bred crops.

To reach goals of reduced poverty and improved livelihoods in aquatic agricultural systems, it is necessary to understand how and in which contexts productivity interventions lead to development outcomes. We found that most interventions reported some increases in productivity, but development benefits were mixed between cases and were variable between social groups. Across all cases, we found there to be insufficient data that reliably measured changes in productivity or environmental sustainability. To understand gains and shortcomings in reaching development goals, appropriate methods to measure productivity and environmental impact will need to be identified and implemented. Further, these data are necessary to guide decisions and manage tradeoffs between different options for land and resource use-tradeoffs that will increasingly emerge as competition for resources intensifies at all levels, from the farm to landscape, national, regional, and global levels. To address the demand for increased food, and to improve the livelihoods of AAS-dependent rural people in developing countries, research must go beyond simply measuring productivity and sustainability. Research must develop solutions that increase productivity and ensure sustainability while also delivering development outcomes to the social groups who are most in need. The combination of more conventional commodity/productivity-oriented research connected to a community-owned participatory action research approach appears particularly attractive in achieving this challenge. The effective dissemination of methods or technologies proven to enhance productivity ideally means that more people benefit. However, widespread uptake of new technologies or methods may result in additive and subtractive effects that cannot necessarily be predicted at the local scale; for example, reducing prices received as markets are flooded with a new product, enhancing efficiency (e.g., of transport) with economies of scale, or introducing new sources of vulnerability to environmental variability or fluctuation in prices of inputs. The potential, the limitations, and the unintended costs and benefits of productivity interventions need to be better understood at both local and higher scales. 


\section{References}

AAS. (2012). Scoping report: Barotse floodplain system, Zambia. CGIAR Research Program.

Abrogena, N.Q., Catudan, B.M., Castro, R.C., Cruz, L.M.C.D., and Aguinaldo, A.C. (2006). Economic benefits and production efficiencies of Palayamanan in northwest Luzon. Philippine Journal of Crop Science 31: 47-60.

Adato, M., and Meinzen-Dick, R. (2002). Assessing the impact of agriculture research on poverty using the sustainable livelihoods framework. Washington, D.C.: International Food Policy Research Institute. FCND discussion paper no. 128; EPTD discussion paper no. 89.

Ahmed, N., Allison, E., and Muir, J. (2008). Using the sustainable livelihoods framework to identify constraints and opportunities to the development of freshwater prawn farming in southwest Bangladesh. Journal of the World Aquaculture Society 39: 598-611.

Ahmed, N., Allison, E.H., and Muir, J.F. (2010). Rice fields to prawn farms: A blue revolution in southwest Bangladesh? Aquaculture International 18: 555-574.

Ahmed, N., and Garnett, S.T. (2010). Sustainability of freshwater prawn farming in rice fields in southwest Bangladesh. Journal of Sustainable Agriculture 34: 659-679.

Ahmed, N., and Garnett, S.T. (2011). Integrated rice-fish farming in Bangladesh: Meeting the challenges of food security. Food Sec. 3: 81-92.

Ahmed, N., Rahman, S., Bunting, S.W., and Brugere, C. (2013). Socio-economic and ecological challenges of small-scale fishing and strategies for its sustainable management: A case study of the Old Brahmaputra River, Bangladesh. Singapore Journal of Tropical Geography 34: 86-102.

Ahmed, N., Zander, K.K., and Garnett, S.T. (2011). Socioeconomic aspects of rice-fish farming in Bangladesh: Opportunities, challenges and production efficiency. The Australian Journal of Agricultural and Resource Economics 55: 199-219.

Ajayi, O.C., Place, F., Akinnifesi, F.K., and Sileshi, G.W. (2011). Agricultural success from Africa: The case of fertilizer tree systems in southern Africa (Malawi, Tanzania, Mozambique, Zambia and Zimbabwe). International Journal of Agricultural Sustainability 9: 129-136.

Alam, M.J., Islam, M.L., Saha, S.B., Toung, T.P., and Joffre, O. (2007). Improving the productivity of the rice-shrimp system in the south-west coastal region of Bangladesh. In Tropical Deltas and Coastal Zones: Food Production, Communities and Environment at the Land-Water Interface. C.T. Hoanh, B.W. Szuster, K. Suan-Pheng, A.M. Ismail, and A.D. Noble (Eds.). Oxfordshire, UK: CAB International.

Albert, J., Beare, D., and Andrew, N. (2013). Nearshore fads in Solomon Islands: Monitoring their effectiveness and the costs and benefits of their deployment. WorldFish Honiara, Solomon Islands: 21.

Albert, S., Grinham, A., Bythell, J., Olds, A., Schwartz, A., Aranani, K., Sirikolo, M., Watoto, C., Duke, N., McKenzie, J., Roelfsema, C., Liggins, L., Brokovich, E., Pantos, O., Oeta, J., and Gibbes, B. (2012). Building social and ecological resilience to climate change in Roviana, Solomon Islands. Brisbane: The University of Queensland.

Amilhat, E., Lorenzen, K., Morales, E.J., Yakupitiyage, A., and Little, D.C. (2009). Fisheries production in Southeast Asian farmer managed aquatic systems (FMAS): I. Characterisation of systems. Aquaculture 296: 219-226.

Amin, M.N. (2001). Status of plant biodiversity in Bangladesh. In Biodiversity and Medicinal Plantwealth of South Asian Countries Country Reports of Bangladesh, Bhutan, India, Iran, Maldives, Nepal, Pakistan and Sri lanka. UNESCO-sponsored "Regional training programme on biodiversity systematics: Evaluation and monitoring with emphasis on medicinal plants." P. Pushpangadan, K.N. Nair, and M.R. Ahmad (Eds.) Lucknow, India: Army Printing Press.

Anas, I., Rupela, O.P., Thiyagarajan, T.M., and Uphoff, N. (2011). A review of studies on SRI effects on beneficial organisms in rice soil rhizospheres. Paddy and Water Environment 9: 53-64.

Andersen, A.B., Thilsted, S.H., and Schwartz, A. (2013). Food and nutrition security in Solomon Islands. Penang, Malaysia: CGIAR Research Program on Aquatic Agricultural Systems. Working paper AAS-2013-06.

Anthofer, J. (2004). The potential of the system of rice intensification (SRI) for poverty reduction in Cambodia. Conference on International Agricultural Research for Development, October 5-6, 2004. Berlin: Deutscher Tropentag.

Asche, F., Guttormsen, A.G., and Nielsen, R. (2013). Future challenges for the maturing Norwegian salmon aquaculture industry: An analysis of total factor productivity change from 1996 to 2008. Aquaculture 396-399: 43-50.

Ashley, C., and Carney, D. (1999). Sustainable livelihoods: Lessons from early experience. London, UK: Russell Press Ltd.

Baars, R.M.T., and Ottens, J.J. (2001). Grazing behaviour and diet selection of Barotse cattle on a communally grazed floodplain in west Zambia. African Journal of Range and Forage Science 18: 5-12.

Ballard, B.M., Christian, S., Wharton, D., FitzGerald, I., Murshid, K.A.S., Hansen, K.K., Runsinarith, P., and Sovannara, L. (2007). We are living with worry all the time: A participatory poverty assessment of the Tonle Sap. Phnom Penh, Cambodia: Cambodia Development Resource Institute (CDRI).

Bangladesh Bureau of Statistics. (2010). Report of the household income and expenditure survey 2010. Dhaka: New Panama Printing Press.

Baynes, J., Herbohn, J., Russell, I., and Smith, C. (2011). Bringing agroforestry technology to farmers in the Philippines: Identifying constraints to the success of extension activities using systems modelling. Small-Scale Forestry 10: 357-376. 
Bell, J.D., Kronen, M., Vunisea, A., Nash, W.J., Keeble, G., Demmke, A., Pontifex, S., and Andrefouet, S. (2009). Planning the use of fish for food security in the Pacific. Marine Policy 33: 64-76.

Belton, B., Karim, M., Thilsted, S., Jahan, K., Collis, W., and Phillips, M. (2011). Review of aquaculture and fish consumption in Bangladesh. Studies and Reviews 2011: 53.

Bertomeu, M. (2012). Growth and yield of maize and timber trees in smallholder agroforestry systems in Claveria, Northern Mindanao, Philippines. Agroforestry Systems 84: 73-87.

Boso, D., Paul, C., Hilly, Z., and Pita, J. (2010). Community-based adaptive resource management in Solomon Islands: Lessons learned. WorldFish Center and FSPI.

Braithwaite, V.A., and Salvanes, A.G.V. (2010). Aquaculture and restocking: Implications for conservation and welfare. Animal Welfare 19: 139-149.

Burney, J.A., Davis, S.J., and Lobell, D.B. (2010). Greenhouse gas mitigation by agricultural intensification. Proceedings of the National Academy of Sciences of the United States of America 107: 12052-12057.

Cabili, T.M., and Cuevas, V.C. (2010). Impact of coconut-based upland farming system on the coastal ecosystem of the island municipality of Capul, Northern Samar. Philippine Journal of Crop Science 35: 62-79.

Cardoso, L.A. (2012). Environmental and economic impacts of livestock productivity increase in Sub-Saharan Africa. Trop Anim Health Prod 44: 1879-1884.

Carney, D. (1998). Sustainable rural livelihoods: What contribution can we make? Natural Resources Advisers' Conference, London, England. Department for International Development.

Casimero, M.C. (2010). Securing food and enabling farmers towards a profitable rice-based farming system. In Vegetables: Enhancing Its Implementation in Rice-Based Cropping Systems, pp. 1-24. M.C. Casimero and P.A.C. Ooi (Eds.). Manila, Philippines: Bureau of Agricultural Research.

Cassman, K.G. (1999). Ecological intensification of cereal production systems: Yield potential, soil quality, and precision agriculture. Proc. Natl. Acad. Sci. USA 96: 5952-5959.

Cassman, K.G., and Wood, S. (2005). Cultivated systems. In Ecosystems and Human Well-Being: Current State and Trends. R. Hassan, R. Scholes, and N. Ash (Eds.). Washington, D.C.: Island Press.

CDRI. (2013). Removing constraints to Cambodia's agricultural development. Cambodia Outlook Brief No. 02. Cambodian Outlook Conference, Phnom Penh, Cambodia.

CEDAC. (2008). Evaluation study: Adoption and non-adoption of system of rice intensification (SRI) in Cambodia. Cambodia Center for Study and Development in Agriculture.

Cedamon, E.D., Emtage, N.F., Suh, J., Herbohn, J.L., Harrison, S.R., and Mangaoang, E.O. (2005). Present tree planting and management activities in four rural communities in Leyte Province. Annals of Tropical Research 27: 19-34.

CGIAR (2012a). CGIAR research program on aquatic agricultural systems: Program proposal. Penang, Malaysia: WorldFish. AAS-2012-07.

CGIAR (2012b). Resilient livelihoods and food security in coastal aquatic agricultural systems: Investing in transformational change. Penang, Malaysia: CGIAR Research Program on Aquatic Agricultural Systems. Project report AAS-2012-28.

Chapin, S.F., Zavaleta, E.S., Eviner, V.T., Naylor, R.L., Vitousek, P.M., Reynolds, H.L., Hooper, D.U., Lavorel, S., Sala, O.E., Hobbie, S.E., Mack, M.C., and Díaz, S. (2000). Consequences of changing biodiversity. Nature 405: 234-242.

Chidumayo, E.N. (1992). The utilization and status of dambos in southern Africa: A Zambian case study. In Wetlands Conservation Conference for Southern Africa. T. Matiza and H.N. Chabwela (Eds.). Proceedings of the Southern African Development Coordination Conference held in Gaborone, Botswana, June 3-5, 1991.

Chisembele, C. (2005). Knowledge and disease management skills of cattle owners on East Coast Fever and Foot and Mouth Disease in Kazungula and Livingstone Districts of Zambia. Tropicultura 23: 21-27.

Chiuta, T.M., Hüsken, S.M.C., and Madzudzo, E. (2011). Transforming aquatic agricultural systems (AAS) towards gender equality: A five country review. Penang, Malaysia: CGIAR Research Program on Aquatic Agricultural Systems. Working paper AAS-2012-21.

Christie, P., Armada, N.B., White, A.T., Gulayan, A.M., and de Dios, H.H.Y. (2006). Coastal environment and fisheries profile of Danajon Bank, Bohol, Philippines. Cebu City, Philippines: Fisheries Improved for Sustainable Harvest (FISH) Project.

CIA. (2012). The world factbook, vol. 2012. Washington, D.C.: Central Intelligence Agency.

CIAT. (2008). Improved multipurpose forages for the developing world. SBA3. Summary annual report.

Cinner, J., Marnane, M.J., McClanahan, T.R., and Almany, G.R. (2006). Periodic closures as adaptive coral reef management in the Indo-Pacific. Ecology and Society 11: 31.

Cohen, P., and Alexander, T.J. (2013) Catch rates, composition and fish size from reefs managed with periodically harvested closures. PLOS ONE 8(9): e73383. 
Cohen, P., Cinner, J., and Foale, S. (2013). Fishing patterns associated with periodically harvested marine closures. Global Environmental Change. http://dx.doi.org/10.1016/j.gloenvcha.2013.08.010

Cohen, P., Evans, L., and Mills, M. (2012). Social networks supporting governance of coastal ecosystems in Solomon Islands. Conservation Letters 5: 376-386.

Cohen, P.J., and Foale, S.J. (2013). Sustaining small-scale fisheries with periodically harvested marine reserves. Marine Policy 37: $278-287$.

Concern Worldwide Zambia. (2012). Integrated poverty reduction and women's empowerment programme (IPRWEP). Programme Baseline, Volume 1: Summary Report. Draft of September 13, 2012.

D'Agnes, H., Castro, J., D'Agnes, L., and Montebon, R. (2005). Gender issues within the population-environment nexus in Philippine coastal areas. Coastal Management 33: 447-458.

Datta, D., Chattopadhyay, R.N., and Guha, P. (2012). Community-based mangrove management: A review on status and sustainability. Journal of Environmental Management 107: 84-95.

Dey, M.M., Spielman, D.J., Haque, A.B.M.M., Rahman, M.S., and Valmonte-Santos, R. (2013). Change and diversity in smallholder rice-fish systems: Recent evidence and policy lessons from Bangladesh. Food Policy 43: 108-117.

Dobermann, A. (2004). A critical assessment of the system of rice intensification (SRI). Agricultural Systems 79: 261-281.

Doma, D., and Yakupitiyage, A. (2011). A policy alternative for lagoon management: Case study of Sre Ambel coastal marine fisheries, Cambodia. Journal of Coastal Conservation 15: 23-35.

Evans, L., Cherrett, N., and Pemsl, D. (2011). Assessing the impact of fisheries co-management interventions in developing countries: A meta-analysis. Journal of Environmental Management 92: 1938-1949.

Fan, S., and Hazell, P. (2001). Returns to public investments in the less-favored areas of India and China. Amer. J. Agr. Econ. 83: 1217-1222.

FAO. (1997). Recognising CBPP. A field manual for recognition. Rome, Italy: Food and Agriculture Organization of the United Nations.

FAO. (2005). Fact sheet Philippines: Women in agriculture, environment and rural production. Regional Office for Asia and the Pacific. http://www.fao.org/docrep/008/ae946e/ae946e03.htm

FAO. (2012a). Fishery and aquaculture statistics yearbook 2010. Rome, Italy: Food and Agriculture Organization of the United Nations

FAO. (2012b). The state of world fisheries and aquaculture 2012. Rome, Italy: Food and Agriculture Organization of the United Nations.

FAO. (2013). National aquaculture sector overview: Zambia. National Aquaculture Sector Overview Fact Sheets, FAO Fisheries and Aquaculture Department. http://www.fao.org/fishery/countrysector/naso_zambia/en

FAOSTAT (2012). Statistic yearbook 2012. World food and agriculture. Rome, Italy: Food and Agriculture Organization of the United Nations. ISBN 978-92-5-106913-4.

Feed the Future. (2012). Women's empowerment in agriculture index. International Food Policy Research Institute.

FIES. (2006). Philippines: 2006 family income and expenditure survey. http://www.census.gov.ph/nsoda/index.php/catalog/9/overview

Foale, S., Cohen, P., Januchowski-Hartley, S., Wenger, A., and Macintyre, M. (2011). Tenure and taboos: Origins and implications for fisheries in the pacific. Fish and Fisheries 12: 357-369.

Foale, S.J., and Manele, B. (2004). Social and political barriers to the use of marine protected areas for conservation and fishery management in Melanesia. Asia Pacific Viewpoint 45: 373-386.

Foley, J.A., DeFries, R., Asner, G.P., Barford, C., Bonan, G., Carpenter, S.R., Chapin, S.F., Coe, M.T., Daily, G.C., Gibbs, H.K., Helkowski, J.H., Holloway, T., Howard, E.A., Kucharik, C.J., Monfreda, C., Patz, J.A., Prentice, I.C., Ramankutty, N., and Snyder, P.K. (2005). Global consequences of land use. Science 309: 570-573.

Frei, M., Razzak, M.A., Hossain, M.M., Oehme, M., Dewan, S., and Becker, K. (2007). Methane emissions and related physicochemical soil and water parameters in rice-fish systems in Bangladesh. Agriculture, Ecosystems and Environment 120: 391-398.

Gillett, R., and Lightfoot, C. (2001). The contribution of fisheries to the economies of Pacific island countries. A report prepared for the Asian Development Bank, the Forum Fisheries Agency, and the World Bank. http://www.adb.org/sites/default/files/pub/2002/ contribution_fisheries.pdf

Govan, H. (2009). Achieving the potential of locally managed marine areas in the South Pacific. SPC Traditional Marine Resource Management and Knowledge Information Bulletin 25: 16-25.

Govan, H., Schwartz, A.-M., and Boso, D. (2011). Towards integrated island management: Lessons from Lau, Malaita, for the implementation of a national approach to resource management in Solomon Islands. Honiara, Solomon Islands: WorldFish Report to SPREP: 69.

Grace, D., Randolph, T., Diall, O., and Clausen, P.-H. (2008). Training farmers in rational drug-use improves their management of cattle trypanosomosis: A cluster-randomised trial in south Mali. Preventive Veterinary Medicine 83: 83-97.

Grant, C. (2010). Cambodia country strategy development paper. Methodist Relief \& Development Fund. 
Grayson, R. (2002). Blue seas and bush gardens: The story of an innovative NGO in the Solomon Islands. Kaston Gaden Association. http://www.terracircle.org.au/kga/reports/blue_seas_06.pdf

Grayson, R. (2005). People on the edge. Sustainable Livelihoods for Isolated Rural Areas Project. AusAID.

Gregory, R. (1997). Ricefield fisheries handbook. Phnom Penh, Cambodia: Cambodia-IRRI-Australia Project.

Gutiérrez, N.L., Hilborn, R., and Defeo, O. (2011). Leadership, social capital and incentives promote successful fisheries. Nature 470: 386-389.

Guttman, H. (1999). Rice field fisheries: A resource for Cambodia. The ICLARM Quarterly 22: 11-15.

Hakiza, J.J., Odogola, W., Mugisha, J., Semana, A.R., Nalukwago, J., Okoth, J., and Ekwamu, A. (2004). Challenges and prospects of disseminating technologies through farmer field schools: Lessons learnt based on experience from Uganda. Uganda Journal of Agricultural Sciences 9: $163-175$.

Hall, D., and Bouapao, L. (2010). Social impact monitoring and vulnerability assessment. Regional report. Vientiance, Lao: Mekong River Commission. 179 pp.

Halwart, M., and Gupta, M.V. (2004). Culture of fish in rice fields. FAO and WorldFish.

Hap, N., Seng, L., and Chuenpagdee, R. (2006). Socioeconomics and livelihood values of Tonle Sap Lake fisheries. Phnom Penh, Cambodia: Inland Fisheries Research and Development Institute.

Haque, M.M., Little, D.C., Barman, B.K., and Wahab, M.A. (2010). The adoption process of ricefield-based fish seed production in northwest Bangladesh: An understanding through quantitative and qualitative investigation. Journal of Agricultural Education and Extension 16: 161-177.

Harding, M., Quirke, D., and Warner, R. (2007). Cattle and buffalo in Cambodia and Laos: The economics and policy environment for smallholders. ACIAR project number plia/2006/012 - part 2. Project final report.

Henriksson, P.J.G., Guinée, J.B., Kleijn, R., and de Snoo, G.R. (2012). Life cycle assessment of aquaculture systems: A review of methodologies. Int. J. Life Cycle Assess. 17: 304-313.

HIES (2006). Household income and expenditure survey 2005/6. Solomon Islands Statistics Office. Department of Finance and Treasury Honiara.

Hill, J., and Mustafa, S. (2011). Natural resources management and food security in the context of sustainable development. Sains Malaysiana 40: 1331-1340.

Homann, S., van Rooyen, A., Moyo, T., and Nengomasha, Z. (2007). Goat production and marketing: Baseline information for semi-arid Zimbabwe. Bulawayo, Zimbabwe: International Crops Research Institute for the Semi-Arid Tropics.

Hori, M., Ishikawa, S., Heng, P., Thay, S., Ly, V., Nao, T., and Kurokura, H. (2006). Role of small-scale fishing in Kompong Thom Province, Cambodia. Fisheries Science 72: 846-854.

Horlte, K.G. (2007). Consumption and yield of fish and other aquatic animals from the lower Mekong basin. MRC Technical Paper No. 16. Vientiane, Lao PDR: Mekong River Commission.

Horlte, K.G., Troeung, R., and Lieng, S. (2008). Yield and value of the wild fishery of rice fields in Battambang Province, near the Tonle Sap Lake, Cambodia. MRC Technical Paper No. 18. Vientiane, Lao PDR: Mekong River Commission.

Hossain, M., Bose, M., and Mustafi, B.A.A. (2006). Adoption and productivity impact of modern rice varieties in Bangladesh. The Developing Economies XLIV-2: 149-166.

Hossain, M., Lewis, D., Bose, M.L., and Chowdhury, A. (2007). Rice research, technological progress, and poverty: The Bangladesh case. In Agricultural Research, Livelihoods, and Poverty: Studies of Economic and Social Impacts in Six Countries, pp. 56-102. M.R.M.-D. Adato (Ed.). Baltimore and Washington, D.C.: Johns Hopkins University Press and International Food Policy Research Institute.

Hossain, M.A.R. (1996). Agricultural policies in Bangladesh: Evolution and impact on crop production. In State, Market and Development: Essays in Honor of Rehman Sobhan. A.A. Abdullah and A.R. Khan (Eds.). Dhaka, Bangladesh: University Press.

Howden, S.M., Soussana, J.-F., Tubiello, F.N., Chhetri, N., Dunlop, M., and Meinke, H. (2007). Adapting agriculture to climate change. PNAS 104: 19691-19696.

Howlader, M.Z.H., and Biswas, S.K. (2009). Screening for nutritionally rich and low glycemic index Bangladeshi rice varieties. National Food Policy Capacity Strengthening Programme.

Hussain, M.G. (2010). Freshwater fishes of Bangladesh: Fisheries, biodiversity and habitat. Aquatic Ecosystem Health and Management 13: 85-93.

IFAD (2010). Rural poverty report 2011. Rome, Italy: IFAD.

Irfanullah, H.M., Adrika, A., Ghani, A., Khan, Z.A., and Rashid, M.A. (2008). Introduction of floating gardening in the north-eastern wetlands of Bangladesh for nutritional security and sustainable livelihood. Renewable Agriculture and Food Systems 23: 89-96. 
Irfanullah, H.M., Azad, M.A.K., Kamruzzaman, M., and Wahed, M.A. (2011). Floating gardening in Bangladesh: A means to rebuild lives after devastating flood. Indian Journal of Traditional Knowledge 10: 31-38.

Islam, M.R. (2006). Managing diverse land uses in coastal Bangladesh: Institutional approaches. In Environment and Livelihoods in Tropical Coastal Zones. C.T. Hoanh, T.P. Toung, J.W. Gowing, and B. Hardy (Eds.). Penang, Malaysia: CAB International.

IUCN (2003). Barotse floodplain, Zambia: Local economic dependence on wetland resources. Integrating Wetland Economic Values Into River Basin Management Valuation \#2.

Jahan, K., Beveridge, M.C.M., and Brooks, A.C. (2008). Impact of long-term training and extension support on small-scale carp polyculture farms of Bangladesh. Journal of the World Aquaculture Society 39: 441-453.

Jahan, K., Crissman, C., and Antle, J. (2013). Economic and social impacts of integrated aquaculture-agriculture technologies in Bangladesh. Penang, Malaysia: CGIAR Research Program on Aquatic Agricultural Systems. Working paper AAS-2013-02.

Jahan, K., and Pemsl, D.E. (2011). The impact of integrated aquaculture-agriculture on small-scale farm sustainability and farmers' livelihoods: Experience from Bangladesh. Agricultural Systems 104: 392-402.

Jansen, T., Mullen, B.F., Pollard, A.A., Maemouri, R.K., Watoto, C., and Iramu, E. (2006). Solomon Islands smallholder agriculture study. Volume 2: Subsistence Production, Livestock and Social Analysis. Canberra, Australia: AusAID.

Janssen, R., and Padilla, J.E. (1999). Preservation or conversion? Valuation and evaluation of a mangrove forest in the Philippines. Environmental \& Resource Economics 14: 297-331.

Joffre, O., Kosal, M., Kura, Y., Sereywath, P., and Thuok, N. (2012). Community fish refuges in Cambodia: Lessons learned. Phnom Penh, Cambodia: WorldFish.

Joffre, O., Kura, Y., Pant, J., and Nam, S. (2010). Aquaculture for the poor in Cambodia: Lessons learned. Phnom Penh, Cambodia: WorldFish.

Joffre, O., and Sheriff, N. (2011). Conditions for collective action: Understanding factors supporting and constraining community-based fish culture in Bangladesh, Cambodia and Vietnam. WorldFish Studies and Reviews 2011-21. Penang, Malaysia: WorldFish.

Kadir, A., Kundu, R.S., Milstein, A., and Wahab, M.A. (2006). Effects of silver carp and small indigenous species on pond ecology and carp polycultures in Bangladesh. Aquaculture 261: 1065-1076.

Kaggwa, C. (2006). Fingerponds: Managing nutrients and primary productivity for enhanced fish production in Lake Victoria's wetlands, Uganda. Ph.D. dissertation. UNESCO-IHE Institute for Water and Education. Delft, The Netherlands: Wageningen University.

Karim, M., Sarwer, R.H., Brooks, A.C., Gregory, R., Jahan, K., and Belton, B. (2012). The incidence of suspected white spot syndrome virus in semi-intensive and extensive shrimp farms in Bangladesh: Implications for management. Aquaculture Research 43(9): 1357-1371.

Kent, R., and MacRae, M. (2010). Agricultural livelihoods and nutrition: Exploring the links with women in Zambia. Gender and Development 18: 387-409.

Kipkemboi, J., Kilonzi, C.M., van Dam, A.A., Kitaka, N., Mathooko, J.M., and Denny, P. (2010). Enhancing the fish production potential of Lake Victoria papyrus wetlands, Kenya, using seasonal flood-dependent ponds. Wetlands Ecol Manage 18: 471-483.

Kipkemboi, J., Van Dam, A.A., Ikiara, M.M., and Denny, P. (2007). Integration of smallholder wetland aquaculture-agriculture systems (fingerponds) into riparian farming systems on the shores of Lake Victoria, Kenya: Socio-economics and livelihoods. Geographical Journal 173: 257-272.

Kruijssen, F. (2009). Assessing the impact of the Bioversity International project "overcoming poverty in coconut growing communities." FAO and Bioversity International Radboun University Nijmegen.

Kumar, N., and Quisumbing, A.R. (2010). Access, adoption and diffusion: Understanding the long-term impacts of improved vegetable and fish technologies in Bangladesh. IFPRI discussion paper 00995.

Kuntashula, E., Sileshi, G., Mafongoya, P.L., and Banda, J. (2006). Farmer participatory evaluation of the potential for organic vegetable production in the wetlands of Zambia. Agriculture 35: 299-305.

Kwashimbisa, M.I. (2012). Gender situational analysis of the Barotse floodplain. CGIAR Research Program on Aquatic Agricultural Systems.

Lapar, M.L.A., and Ehui, S. (2004). Factors affecting adoption of dual-purpose forages in the Philippine uplands. Agricultural Systems 81: 95-114.

Lasco, R.D., Evangelista, R.S., and Pulhin, F.B. (2010). Potential of community-based forest management to mitigate climate change in the Philippines. Small-Scale Forestry 9: 429-443.

Lebata, M., Le Vay, L., Walton, M.E., Binas, J.B., Quinitio, E.T., Rodriguez, E.M., and Primavera, J.H. (2009). Evaluation of hatchery-based enhancement of the mud crab, Scylla spp., fisheries in mangroves: Comparison of species and release strategies. Marine and Freshwater Research 60: 58-69.

Lebata, M.J.H., Walton, M.E., Binas, J.B., Primavera, J.H., and Le Vay, L. (2012). Identifying mangrove areas for fisheries enhancement: Population assessment in a patchy habitat. Aquatic Conservation-Marine and Freshwater Ecosystems 22: 652-664. 
Lewis, D., Bell, S.D., Fay, J., Bothi, K.L., Gatere, L., Kabila, M., Mukamba, M., Matokwani, E., Mushimbalume, M., Moraru, C.I., Lehmann, J., Lassoie, J., Wolfe, D., Lee, D.R., Buck, L., and Travis, A.J. (2011). Community markets for conservation (COMACO) links biodiversity conservation with sustainable improvements in livelihoods and food production. Proceedings of the National Academy of Sciences of the United States of America 108: 13957-13962.

Li, S., Li, H., Liang, X.Q., Chen, Y.X., Cao, Z.H., and Xu, Z.H. (2009). Rural wastewater irrigation and nitrogen removal by the paddy wetland system in the Tai Lake region of China. Journal of Soils and Sediments 9: 433-442.

Lightfoot, C., Ryan, T., and Quitazol, J. (2003). Poverty: Is it an issue in the Pacific? Asian Development Bank. Office of Pacific Operations.

Longley, K., and Thilsted, S.H. (2012). Food nutrition security in the Barotse floodplain system. Draft report. Penang, Malaysia: CGIAR Research Program on Aquatic Agricultural Systems.

Lorenzen, K. (2008). Understanding and managing enhancement fisheries systems. Reviews in Fisheries Science 16: 10-23.

Ly, P., Jensen, L.S., Bruun, T.B., Rutz, D., and de Neergaard, A. (2012). The system of rice intensification: Adapted practices, reported outcomes and their relevance in Cambodia. Agricultural Systems 113: 16-27.

M4P Hub. (2010). Sharing knowledge on making markets work for the poor. http://www.m4phub.org/

Mabeza, C.M., and Mawere, M. (2012). Dambo cultivation in Zimbabwe: Challenges faced by small-scale dambo farming communities in Seke-Chitungwiza communal area. Journal of Sustainable Development in Africa 14: 39-53.

Mackill, D.J., Ismail, A.M., Singh, U.S., Labios, R.V., and Paris, T.R. (2012). Development and rapid adoption of submergence-tolerant (sub1) rice varieties. In Advances in Agronomy, pp. 299-352. Burlington: Academic Press.

Mafongoya, P.L., Dzowela, B.H., and Nair, P.K. (1997). Effect of multipurpose trees, age of cutting and drying method on pruning quality. In Driven by Nature: Plant Litter Quality and Decomposition, pp. 167-174. G. Cadisch and K.E. Giller (Eds.). Wallingford: CAB International.

Magalhães, A., da Costa, R.M., da Silva, R., and Pereira, L.C.C. (2007). The role of women in the mangrove crab (Ucides cordatus, Ocypodidae) production process in North Brazil (Amazon region, para). Ecological Economics 61: 559-565.

Magat, S.S. (2009). Productive and sustainable coconut farming ecosystems as potential carbon "sinks" in climate-change minimization: A review and advisory notes. Pasig City, Metro Manila: S \& T Challenges and Opportunities in the Midst of Climate Change.

Magat, S.S., Canja, L.H., and Rivera, S.M. (2007). Coconut productivity and profitability of two important Philippine PCA hybrids: A critical review. Cord 23: 32-61.

Magat, S.S., and Secretaria, M.I. (2007). Coconut intercropping guide no. 7: Coconut-cacao (cocoa) cropping model. Philippine Coconut Authority. Research and Development, and Extension Branch Diliman, Quezon City.

Magcale-Macandog, D.B., Rañola, F.M., Rañola, R.F., Ani, P.A.B., and Vidal, N.B. (2010). Enhancing the food security of upland farming households through agroforestry in Claveria, Misamis Oriental, Philippines. Agroforest Sys 79: 327-342.

Mapedza, E., Geheb, K., van Koppen, B., and Chisaka, J. (2012). Narratives from a wetland: Sustainable management in Lukanga, Zambia. Development Southern Africa 29: 379-390.

Masset, E., Haddad, L., Cornelius, A., and Isaza-Castro, J. (2011). A systematic review of agricultural interventions that aim to improve nutritional status of children. London: EPPI-Centre, Social Science Research Unit, Institute of Education, University of London.

Maxwell, T.W., You, S., Boratana, U., Leakhna, P., and Reid, J. (2012). The social and other impacts of a cattle/crop innovation in Cambodia. Agricultural Systems 107: 83-91.

Mercado, A. (2007). Potential of timber based hedgerow intercropping for smallholder agroforestry on degraded soils in the humid tropics of Southeast Asia. Laguna, Philippines: World Agroforestry Center ICRAF Southeast Asia Regional Research Programme.

Mercado, A., Don Immaneul, E., and Harrison, S. (2010). Technical and financial aspects of clonally propagated rubber planting stock for rubber agroforestry in Mindanao. Proceedings of End-of-Project Workshop: ASEM/2006/091 Enhancing Tree Seedling Supply via Economic and Policy Changes in the Philippines Nursery Sector. Leyte, Philippines.

Mercado, A., Duque-Piñon, C., Palada, M., and Reyes, M. (2012). Vegetable-agroforestry (VAF) system: Understanding vegetable-tree interaction as a key to successful vegetable farming in the uplands of Southeast Asia. In Vegetable-Agroforestry Systems in the Philippines, pp. 79-112. D.C. Catacutan, J.A.R. Mercado, M.E. Choing-Javier, V.B. Ella, M.V.O. Espaldon, A.C. Rola, C. Duque-Piñon, J.A. Saludadez, A.M. Penaso, M.R. Nguyen, C.T. Pailagao, I.B. Bagares, N.R. Alibuyog, D. Midmore, M.R. Reyes, W. Suthumchai, K. Kunta, and S. Sombatpanit (Eds.). Vol. Special Publication No. 6b. Beijing, China: World Association of Soil and Water Conservation (WASWAC); Nairobi, Kenya: World Agroforestry Center (ICRAF).

Mercado, A., Patindol, M., and Garrity, D. (2001). The landcare experience in the Philippines: Technical and institutional innovations for conservation farming. Development in Practice 11: 495-508.

Mertz, O., Birch-Thomsen, T., Elberling, B., Rothausen, S., Bruun, T.B., Reenberg, A., Fog, B., Egsmose, R.M.R., and Breuning-Madsen, H. (2012). Changes in shifting cultivation systems on small Pacific islands. Geographical Journal 178: 175-187.

Milstein, A., Islam, M.S., Wahab, M.A., Kamal, A.H.M., and Dewan, S. (2005). Characterization of water quality in shrimp ponds of different sizes and with different management regimes using multivariate statistical analysis. Aquaculture International 13: 501-518.

Milstein, A., Wahab, M.A., Kadir, A., Sagor, M.F.H., and Islam, M.A. (2009). Effects of intervention in the water column and/or pond bottom through species composition on polycultures of large carps and small indigenous species. Aquaculture 286: 246-253. 
Milstein, A., Wahab, M.A., and Rahman, M.M. (2002). Environmental effects of common carp Cyprinus carpio (L.) and mrigal Cirrhinus mrigala (Hamilton) as bottom feeders in major Indian carp polycultures. Aquaculture Research 33: 1103-1117.

Molden, D. (2007). Water for food, water for life. London: Earthscan.

Mondal, M.K., Tuong, T.P., Sharifullah, A.K.M., and Sattar, M.A. (2010). Water supply and demand for dry-season rice in the coastal polders of Bangladesh. In Tropical Deltas and Coastal Zones: Food Prodution, Communities and Environment at the Land-Water Interface. C.T. Hoanh et al. (Eds.). CAB International.

Moser, C.M., and Barrett, C.B. (2003). The disappointing adoption dynamics of a yield-increasing, low external-input technology: The case of SRI in Madagascar. Agricultural Systems 76: 1085-1100.

Mueller, N.D., Gerber, J.S., Johnston, M., Ray, D.K., Ramankutty, N., and Foley, J.A. (2013). Closing yield gaps through nutrient and water management. Nature 409. doi: 10.1038/nature11420

Muma, J.B., Munyeme, M., Samui, K.L., Siamudaala, V., Oloya, J., Mwacalimba, K., and Skjerve, E. (2009). Mortality and commercial off-take rates in adult traditional cattle of Zambia. Tropical Animal Health and Production 41: 783-789.

Mundenda, M.D., Sinkala, G., Mulenga, V., Lulemba, G., Mubanga, B., and Maembe, E. (2005). Intensification and commercialisation of aquaculture in agriculture support programme areas. Department of Biological Sciences, UNZA.

Musumali, M.M., Heck, S., Husken, S.M.C., and Wishart, M. (2009). Fisheries in Zambia: An undervalued contributor to poverty reduction. WorldFish and the World Bank, Policy Brief 1913.

Nagabhatla, N., Beveridge, M., Haque, A.B.M., Nguyen-Khoa, S., and Van Brakel, M. (2012). Multiple water use as an approach for increased basin productivity and improved adaptation: A case study from Bangladesh. International Journal of River Basin Management 10: $121-136$.

Nampanya, S., Suon, S., Rast, L., and Windsor, P.A. (2012). Improvement in smallholder farmer knowledge of cattle production, health and biosecurity in Southern Cambodia between 2008 and 2010. Transboundary and Emerging Diseases 59: 117-127

National Institute of Statistics and Directorate General for Health. (2011). Cambodia demographic and health survey 2010. Calverton, Maryland, USA.

National Statistics Office, SPC, Macro International Inc. (2007). Solomon Islands 2006-2007 demographic and health survey.

Newby, J.C., and Cramb, R.A. (2012). Economic impacts of conservation farming in a marginal environment: The case of "landcare" in the Philippines. International Journal of Agricultural Sustainability 9: 456-470.

NSCB. (2012). Philippines' policy making and coordinating body on statistical matters. In Poverty Statistics, Vol. 2012. Makati City, Philippines: National Statistical Coordination Board. http://www.nscb.gov.ph/poverty/default.asp

Nyirenda, D.B., Musukwa, M., and Mugode, R.H. (2007). The common Zambian foodstuff, ethnicity, preparation and nutrient composition of selected foods. Zambia: Child Health Project of the Ministry of Health, and Boston, USA: Boston University.

Oehme, M., Frei, M., Razzak, M.A., Dewan, S., and Becker, K. (2007). Studies on nitrogen cycling under different nitrogen inputs in integrated rice-fish culture in Bangladesh. Nutrient Cycling in Agroecosystems 79: 181-191.

Osei-Bonsu, K., Opoku-Ameyaw, K., Amoah, F.M., and Oppong, F.K. (2002). Cacao-coconut intercropping in Ghana: Agronomic and economic perspectives. Agroforest Sys 55: 1-8.

Paningbatan, E.P., Ciesiolka, C.A., Coughlan, K.J., and Rose, C.W. (1995). Alley cropping for managing soil erosion of hilly lands in the Philippines. Soil Technology 8: 193-204.

Paul, B.G. and Vogl, C.R. (2011). Impacts of shrimp farming in Bangladesh: Challenges and alternatives. Ocean and Coastal Management 54: 201-211.

Perez, M.L., Pido, M.D., Garces, L.R., and Salayo, N.D. (2012). Towards sustainable development of small-scale fisheries in the Philippines: Experiences and lessons learned from eight regional sites. WorldFish.

Philippart, J.C. (1995). Is captive breeding an effective solution for the preservation of endemic species? Biological Conservation 72: $281-295$.

Philippine Coconut Authority. (2004). Growing of intercrops in coconut lands to generate more food and agricultural products, jobs, and enhancing farm incomes. Coconut Intercropping Primer. Department of Agriculture.

Philippine Coconut Authority. (2011). Coconut industry production status, growing zones, productivity and potential to increase nut supply in coconut farms through practical and efficient farming technologies (PEFT). Diliman, Quezon City: Research, Development and Extension Branch, PCA Central Office.

Philippine Rice Research Inst. (2005). Palayamanan: Making the most out of rice farms. Rice Technology Bulletin (Philippines). 0117-9799, no. 53 PRRI.

Phiri, A.M. (2006). Common conditions leading to cattle carcass and offal condemnations at three abattoirs in the Western Province of Zambia and their zoonotic implications to consumers. Journal of the South African Veterinary Association/Tydskrif Van Die Suid-Afrikaanse Veterinere Vereniging 77: 28-32. 
Phiri, E., Verplancke, H., Kwesiga, F., and Mafongoya, P.L. (2003). Water balance and maize yield following improved sesbania fallow in Eastern Zambia. Agroforest Sys 59: 197-205.

Pingali, P.L. (2012). Green revolution: Impacts, limits, and the path ahead. Proceedings of the National Academy of Sciences of the United States of America 109: 12302-12308.

Pretty, J. (2008). Agricultural sustainability: Concepts, principles and evidence. Philosophical Transactions of the Royal Society B-Biological Sciences 363: 447-465.

Pretty, J., Toulmin, C., and Williams, S. (2011). Sustainable intensification in African agriculture. International Journal of Agricultural Sustainability 9: 5-24.

Purcell, T., Nacalaban, W., Gabunada, F.A., and Cramb, R.A. (2000). Assessing the impact of agricultural technologies in smallholder farming systems: Results from a participatory monitoring and evaluation study on forages in Malitbog, Northern Mindanao, Philippines. In Working With Farmers: The Key to Adoption of Forage Technologies, pp. 297-308. W.W. Stür, P.M. Horne, J.B. Hacker, and P.C. Kerridge (Eds.). Canberra, Australia: ACIAR Proceedings No. 95.

Quoc, N.C., Vromant, N., Thanh, T.B., and Ollevier, F. (2012). Investigation of the predation potential of different fish species on brown planthopper (Nilaparvata lugens [stål]) in experimental rice-fish aquariums and tanks. Crop Protection 38: 95-102.

Rahman, A.A., Quddus, A.H.G., Pokrant, B., and Ali, M.L. (2006). Shrimp farming and industry: Sustainability, trade and livelihoods. Dhaka, Bangladesh: The University Press Limited.

Rahaman, M.H., Lund, T., and Bryceson, I. (2011). Salinity impacts on agro-biodiversity in three coastal, rural villages of Bangladesh. Ocean and Coastal Management 54: 455-468.

Rahman, S., and Barmon, B.K. (2012). Energy productivity and efficiency of the "gher" (prawn-fish-rice) farming system in Bangladesh. Energy 43: 293-300.

Ratner, B.D., Barman, B., Cohen, P., Mam, K., Nagoli, J., and Allison, E.H. (2012). Strengthening governance across scales in aquatic agricultural systems. Penang, Malaysia: WorldFish. Working paper AAS-2012-10.

Ray, D.K., Mueller, N.D., West, P.C., and Foley, J.A. (2013). Yield trends are insufficient to double global crop production by 2050. PLoS ONE 8. doi: 10.1371/journal.pone.0066428

Renkow, M. (2011). Assessing the environmental impacts of CGIAR research: Toward an analytical framework. Measuring the Environmental Impacts of Agricultural Research: Theory and Applications to CGIAR Research. Rome, Italy: CGIAR Independent Science and Partnership Council (ISPC) Secretariat.

Resurreccion, B.P., Sajor, E.E., and Sophea, H. (2008). Gender dimensions of the adoption of the system of rice intensification (SRI) in Cambodia. Asian Institute of Technology and Royal University of Phnom Penh.

Rockström, J., Steffen, W., Noone, K., Persson, Å., Chapin, F., Stuart, I.I.I., Lambin, E., Lenton, T.M., Scheffer, M., Folke, C., Joachim Schellnhuber, H., Nykvist, B., de Wit, C.A., Hughes, T., van der Leeuw, S., Rodhe, H., Sörlin, S., Snyder, P.K., Costanza, R., Svedin, U., Falkenmark, M., Karlberg, L., Corell, R.W., Fabry, V.J., Hansen, J., Walker, B., Liverman, D., Richardson, K., Crutzen, P., and Foley, J.A. (2009). Planetary boundaries: Exploring the safe operating space for humanity. Ecology and Society 14: 32.

Rodrigues, G.S., Rodrigues, I.A., Buschinelli, C.C.D., and de Barros, I. (2010). Integrated farm sustainability assessment for the environmental management of rural activities. Environmental Impact Assessment Review 30: 229-239.

Rodriguez, D.G.P., Rejesus, R.M., and Aragon, C.T. (2007). Impacts of an agricultural development program for poor coconut producers in the Philippines: An approach using panel data and propensity score matching techniques. Journal of Agricultural and Resource Economics 32: 534-557.

Roger, P.A. (1996). Biology and management of the floodwater ecosystem in ricefields. Manila, Philippines: International Rice Research Institute.

Romanillos, R.D., Movillon, M.M., and Bumatay, E.L. (2012). Community participation and intervention framework (CPIF): Mechanism of change in rice farming in Calatrava, Romblon, Philippines. http://ssrn.com/abstract=2019341

Roos, N., Wahab, M.A., Hossain, M.A.R., and Thilsted, S.H. (2007). Linking human nutrition and fisheries: Incorporating micronutrient-dense, small indigenous fish species in carp polyculture production in Bangladesh. Food and Nutrition Bulletin 28: S280-S293.

Runnebaum, J.M., Beveridge, M.C.M, Hüsken, S.M.C., Lungu, P., and Enright, N. (2011). Aquaculture big numbers study: Zambia. Unpublished WorldFish report.

Salmo, S.G., and Duke, N.C. (2010). Establishing mollusk colonization and assemblage patterns in planted mangrove stands of different ages in Lingayen Gulf, Philippines. Wetlands Ecol Manage 18: 745-754.

Sampa, J. (2007). Sustainable dambo cultivation. Report of Striking a Balance Project.

Scheewe, W. (2003). Coconut farm diversification: Ideas and considerations. Generoso, Davao Oriental: Training Workshop on Coconut Farm Diversification, May 28-31, 2001.

Schwarz, A.-M., Alexander, T., and Bodo, D. (2012). Improving resilience and adaptive capacity of fisheries-dependent communities in Solomon Islands. Canberra, Australia: Australian Centre for International Agricultural Research. 
Schwarz, A., Andrew, N., and Nash, W. (2009). Improving sustainability and profitability of village sea cucumber fisheries in Solomon Islands. Canberra, Australia: Australian Centre for International Agricultural Research.

Scoones, I. (1998). Sustainable rural livelihoods: A framework for analysis. Brighton, UK: IDS. Working Paper 72.

SDSN. (2013). An action agenda for sustainable development. Report for the UN Secretary-General. www.unsdsn.org

Sechrest, E.K. (2008). Agroforestry practice adoption among Solomon Islands women on the island of Malaita. Master of Science thesis. Logan, Utah: Utah State University.

Shepherd, K.D., Farrow, A., Ringler, C., Gassner, A., and Jarvis, D. (2013). Review of the evidence on indicators, metrics and monitoring systems. Department for International Development, CGIAR and the World Agroforestry Centre.

Sheriff, N., Joffre, O., Hong, M.C., Barman, B., Haque, A.B.M., Rahman, F., Zhu, J., Nguyen V. H., Russell, A., van Brakel, M., Valmonte-Santos, R., Werthmann, C., and Kodio, A. (2010). Community-based fish culture in seasonal floodplains and irrigation systems. CPWF project number 35. CGIAR challenge program on water and food project report series.

Siliota, C., Weinberger, K., and Wu, M.-H. (2008). Baseline report: Vegetable production in Guadalcanal and Malaita, Solomon Islands. The World Vegetable Center AVRDC Publication: 09-716.

Snelder, D.J., Klein, M., and Schuren, S.H.G. (2007). Farmers preferences, uncertainties and opportunities in fruit-tree cultivation in Northeast Luzon. Agroforestry Systems 71: 1-17.

So, N. (2009). Impact survey of the freshwater aquaculture improvement and extension project (FAIEX). Phnom Penh, Cambodia: JICA/FAIEX.

So, N., Eng, T., Souen, N., and Hortle, K.G. (2005). Use of freshwater low value fish for aquaculture development in Cambodia's Mekong Basin. Phnom Penh, Cambodia: Department of Fisheries.

So, N., and Haing, L. (2007). A review of freshwater fish seed resources in Cambodia. In Assessment of Freshwater Fish Seed Resource for Sustainable Aquaculture, pp. 145-170. M.B. Bondad-Reantaso (Ed.). Vol. 628. Rome, Italy: FAO. FAO Fisheries Technical Report Series 501.

Solomon Islands Government (2009). Census 2009: Basic tables and census description. Honiara: Statistical Bulletin No: 6/2012.

Solomon Islands National Statistics Office and UNDP Pacific Centre. (2008). Analysis of the 2005/6 household income and expenditure survey. http://www.undppc.org.f/_resources/article/files/solomon\%20report\%20final\%20LOW.pdf

Soviet, L. (2007). Experiences in multi-purpose farm development: Raising household incomes in Cambodia by utilizing productivity gains from the systems of rice intensification. CEDAC. Entry Meas Printing House.

SPC. (2011). Pacific island's population tops 10 million: Now putting pressure on stretched resources. Islands Business Magazine. http://www.spc.int/sdd/index.php/en/component/content/article/1/74-pacific-islands-population-tops-10-million

SRI-Rice. (2012). System of rice intensification. Cambodia. http://sri.ciifad.cornell.edu/countries/cambodia/index.html

Stür, W.W., Horne, P.M., Gabunada, F.A., Phengsavanh, P., and Kerridge, P.C. (2002). Forage options for smallholder crop-animal systems in Southeast Asia: Working with farmers to find solutions. Agricultural Systems 71: 75-98.

Sumberg, J. (2002). The logic of fodder legumes in Africa. Food Policy 27: 285-300.

Suryavanshi, P., Singh, Y.V., Prasanna, R., Bhatia, A., and Shivay, Y.S. (2013). Pattern of methane emission and water productivity under different methods of rice crop establishment. Paddy and Water Environment 11: 321-329.

The World Bank. (2008). Poverty assessment for Bangladesh: Creating opportunities and bridging the East-West divide.

The World Bank. (2010). Philippines. Fostering more inclusive growth. Main report. Human development sector unit and poverty reduction and economic management unit. East Asia and Pacific region.

The World Bank. (2012a). Skills for Solomon Islands. Opening new opportunities

The World Bank. (2012b). Cambodia. http://data.worldbank.org/country/cambodia

The World Bank. (2012c). Bangladesh. http://data.worldbank.org/country/bangladesh

The World Bank. (2012d). Solomon Islands. http://data.worldbank.org/country/solomon-islands

The World Bank. (2012e). Philippines. http://data.worldbank.org/country/philippines

The World Bank. (2012f). Republic of Zambia. Livestock development and animal health project. Report no. 65184-ZM.

The World Bank. and UKAID. (2011). What would it take for Zambia's beef and dairy industries to achieve their potential?

Thornton, P., and Cramer, L. (2012). Impacts of climate change on the agricultural and aquatic systems and natural resources within the CGIAR's mandate. CCAFS Working Paper 23. Copenhagen, Denmark: CGIAR Research Program on Climate Change, Agriculture and Food Security (CCAFS).

Thuok, N. (2009). Community fish refuge husbandry in lowland agricultural ecosystem. Ph.D. thesis. Phnom Penh: Build Bright University. 
Tilman, D., Blazer, C., Hill, J., and Befort, B.L. (2011). Global food demand and the sustainable intensification of agriculture. PNAS. doi: 10.1073/ pnas.1116437108 1-5

Tittonell, P., and Giller, K.E. (2013). When yield gaps are poverty traps: The paradigm of ecological intensification in African smallholder agriculture. Field Crops Research 143: 76-90.

Tittonell, P., Scopel, E., van Halsema, G.E., Andrieu, N., Posthumus, H., Mapfumo, P., Lahmar, R., Corbeels, M., Apina, T., Rakotoarisoa, J., Mtambanengwe, F., Pound, B., Chikowo, R., and Mkomwa, S. (2012). Agroecology-based aggradation-conservation agriculture (ABACO): Targeting resource-limited and degraded environments of semi-arid Africa. Field Crops Research 132: 168-174.

Tittonell, P., van Wijk, M.T., Herrero, M., Rufino, M.C., de Ridder, N., and Giller, K.E. (2009). Beyond resource constraints: Exploring the biophysical feasibility of options for the intensification of smallholder crop-livestock systems in Vihiga District, Kenya. Agricultural Systems 101: 1-19.

Triño, A.T., and Rodriguez, E.M. (2002). Pen culture of mud crab Scylla serrata in tidal flats reforested with mangroves trees. Aquaculture 211: 125-134.

Ullah, B., Shahnaz, F., and Van Den Ende, P. (2009). Good practices for community resilience. Department for International Development. Dhaka, Bangladesh: Practical Action Bangladesh.

UNDP. (2007). 2007 Zambia: Human development report. Enhancing household capacity to respond to HIV and AIDS. Lusaka, Zambia.

Uphoff, N., Kassam, A., and Harwood, R. (2011). SRI as a methodology for raising crop and water productivity: Productive adaptations in rice agronomy and irrigation water management. Paddy and Water Environment 9: 3-11.

Vatta, A.F., de Villiers, J.F., Harrison, L.J.S., Krecek, R.C., Pearson, R.A., Rijkenberg, F.H.J., Spickett, A., and Worth, S.H. (2011). A framework for the transfer of animal health knowledge to rural goat owners. Small Ruminant Research 98: 26-30.

VGREEN., (2012). Life cycle assessment of fish feeds: Case study in Bangladesh. Kasetsart University, Thailand: Centre of Excellence on environmental strategy for GREEN business.

Viseth, H., Leap, H., Savry, C., Thon, H., and Doi, M. (2008). Propagation of rice-field fish resources for rural communities through establishment of dry season fish refuges in Cambodia. Freshwater Aquaculture Improvement and Extension Project (FAIEX). Phnom Penh, Cambodia: Fishery Administration.

Wahab, M.A., Ahmad-Al-Nahid, S., Ahmed, N., Haque, M.M. and Karim, M. (2012). Current status and prospects of farming the giant river prawn Macrobrachium rosenbergii (De Man) in Bangladesh. Aquaculture Research 43: 970-983.

Walton, M.E.M., Samonte-Tan, G.P.B., Primavera, J.H., Edwards-Jones, G., and Le Vay, L. (2006). Are mangroves worth replanting? The direct economic benefits of a community-based reforestation project. Environmental Conservation 33: 335-343.

Warren-Rhodes, K., Schwarz, A.M., Boyle, L.N., Albert, J., Agalo, S.S., Warren, R., Bana, A., Paul, C., Kodosiku, R., Bosma, W., Yee, D., Ronnback, P., Crona, B., and Duke, N. (2011). Mangrove ecosystem services and the potential for carbon revenue programmes in Solomon Islands. Environmental Conservation 38: 485-496.

WASSAN. (2006). System of rice intensification: Weeders, a reference compendium. Hyderabad: Charita Impressions. www.wassan.org

Weeratunge, N., Chiuta, T.M., Choudhury, A., Ferrer, A., Hüsken, S.M.C., Kura, Y., Kusakabe, K., Madzudzo, E., Maetala, R., Naved, R., Schwartz, A., and Kantor, P. (2012). Transforming aquatic agricultural systems towards gender equality: A five country review. Working paper AAS-2012-21.

Weeratunge, N., Pemsl, D., Rodriguez, P., Li, C.O., Badjeck, M.-C., Schwarz, A.-M., Paul, C., Prange, J., and Kelling, I. (2011). Planning the use of fish for food security in Solomon Islands. WorldFish.

WFP. (2010). Emergency food security assessment of internally displaced persons and returnees in Mindanao. World Food Program \& Community Family Services International.

Wijeratna, A. (2012). Fed up: Now's the time to invest in agro-ecology. Action Aid.

Williams, I.D., Walsh, W.J., Miyasaka, A., and Friedlander, A.M. (2006). Effects of rotational closure on coral reef fishes in Waikiki-Diamon Head Fishery Management Area, Oahu, Hawaii. Marine Ecology-Progress Series 310: 139-149.

Windsor, R.S. (2006). The eradication of contagious bovine pleuropneumonia from Southwestern Africa. Annals of the New York Academy of Sciences 916: 326-332.

World Food Programme. (2007). Protracted relief and recovery operation Cambodia 10305.1. Projects for executive board approval. Agenda item 9. Rome, October 22-26, 2007.

WorldFish. (2010). Gender and fisheries: Do women support, complement or subsidize men's small-scale fishing activities? Issues brief 2108

WorldFish. (2011a). CGIAR Research Program on Aquatic Agricultural Systems: Program brief. Penang, Malaysia. http://www.worldfishcenter.org/resource_centre/WF_2934.pdf

WorldFish. (2011b). Harnessing the development potential of aquatic agricultural systems for the poor and vulnerable. Brief No. 2011-15.

Yari, M. (2003). Beyond "subsistence affluence": Poverty in Pacific island countries. Bulletin on Asia-Pacific Perspectives 2003/04: Asia-Pacific Economies: Maintaining Dynamism: 41-54. New York, United Nations: Economic and Social Commission for Asia and the Pacific. 
A summary of the key ecosystems and livelihoods in the five program countries.

\begin{tabular}{|c|c|c|c|c|c|}
\hline & Solomon Islands & Zambia & Bangladesh & Cambodia & Philippines \\
\hline $\begin{array}{l}\text { Key Ecosystems } \\
\text { Underpinning } \\
\text { Aquatic } \\
\text { Agricultural } \\
\text { Systems (\& } \\
\text { Ecosystem } \\
\text { Services [ES]- } \\
\text { including only } \\
\text { regulating and } \\
\text { supporting ES) }\end{array}$ & $\begin{array}{l}\text { Coral reefs (habitat, } \\
\text { coastal protection); } \\
\text { mangroves (nursery } \\
\text { habitat, coastal } \\
\text { protection, water/ } \\
\text { nutrient retention, } \\
\text { filtration); seagrass } \\
\text { (habitat, nutrient } \\
\text { cycling, sediment } \\
\text { stabilization), inland } \\
\text { lakes and rivers } \\
\text { (habitat, nutrient } \\
\text { cycling) }\end{array}$ & $\begin{array}{l}\text { Floodplains (water/ } \\
\text { nutrient retention, } \\
\text { nutrient cycling and } \\
\text { filtration, habitat for } \\
\text { grazing species such } \\
\text { as zebra, antelope, } \\
\&>450 \text { species of } \\
\text { birds); rivers and lakes } \\
\text { (habitat, nutrient } \\
\text { cycling) }\end{array}$ & $\begin{array}{l}\text { Coastal deltas with } \\
\text { mangroves (habitat, } \\
\text { water/nutrient } \\
\text { retention, nutrient } \\
\text { cycling and filtration); } \\
\text { inland lakes and rivers } \\
\text { (habitat, nutrient } \\
\text { cycling) }\end{array}$ & $\begin{array}{l}\text { Freshwater lake } \\
\text { recession zone } \\
\text { (habitat, nutrient } \\
\text { cycling); rain-fed } \\
\text { lowland; seasonally } \\
\text { flooded rice fields } \\
\text { (habitat); river (habitat, } \\
\text { nutrient cycling, } \\
\text { sediment transfer); and } \\
\text { floodplain (habitat, } \\
\text { nutrient retention) }\end{array}$ & $\begin{array}{l}\text { Coral reefs (habitat, } \\
\text { coastal protection); } \\
\text { mangroves (nursery } \\
\text { habitat, coastal } \\
\text { protection, water/ } \\
\text { nutrient retention, } \\
\text { filtration); seagrass } \\
\text { (habitat, nutrient } \\
\text { cycling, sediment } \\
\text { stabilization); lowland } \\
\text { and upland hilly } \\
\text { coastal ecosystems }\end{array}$ \\
\hline $\begin{array}{l}\text { Household } \\
\text { Assets }\end{array}$ & $\begin{array}{l}80 \% \text { of the land is } \\
\text { considered customary } \\
\text { land, owned by the } \\
\text { tribe }\end{array}$ & Landholdings $<0.5$ ha & $\begin{array}{l}\text { Landholdings }<0.2-4 \\
\text { ha }\end{array}$ & $\begin{array}{l}\text { Overall level of assets } \\
\text { of fishing households } \\
\text { is higher than in } \\
\text { farming households }\end{array}$ & $\begin{array}{l}26-60 \% \text { suffering } \\
\text { poverty, much higher } \\
\text { in rural areas; farm } \\
\text { holdings } 1-3 \mathrm{ha} \text {; } \\
\text { family size is 5-6 } \\
\text { people }\end{array}$ \\
\hline $\begin{array}{l}\text { Key Livelihood } \\
\text { Strategy }\end{array}$ & $\begin{array}{l}\text { Year-round fishing for } \\
\text { pelagic fish (especially } \\
\text { high-value tuna) for } \\
\text { cash sales, canneries, } \\
\text { and some food; } \\
\text { supplemented with } \\
\text { small-scale coastal } \\
\text { fisheries, coastal } \\
\text { aquaculture, and } \\
\text { agriculture }\end{array}$ & \begin{tabular}{|l|} 
Year-round freshwater \\
fishing, crop \\
agriculture, cattle \\
rearing, and increasing \\
irrigated cropping
\end{tabular} & $\begin{array}{l}\text { Combination of } \\
\text { subsistence agriculture } \\
\text { and commercial } \\
\text { activities including } \\
\text { labor; fishing in } \\
\text { near-shore habitats } \\
\text { in dry season, rice } \\
\text { production during wet } \\
\text { season }\end{array}$ & $\begin{array}{l}\text { Capture fisheries, } \\
\text { aquaculture, rice-fish } \\
\text { fisheries, multi- } \\
\text { purpose integrated } \\
\text { farming, livestock } \\
\text { farming }\end{array}$ & $\begin{array}{l}\text { Agriculture, two crops } \\
\text { per year, rice and } \\
\text { maize; aquaculture } \\
\text { (mud crabs) }\end{array}$ \\
\hline $\begin{array}{l}\text { Livelihood } \\
\text { Activities }\end{array}$ & $\begin{array}{l}\text { Commercial fishing } \\
\text { (tuna-purse seine, } \\
\text { pole \& line); artisanal } \\
\text { fishing (coastal fish, } \\
\text { invertebrates); coastal } \\
\text { aquaculture (seaweed, } \\
\text { marine ornamentals); } \\
\text { farming (cash crops) }\end{array}$ & \begin{tabular}{|l|} 
Floodplain \& \\
freshwater fishing, \\
cattle grazing, \\
small-scale agriculture, \\
and some irrigated \\
cropping
\end{tabular} & $\begin{array}{l}\text { Fishing, coastal } \\
\text { and freshwater } \\
\text { aquaculture, } \\
\text { homestead gardening, } \\
\text { livestock production, } \\
\text { and rice farming }\end{array}$ & $\begin{array}{l}\text { Lake, floodplain, and } \\
\text { rice field fisheries, } \\
\text { aquaculture, rain-fed } \\
\text { and irrigated farming } \\
\text { (rice, cash crops), } \\
\text { livestock production }\end{array}$ & $\begin{array}{l}\text { Coconut farming, pigs, } \\
\text { seaweed farming }\end{array}$ \\
\hline $\begin{array}{l}\text { Livelihood } \\
\text { Commodities }\end{array}$ & $\begin{array}{l}\text { Tuna, other pelagic } \\
\text { fish, sea cucumber, } \\
\text { trochus, marine } \\
\text { ornamentals (giant } \\
\text { clam, coral fragments), } \\
\text { seaweed, coconut, } \\
\text { cocoa, root crops, leafy } \\
\text { vegetables, fruits }\end{array}$ & $\begin{array}{l}\text { Wild-caught fish, } \\
\text { livestock, sugar cane, } \\
\text { rice, maize, sweet } \\
\text { potatoes, cassava, } \\
\text { mangos, and cashew }\end{array}$ & \begin{tabular}{|l|} 
Aquatic animals \\
(shrimp, freshwater \\
prawns, tilapia, carp) \& \\
plants, rice, vegetables, \\
livestock, crops, fruit, \\
timber, and wild \\
animals
\end{tabular} & $\begin{array}{l}\text { Rice, cash crops, fish, } \\
\text { other aquatic animals } \\
\text { (frogs, mollusks, } \\
\text { insects), livestock }\end{array}$ & $\begin{array}{l}\text { Maize, bananas, } \\
\text { coffee, cocoa, fruit } \\
\text { trees, livestock } \\
\text { (crabao, horses, } \\
\text { chickens, pigs, goats) }\end{array}$ \\
\hline $\begin{array}{l}\text { Food Security } \\
\text { Activities }\end{array}$ & $\begin{array}{l}\text { Subsistence fishing } \\
\text { and gleaning (coastal/ } \\
\text { reef and freshwater); } \\
\text { small pond } \\
\text { aquaculture; } \\
\text { household gardens }\end{array}$ & $\begin{array}{l}\text { Small-scale agriculture, } \\
\text { fishing }\end{array}$ & $\begin{array}{l}\text { Fishing, coastal/ } \\
\text { freshwater } \\
\text { aquaculture, } \\
\text { farming }\end{array}$ & $\begin{array}{l}\text { Capture fisheries, } \\
\text { aquaculture, rice-fish } \\
\text { fisheries, multi- } \\
\text { purpose integrated } \\
\text { farming }\end{array}$ & $\begin{array}{l}\text { Subsistence } \\
\text { fishing, smallholder } \\
\text { agriculture, rice } \\
\text { cultivation }\end{array}$ \\
\hline $\begin{array}{l}\text { Food Security } \\
\text { Commodities }\end{array}$ & $\begin{array}{l}\text { Tilapia, milkfish, } \\
\text { reef/coastal fish \& } \\
\text { invertebrates, } \\
\text { snapper, mullet, eels, } \\
\text { horticulture crops, } \\
\text { chickens, pigs }\end{array}$ & $\begin{array}{l}\text { Maize, millet, cassava, } \\
\text { groundnuts, livestock, } \\
\text { fish }\end{array}$ & $\begin{array}{l}\text { Aquatic animals } \\
\text { (shrimp) \& plants, } \\
\text { livestock, crops, fruit, } \\
\text { timber, and wild } \\
\text { animals }\end{array}$ & $\begin{array}{l}\text { Rice, crops, vegetables } \\
\text { and fruits, fish, other } \\
\text { aquatic animals (frogs, } \\
\text { mollusks, insects) }\end{array}$ & $\begin{array}{l}\text { Rice, maize, coconuts, } \\
\text { fish, and shellfish }\end{array}$ \\
\hline $\begin{array}{l}\text { Current } \\
\text { Population }\end{array}$ & $\begin{array}{l}550,000 \text { in } 2010 ; \\
\text { projected } 1.2 \text { million } \\
\text { by } 2050 \text { (high } \\
\text { proportion of youth) }\end{array}$ & $\begin{array}{l}13 \text { million in } 2011 \\
\text { (declining population } \\
\text { due to HIV) }\end{array}$ & 140 million in 2010 & 14.3 million in 2011 & $\begin{array}{l}103.8 \text { million in } 2012, \\
\text { half of whom live in } \\
\text { rural areas }\end{array}$ \\
\hline Poverty Rate & $\begin{array}{l}\text { Mean incidence of } \\
\text { basic needs poverty } \\
\text { (Head Count Index) is } \\
18.8 \%\end{array}$ & $\begin{array}{l}73-83 \% \text { of population } \\
\text { below poverty line in } \\
\text { hubs }\end{array}$ & $\begin{array}{l}32-36 \% \text { of population } \\
\text { (or } 50 \text { million people) } \\
\text { below poverty line }\end{array}$ & $\begin{array}{l}35 \% \text { of the population } \\
\text { living below the } \\
\text { national poverty line } \\
\text { and } 15-20 \% \text { living in } \\
\text { conditions of extreme } \\
\text { poverty }\end{array}$ & $\begin{array}{l}45-60 \% \text { poverty rate } \\
\text { in rural areas; this rate } \\
\text { is much lower in urban } \\
\text { areas }\end{array}$ \\
\hline
\end{tabular}




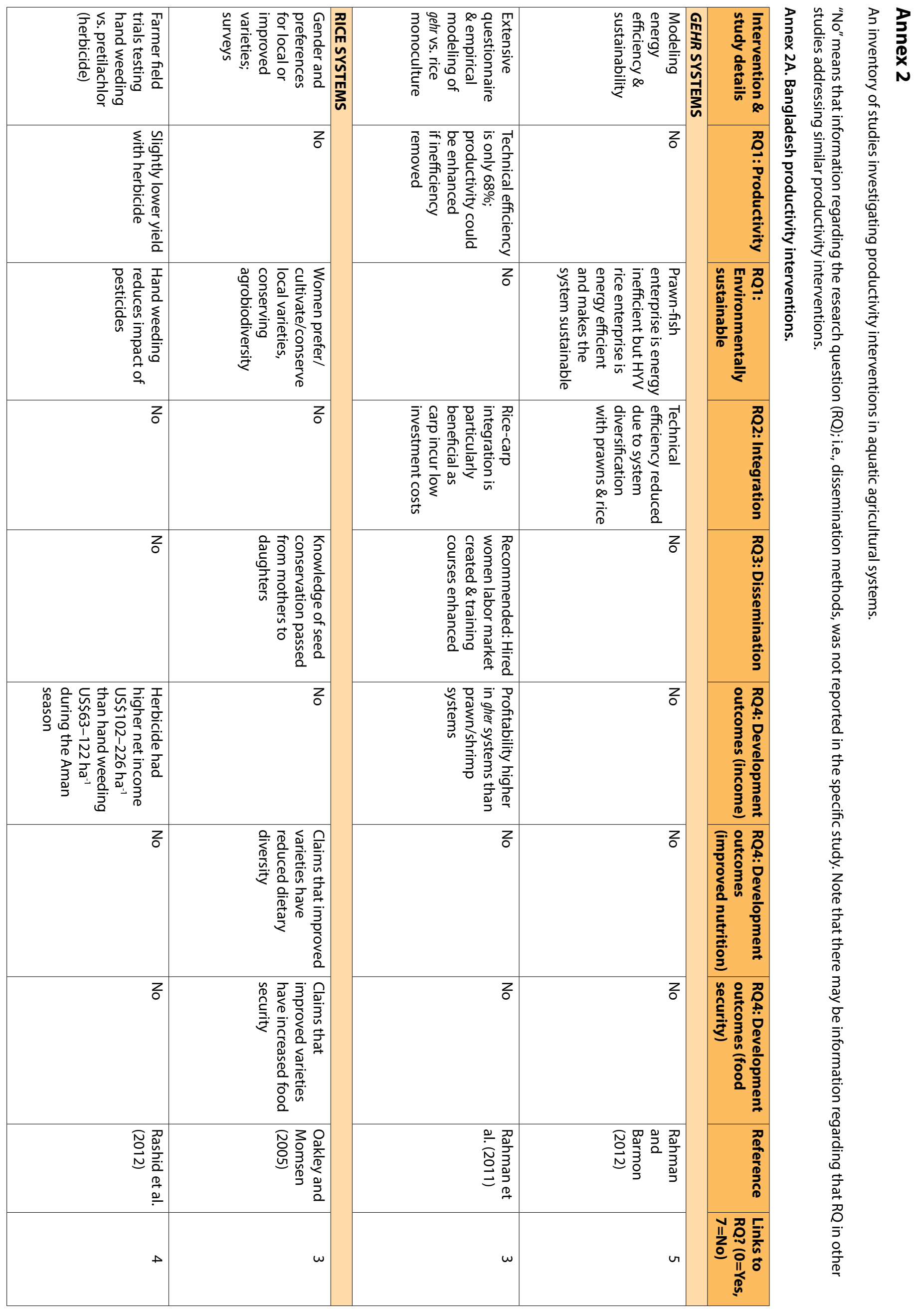




\begin{tabular}{|c|c|c|c|c|c|}
\hline 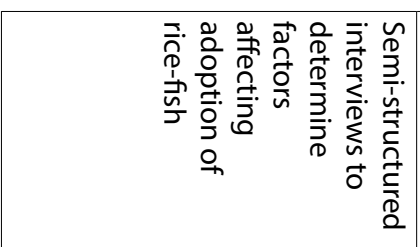 & 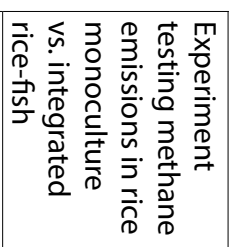 & 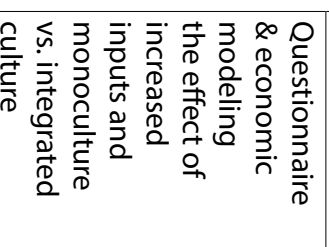 & 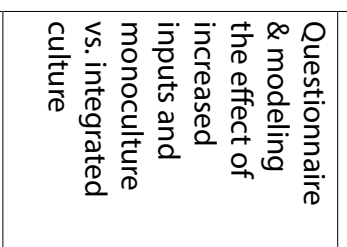 & 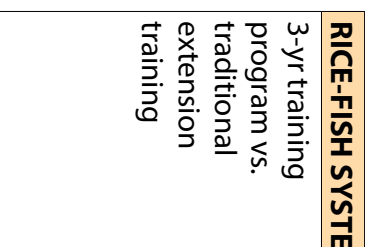 & 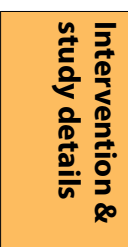 \\
\hline 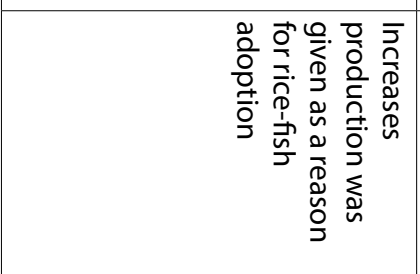 & $z$ & 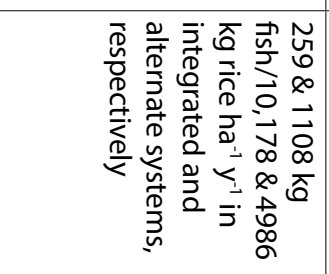 & 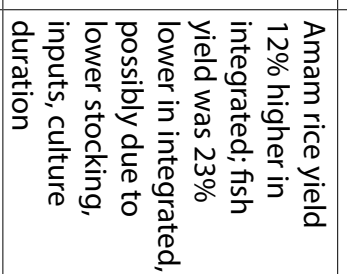 & 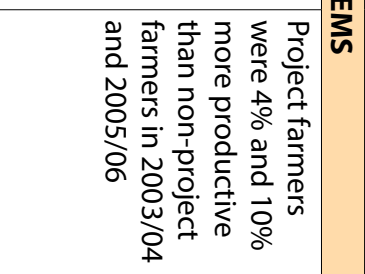 & 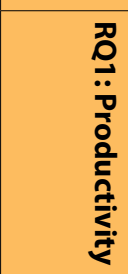 \\
\hline 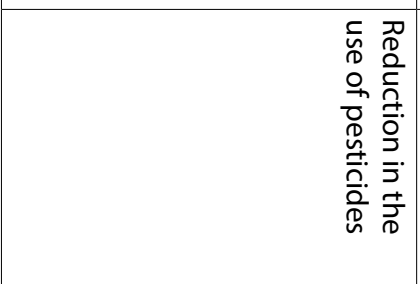 & 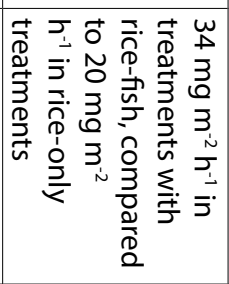 & $z$ & 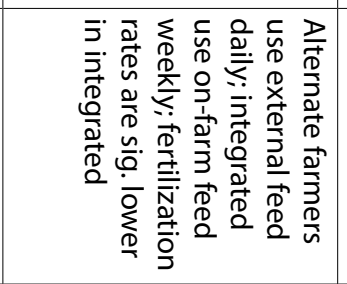 & 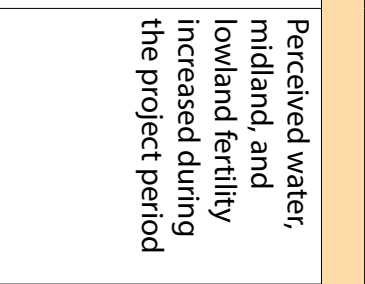 & 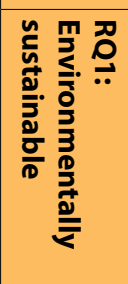 \\
\hline ঐో & ఠ & & 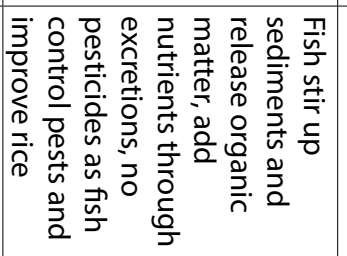 & 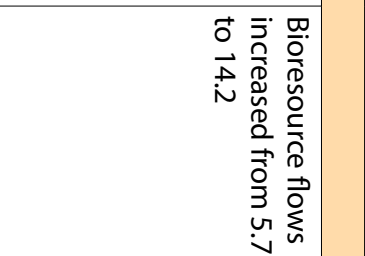 & 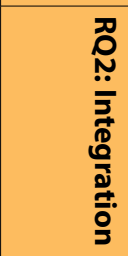 \\
\hline 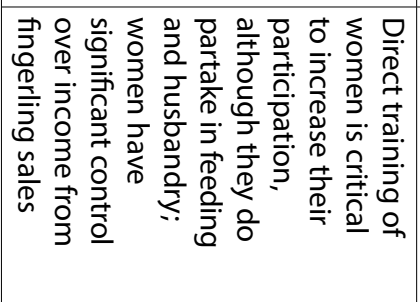 & z & $z$ & & 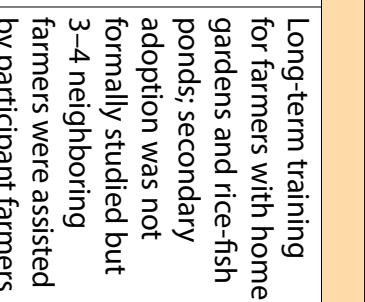 & 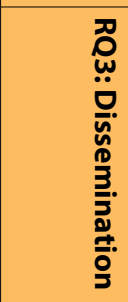 \\
\hline 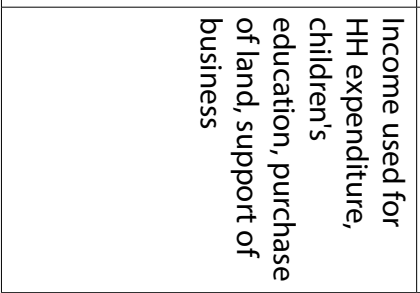 & z & 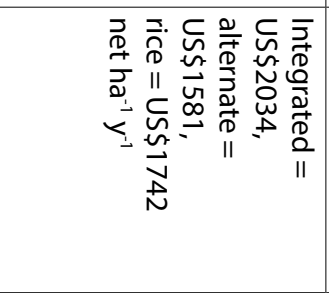 & 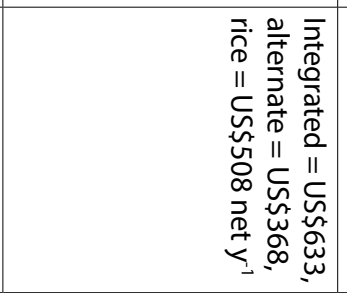 & 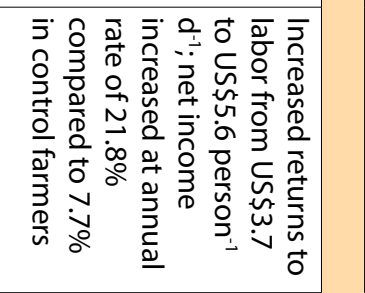 & 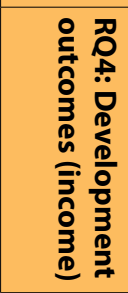 \\
\hline z & $z$ & $z$ & 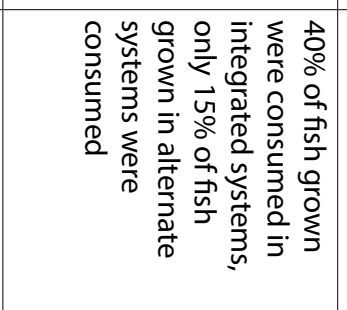 & $z$ & 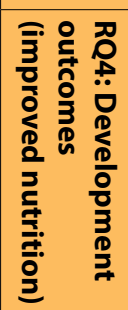 \\
\hline 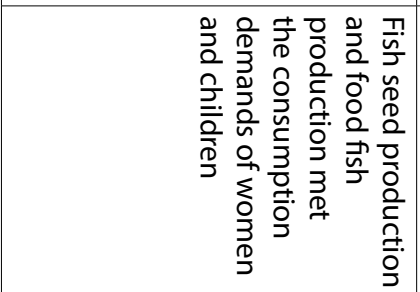 & $z$ & 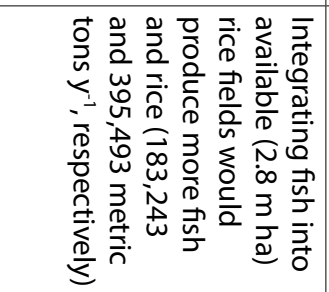 & 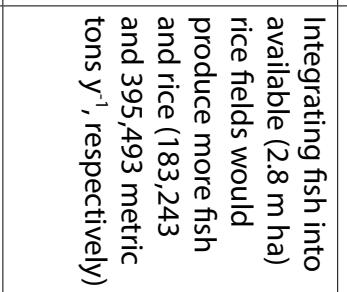 & 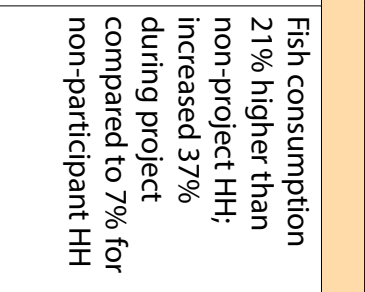 & 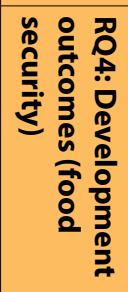 \\
\hline 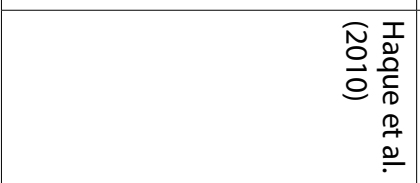 & 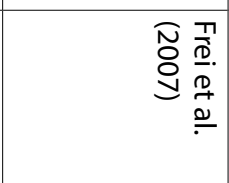 & 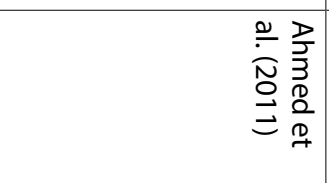 & 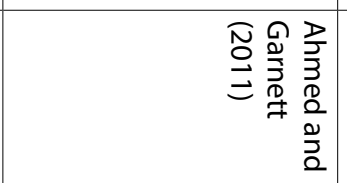 & 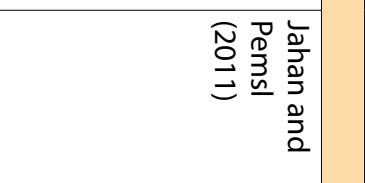 & 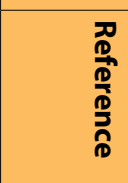 \\
\hline- & v & $\omega$ & - & - & 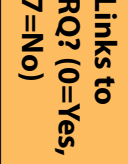 \\
\hline
\end{tabular}




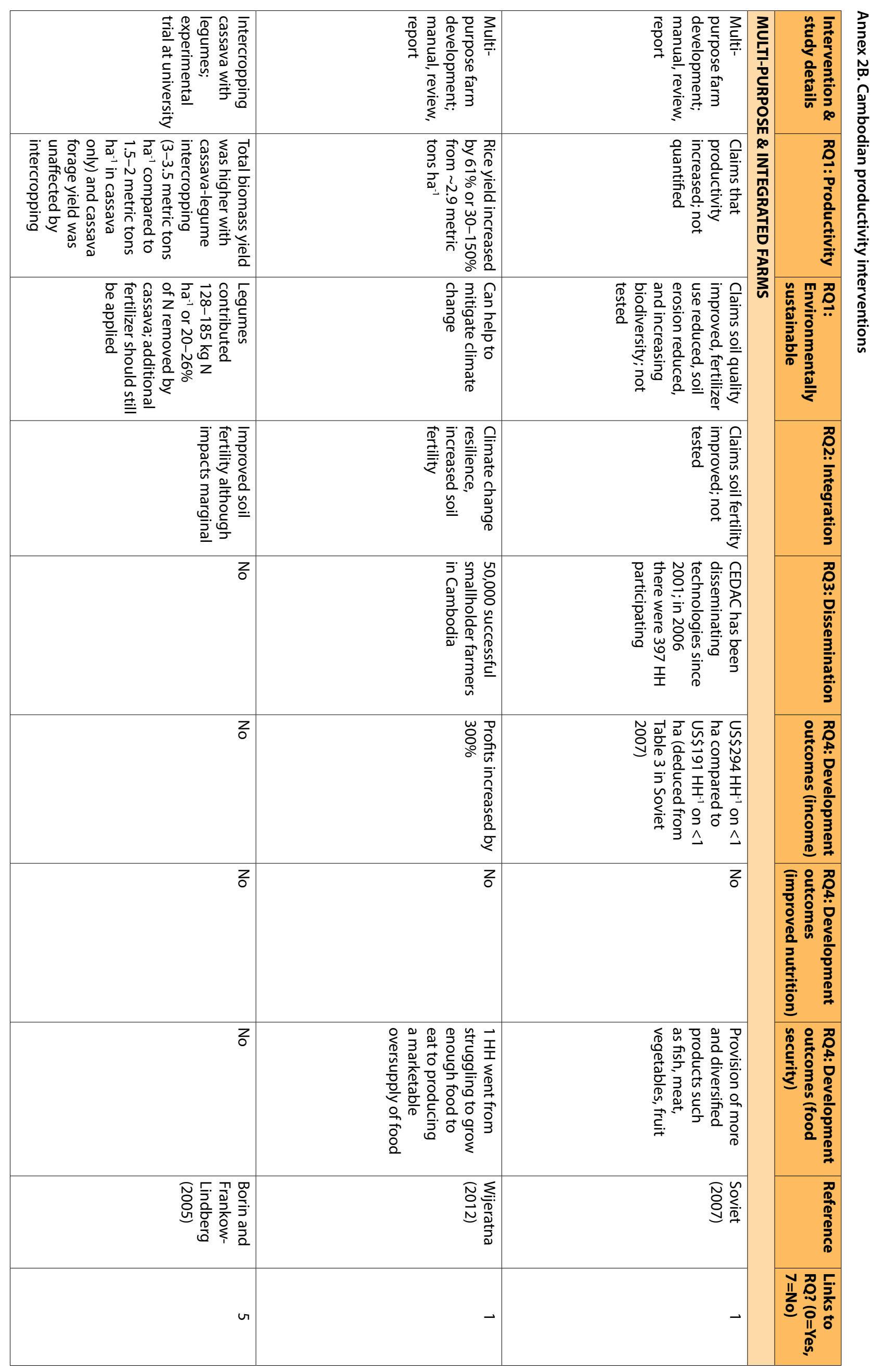




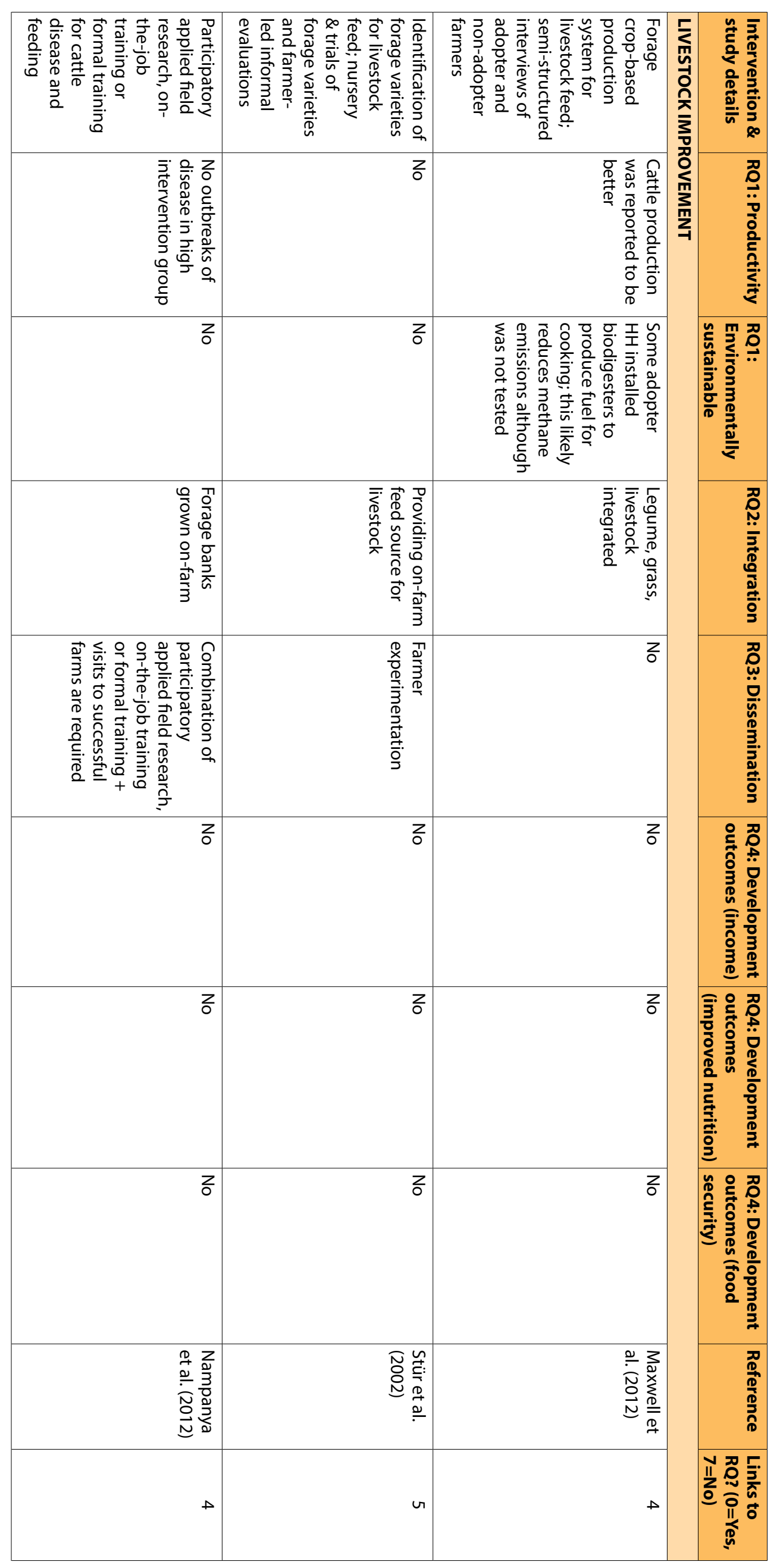




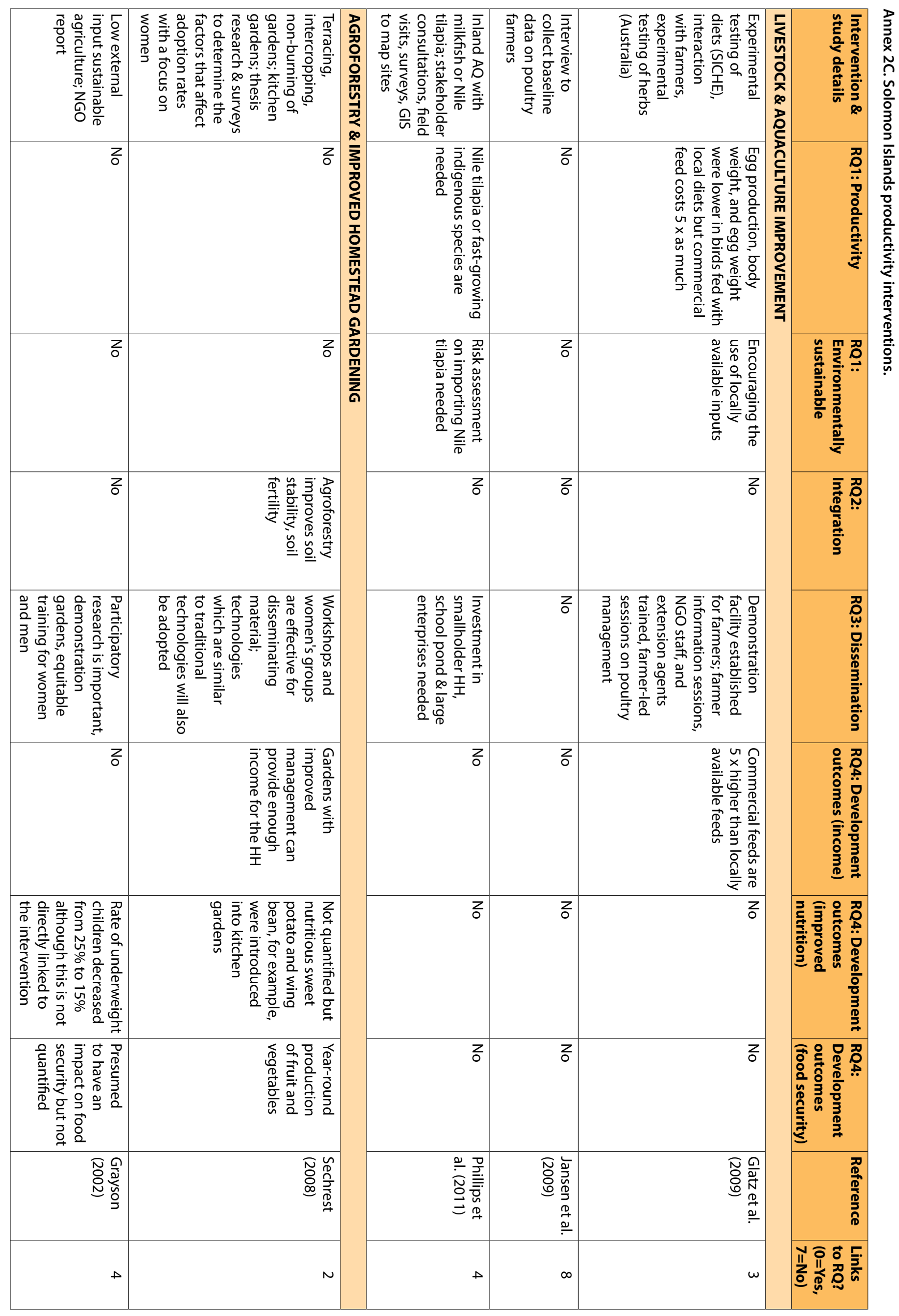




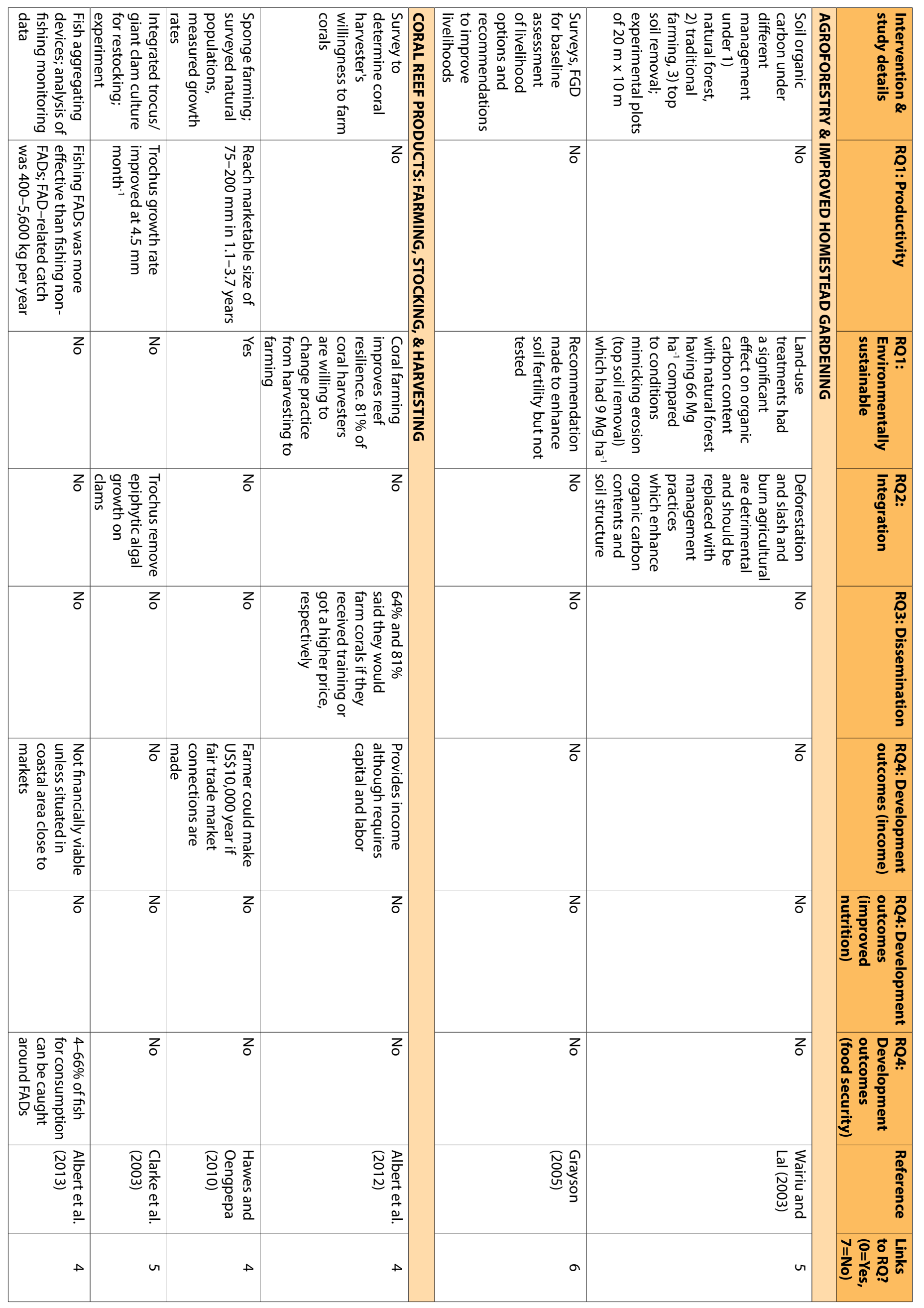




\begin{tabular}{|c|c|c|c|c|c|c|}
\hline 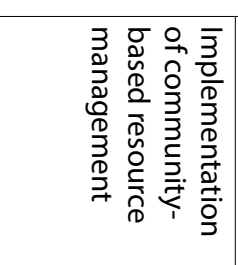 & 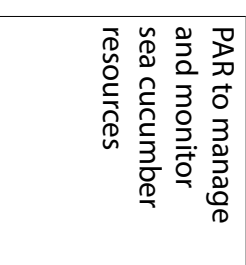 & 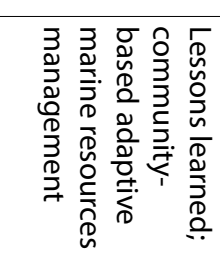 & 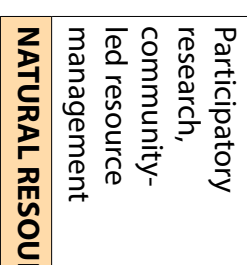 & 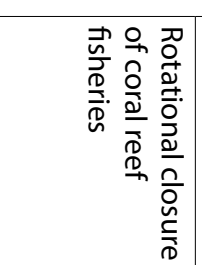 & 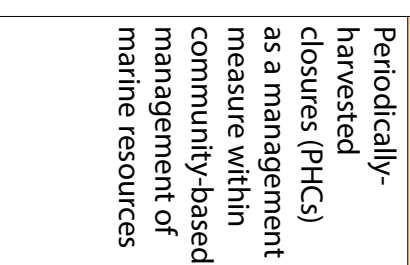 & 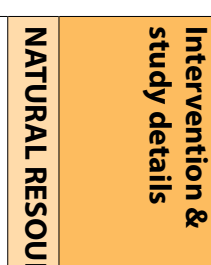 \\
\hline$z$ & 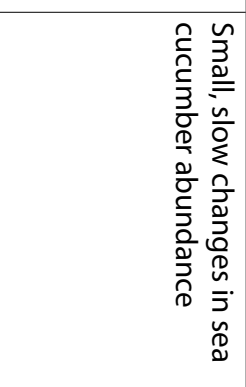 & $z$ & 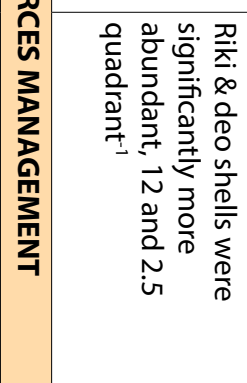 & 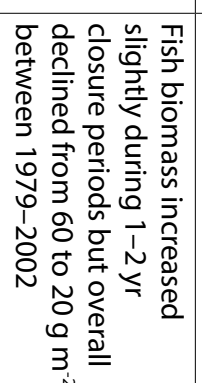 & 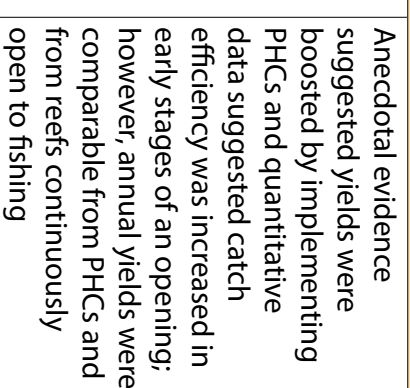 & 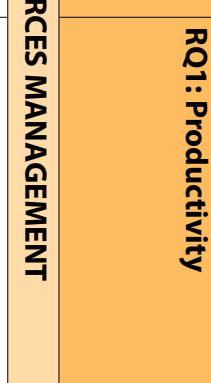 \\
\hline 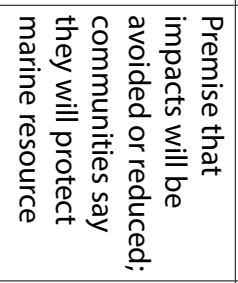 & 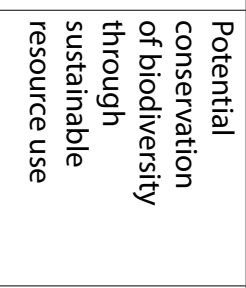 & 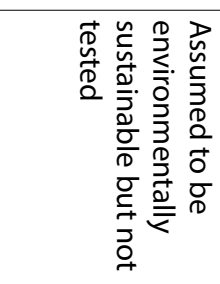 & $z$ & 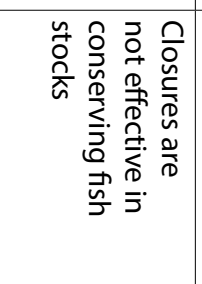 & 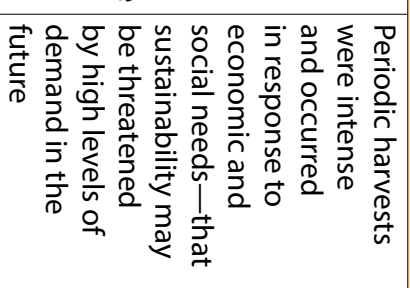 & 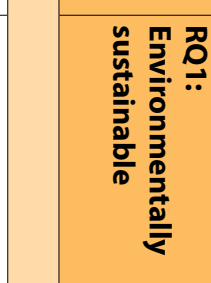 \\
\hline z & $z$ & z & $z$ & $z$ & $z$ & 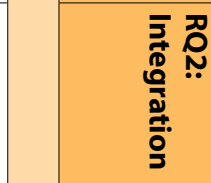 \\
\hline 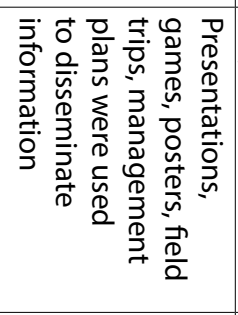 & 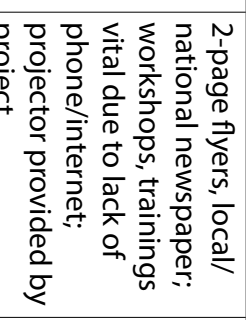 & 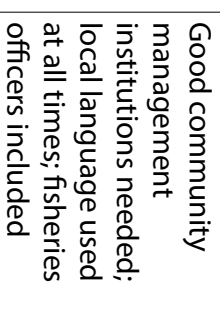 & 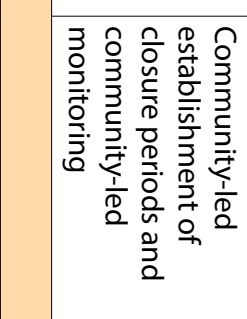 & $z$ & $z$ & 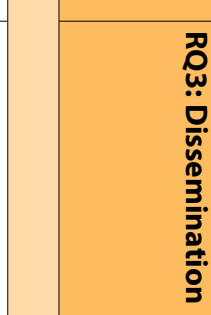 \\
\hline & 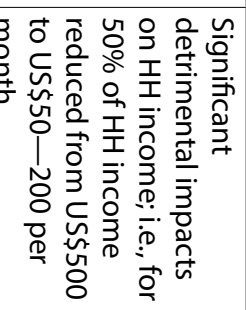 & z & 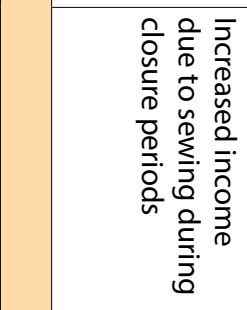 & $z$ & $z$ & 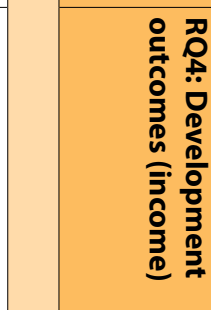 \\
\hline$z$ & z & z & z & $z$ & $z$ & 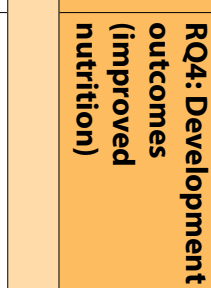 \\
\hline z & $z$ & $z$ & $z$ & $z$ & $z$ & 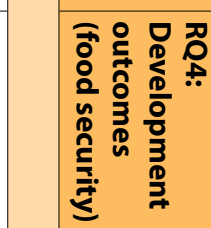 \\
\hline 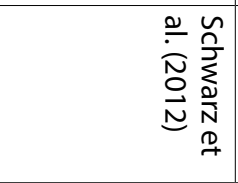 & 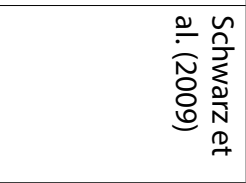 & 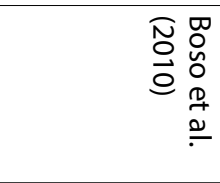 & 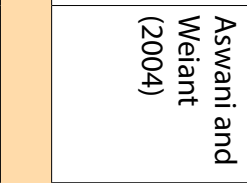 & 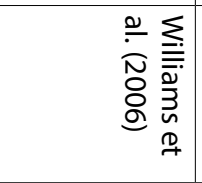 & 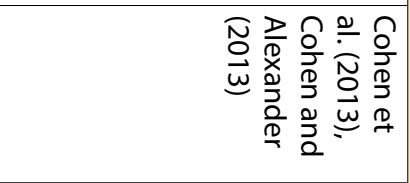 & \\
\hline u & $\omega$ & u & $\rightarrow$ & u & & 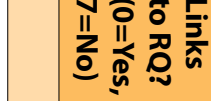 \\
\hline
\end{tabular}




\begin{tabular}{|c|c|c|c|c|c|c|}
\hline 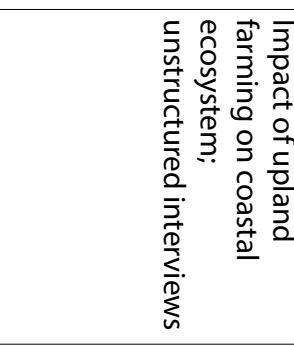 & 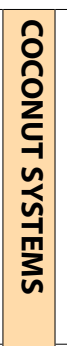 & 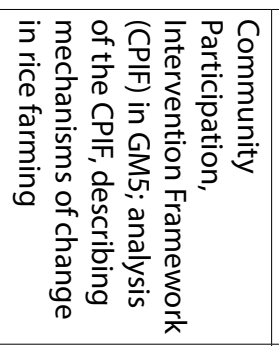 & 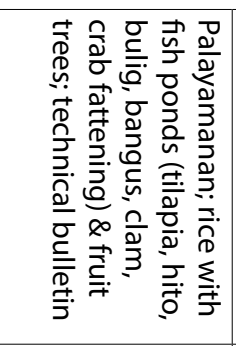 & 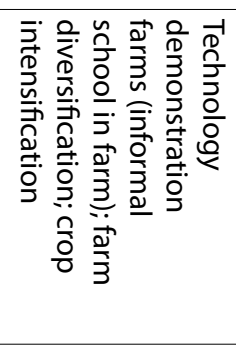 & 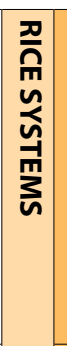 & 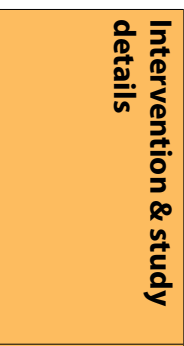 \\
\hline 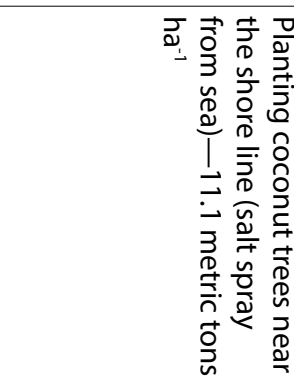 & & 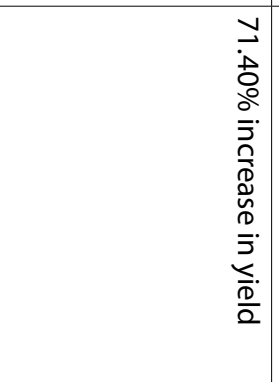 & o & 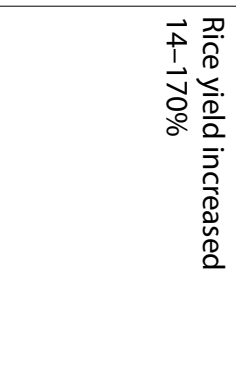 & & 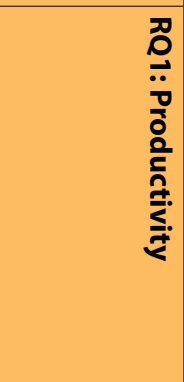 \\
\hline 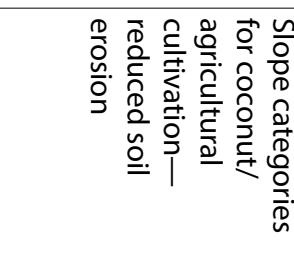 & & z & 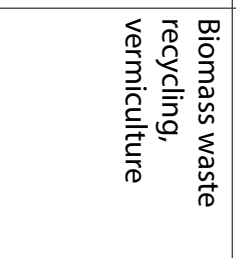 & z & & 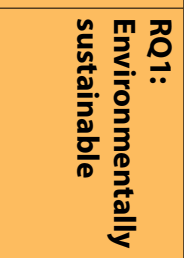 \\
\hline 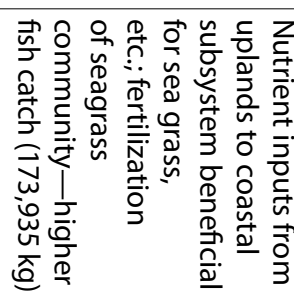 & & z & z & z & & 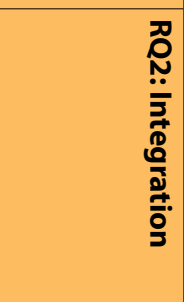 \\
\hline z & & 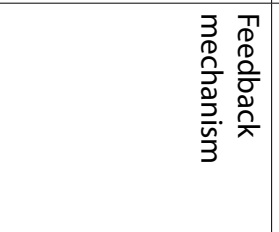 & z & z & & 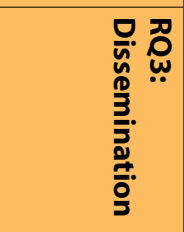 \\
\hline 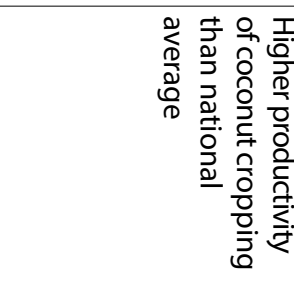 & & 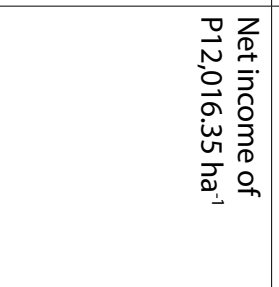 & z & 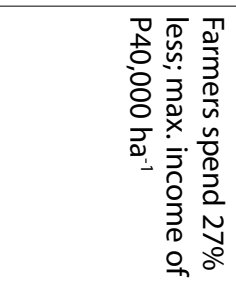 & & 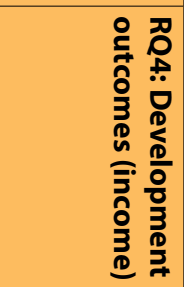 \\
\hline z & & z & $z$ & z & & 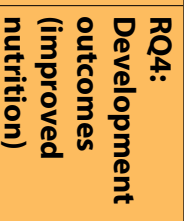 \\
\hline z & & z & 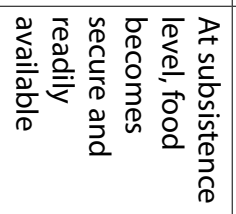 & z & & 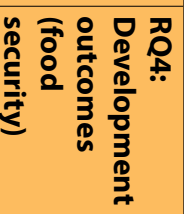 \\
\hline 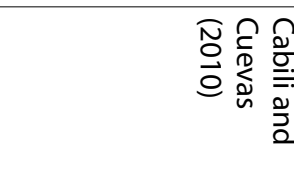 & & 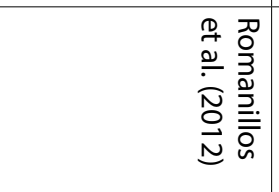 & 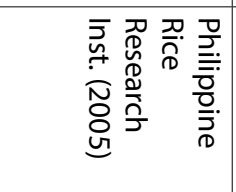 & 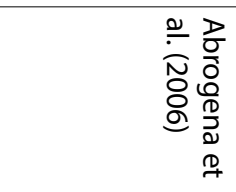 & & 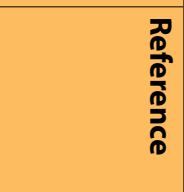 \\
\hline$\omega$ & & $u$ & $\Delta$ & v & & 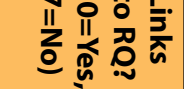 \\
\hline
\end{tabular}




\begin{tabular}{|c|c|c|c|c|c|}
\hline 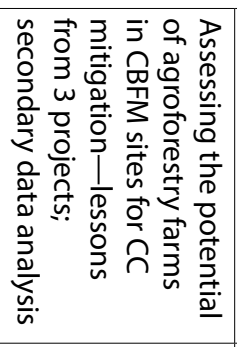 & 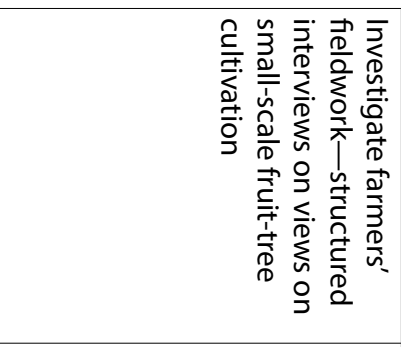 & 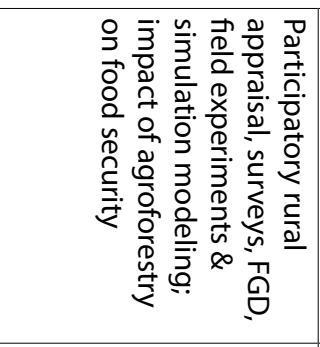 & 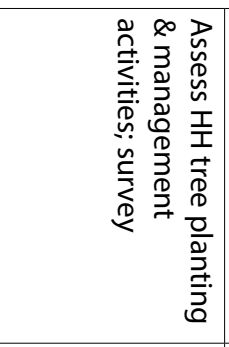 & 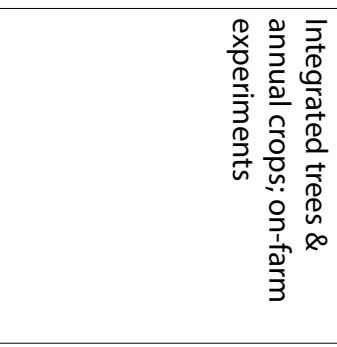 & 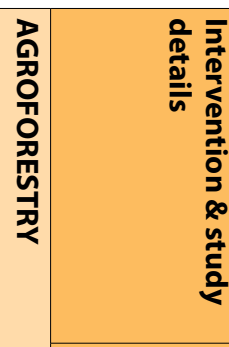 \\
\hline 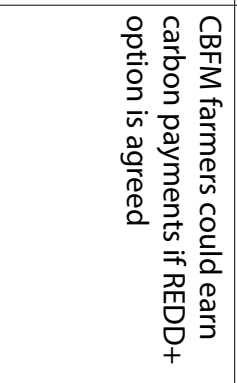 & 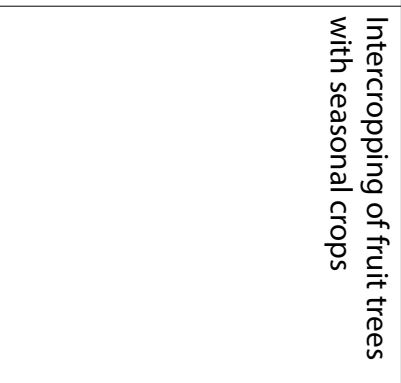 & 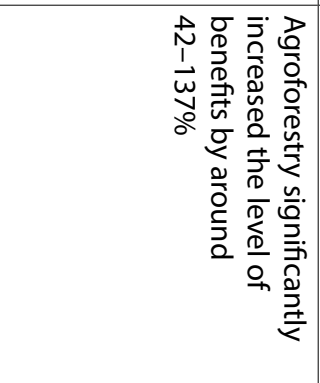 & 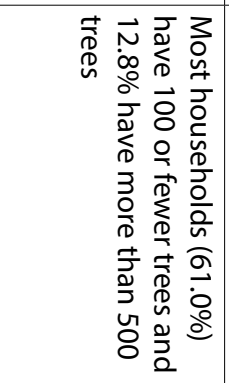 & 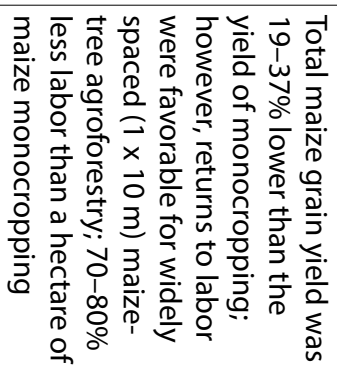 & \\
\hline 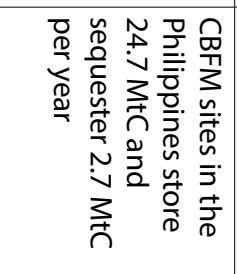 & 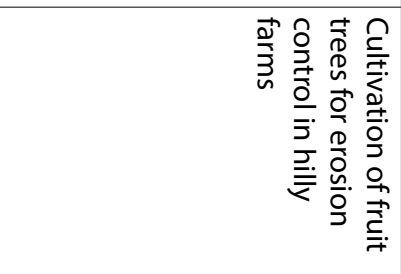 & 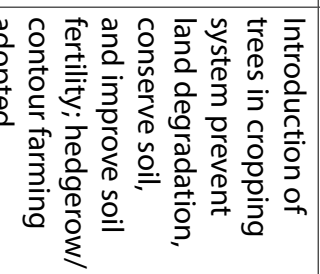 & z & 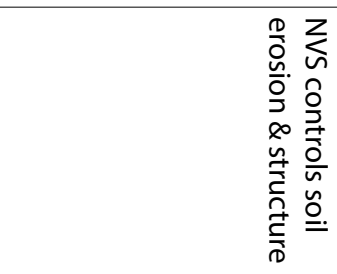 & 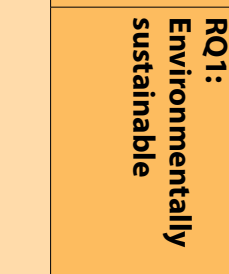 \\
\hline$z$ & 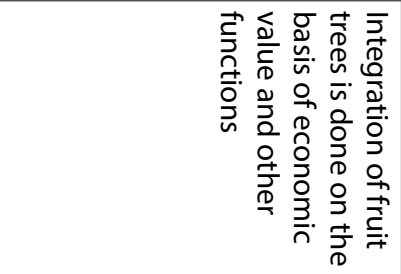 & 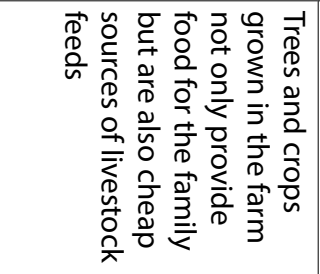 & $z$ & z & 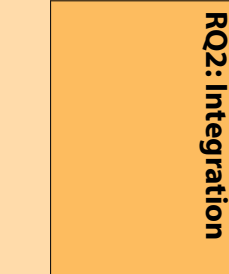 \\
\hline 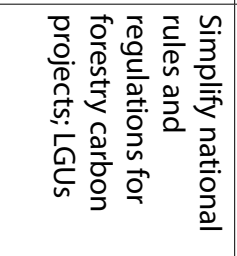 & 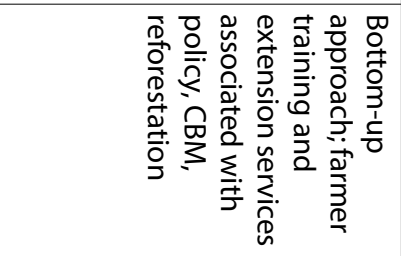 & 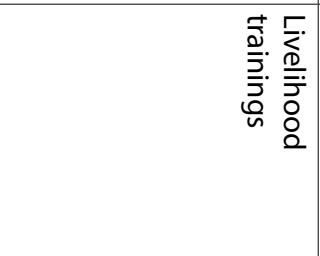 & z & 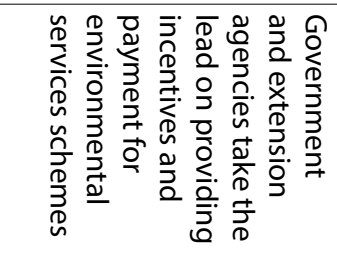 & 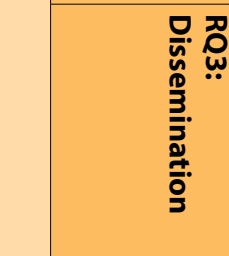 \\
\hline 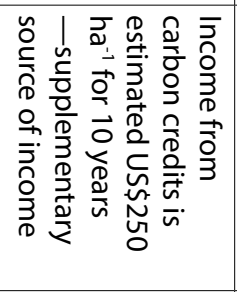 & 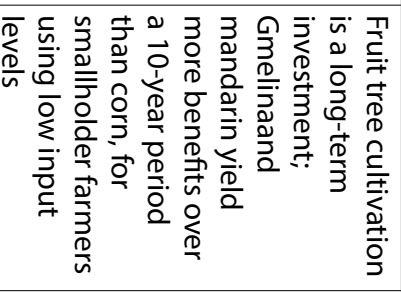 & 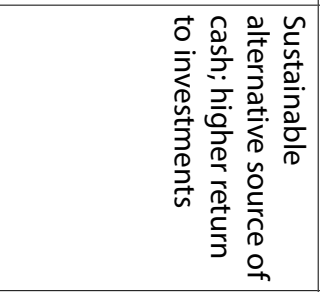 & 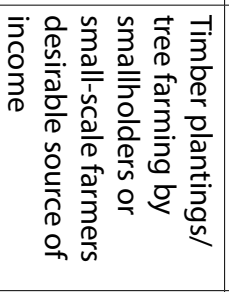 & z & 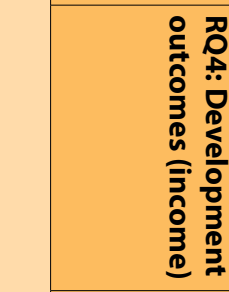 \\
\hline$z$ & $z$ & 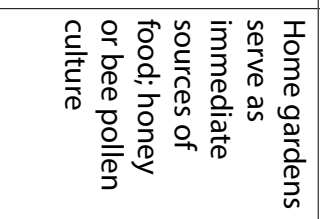 & $z$ & z & 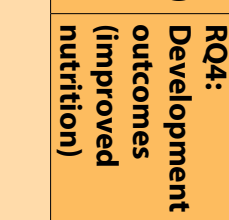 \\
\hline$z$ & 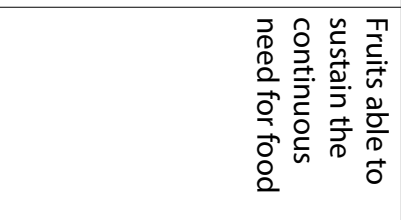 & 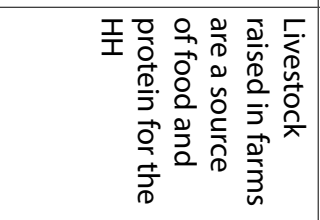 & $z$ & z & 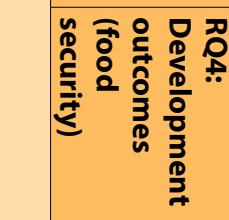 \\
\hline 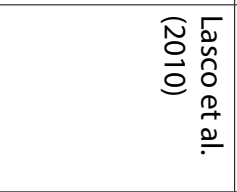 & 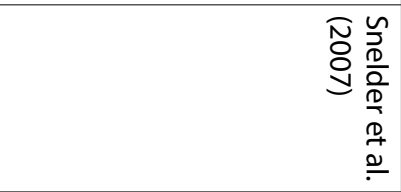 & 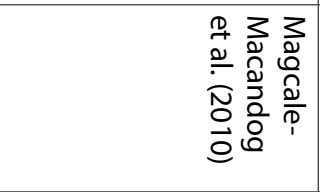 & 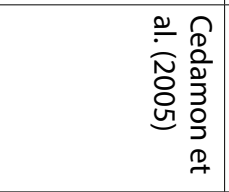 & 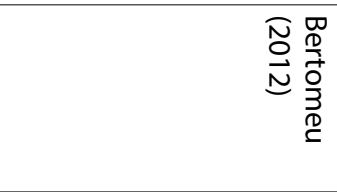 & \\
\hline$\omega$ & $\rightarrow$ & - & $a$ & $u$ & 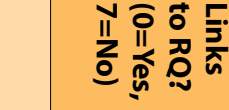 \\
\hline
\end{tabular}




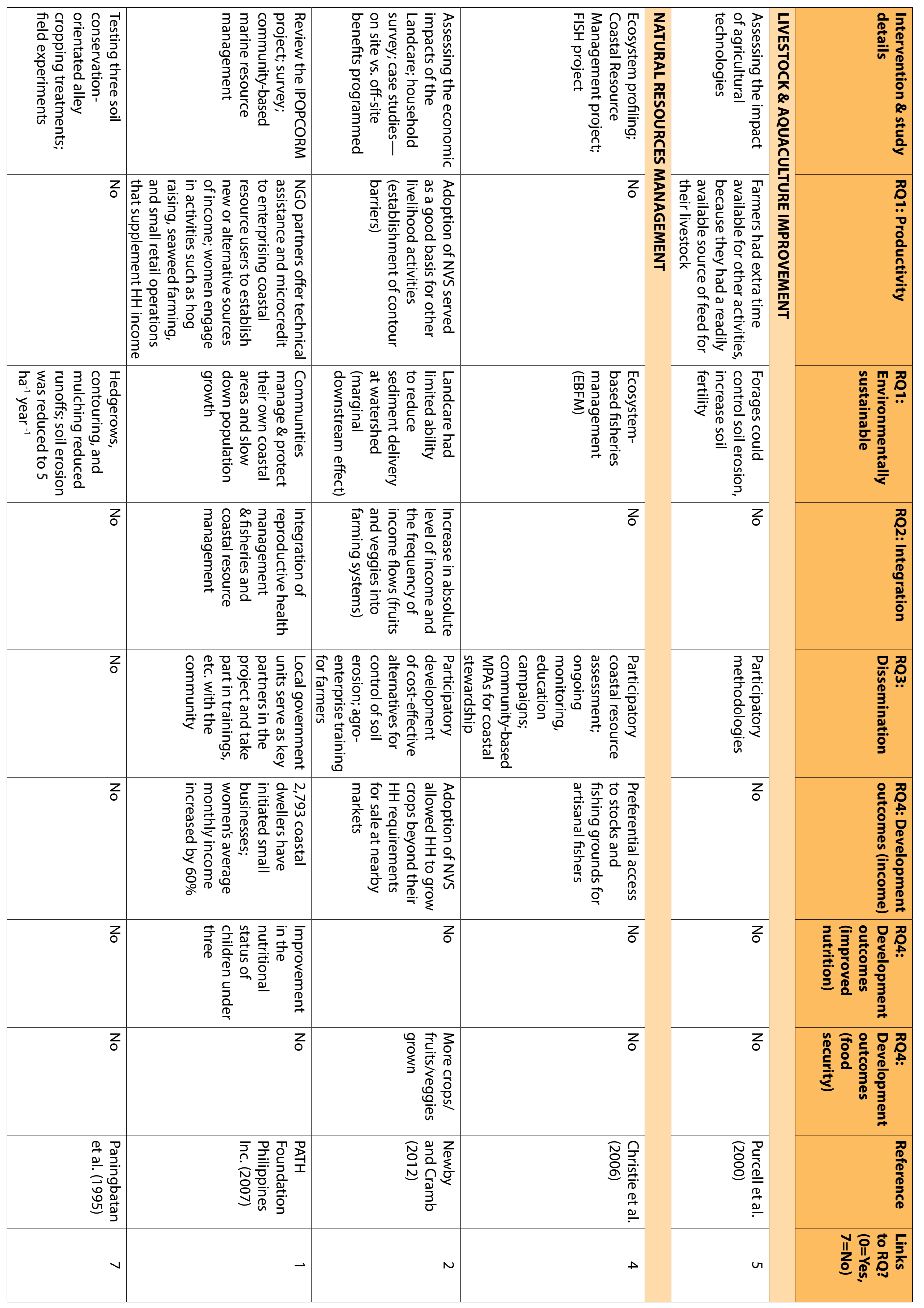




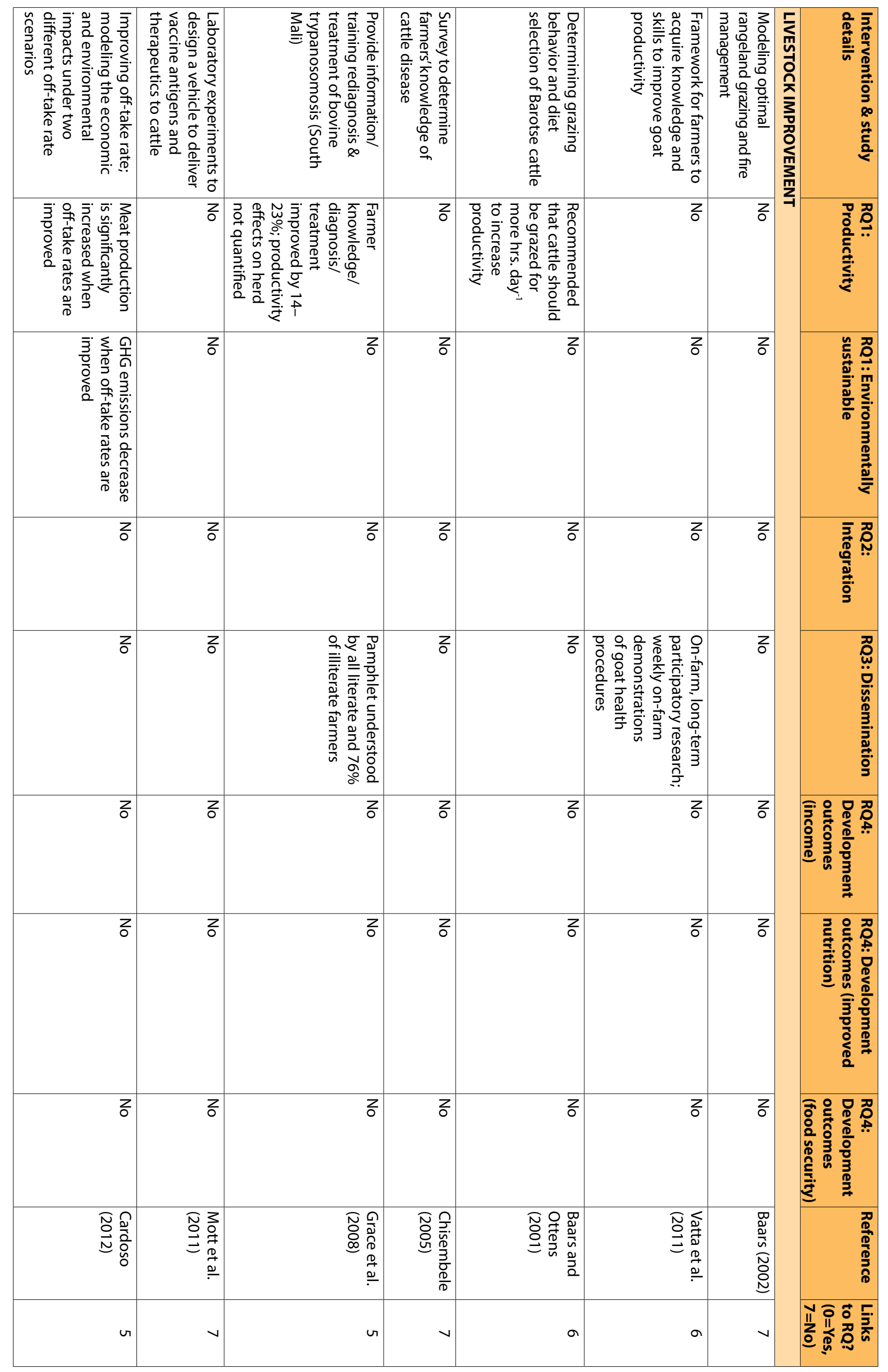




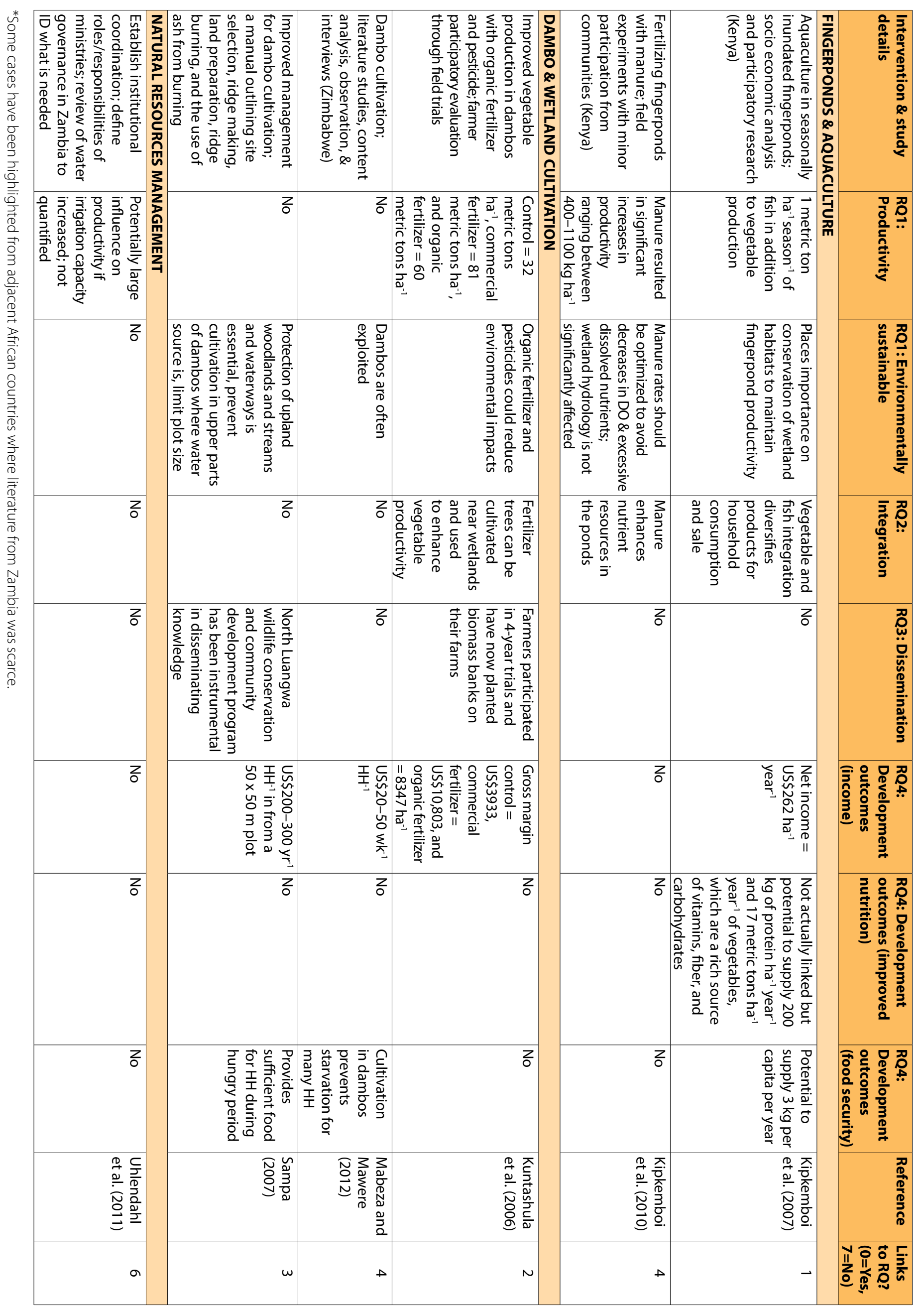




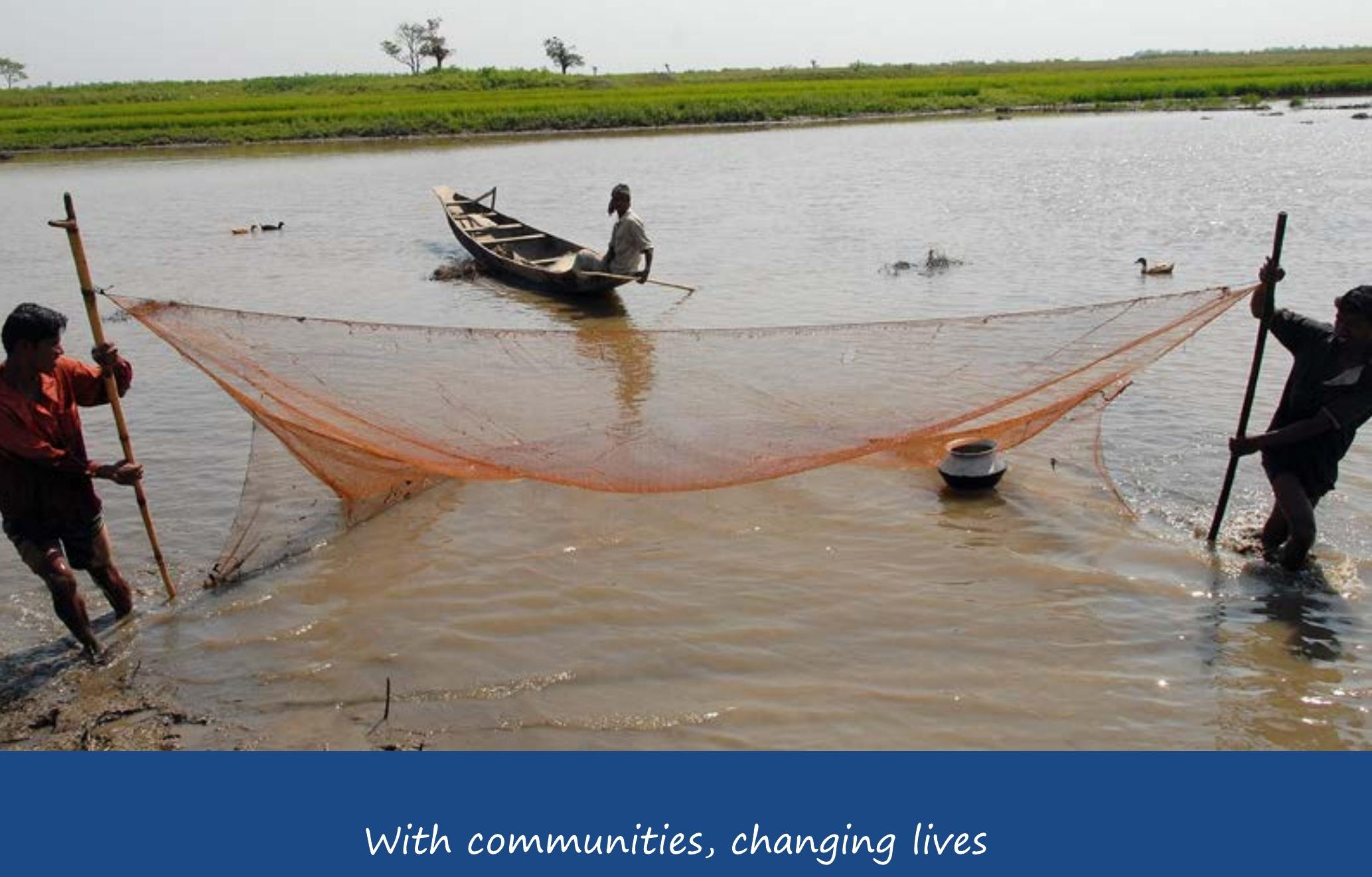

This publication should be cited as: Castine, S.A., Senaratna Sellamuttu, S., Cohen, P., Chandrabalan, D., and Phillips, M. (2013). Increasing productivity and improving livelihoods in aquatic agricultural systems: A review of interventions. CGIAR Research Program on Aquatic Agricultural Systems. Penang, Malaysia. Working Paper: AAS-2013-30.

The CGIAR Research Program on Aquatic Agricultural Systems is a multi-year research initiative launched in July 2011. It is designed to pursue community-based approaches to agricultural research and development that target the poorest and most vulnerable rural households in aquatic agricultural systems. Led by WorldFish, a member of the CGIAR Consortium, the program is partnering with diverse organizations working at local, national and global levels to help achieve impacts at scale. For more information, visit aas.cgiar.org.

Design and layout: Eight Seconds Sdn Bhd.

Printed on $100 \%$ recycled paper.

Photo credits: Front cover, Patrick Dugan; page 10, WorldFish; page 11, Mélody Braun; page 12, WorldFish \& CBFM-Fem Com Bangladesh; page 13, CBFM-Fem Com Bangladesh; page 14, Olivier Joffre; page 15, Olivier Joffre; page 16, Alan Brooks; page 17, Eric Baran; page 18, Pip Cohen; page 20, Wade Fairley; page 21, Juan Karlo Francisco; page 22, Joy Abigail Cañas; page 23, Joy Abigail Cañas, Aisa Shayne Santos; page 24, Juan Karlo Francisco; page 25, Patrick Dugan; page 26, Georgina Smith; page 27, Simon Heck; back cover, WorldFish.

@ 2013. WorldFish. All rights reserved. This publication may be reproduced without the permission of, but with acknowledgment to, WorldFish.

Contact Details:

CGIAR Research Program on Aquatic Agricultural Systems

Jalan Batu Maung, Batu Maung, 11960 Bayan Lepas, Penang, MALAYSIA

Tel: +604 626 1606, fax: +604626 5530, email: aas@cgiar.org 